\title{
La nueva ley sobre el contrato de transporte terrestre de mercancías: una primera aproximación
}

\author{
Carlos Llorente Gómez de Segura \\ Profesor doctor de Derecho mercantil (Universidad de Deusto) \\ Socio de AMYA Abogados
}

Resumen: Tras un meditado y sereno debate, se ha aprobado la ley del contrato de transporte terrestre de mercancías, que sustituye oportunamente, y con vocación de permanencia, a la caduca y desorganizada regulación vigente en esta materia en el Derecho español. La ley moderniza, con una buena técnica y siguiendo modelos contrastados, las reglas básicas regidoras de este tipo de contrato, por lo que merece un juicio positivo, si bien no exento de crítica en algunos aspectos en los que hubiese sido deseable una mayor decisión por parte del legislador, particularmente en lo que respecta a la regulación de los intermediarios del transporte y de la subcontratación. Aunque algunos de los aspectos contemplados por la ley resultarán ya familiares para los operadores del sector, y particularmente para quienes actúan en el ámbito del transporte internacional de mercancías por carretera, es recomendable, no obstante, iniciar una inmediata labor de divulgación sobre esta nueva legislación, tarea a la que se desea contribuir con este artículo en que se señalan sus claves más relevantes.

Palabras clave: Contrato, transporte, mercancías, reforma, legislación.

Abstract: After a well-thought and calmed debate, an Act on the carriage of goods by land has been approved, which substitutes timely and permanently the old and disorganized legislation in force in Spain on this matter. The new Act updates the basic rules applicable to these contracts and does it with a good legal technique and following fully-accepted model legislation. This positive evaluation, however, is not exempted from critical views based on the legislator's lack of decision in addressing questions such as the regulation of transport intermediaries and carriage subcontracting. Some of the new rules will sound familiar to transport operators, especially those working in the area of international carriage of goods by road, but it is highly advisable to start with an immediate task of divulging the new legislation rules, a goal towards which this article is aimed.

Key words: Contract, carriage, cargo, reform, regulation.

Sumario: I. Introducción.-II. Disposiciones generales.-III. Documentación del contrato.-IV. Contenido del contrato de transporte de mercancías.-V. Depósito y enajenación de las mercancías.-VI. Responsabilidad del porteador.-VII. Porteadores sucesivos.-VIII. Transporte multimodal.--IX. Normas especiales del contrato de mudanza.X. Prescripción de acciones. 


\section{Introducción}

El 12 de noviembre de 2009 se publicó en el Boletín Oficial del Estado (BOE) la Ley 15/2009, de 11 de noviembre de 2009, del contrato de transporte terrestre de mercancías ${ }^{1}$. Conforme a su Disposición Adicional Quinta («Entrada en Vigor»), la ley entrará en vigor a los tres (3) meses de su publicación en el BOE, periodo de vacatio legis adecuado y razonable, dada la relevancia del nuevo texto legal, que permite y facilita una adecuada labor de divulgación de los contenidos de la nueva regulación antes de que se cumpla dicho plazo.

En buena lógica, la nueva ley se aplicará a los contratos celebrados tras su entrada en vigor, si bien esta norma contiene una Disposición Transitoria Única («Contratos preexistentes») que señala lo siguiente:

Quedará regulada bajo los términos de esta ley la ejecución de todos los contratos que comience a partir del uno de enero del año siguiente al de la entrada en vigor de esta norma, aunque los mismos se hubieran celebrado con anterioridad.

Si la nueva ley entra en vigor a los tres (3) meses de su publicación en el BOE (que tuvo lugar el 12 de noviembre de 2009), lo anterior significa que el «uno de enero del año siguiente al de la entrada en vigor de esta norma» es el 1 de enero de 2011 (pues la ley entrará en vigor en febrero de 2010). Sorprende mucho, por lo tanto, esta fecha de 2011, sin duda, puesto que no entendemos por qué han de quedar excluidos de la aplicación de la ley los contratos concluidos antes del 12 de febrero de 2010, pero cuya ejecución se vaya a producir entre esa fecha y el 31 de diciembre de 2010. ¿Seguro que el legislador ha querido decir en realidad lo que finalmente ha quedado reflejado en la Disposición Transitoria Única?

Dos son, fundamentalmente, las razones que justifican la promulgación de la nueva ley.

Centrándonos en la primera de estas razones -la necesidad de modernizar la regulación del contrato de transporte terrestre de mercancías-, nadie

${ }^{1}$ BOE núm. 273.

${ }^{2}$ Por cierto, no puede calificarse el Preámbulo de esta ley como su parte más conseguida. Es significativamente breve y pasa por encima de determinados aspectos de la ley que hubiesen merecido mayor justificación y atención en esa sede por su novedad.

${ }^{3}$ Preámbulo, I, primer párrafo: «La presente ley tiene por objeto actualizar el régimen jurídico del contrato de transporte terrestre de mercancías tanto por lo que se refiere al transporte por carretera como por ferrocarril. En sentido estricto, esta ley no venía obligada por la incorporación al Derecho español de directivas comunitarias. Sin embargo, pocos sectores existen más necesitados de reforma que el Derecho del transporte terrestre de mercancías. El Título VII del Libro II del Código de Comercio (artículos 349 a 379), en vigor sin apenas modificaciones desde el momento de la promulgación del Código en 1885, no 
puede poner en duda la justicia de este propósito y, no en vano, el Preámbu$10^{2}$ de la nueva ley le dedica acertadamente sus primeras palabras ${ }^{3}$. Habla incluso de «anacronismo y desfase» de nuestra legislación anterior ${ }^{4}$. Con la nueva ley, por tanto, no se ha hecho más que reconocer y asumir de un modo claro y decidido una aspiración que entre nosotros se había venido reclamando desde hace mucho tiempo ${ }^{5}$ y que, lamentablemente, había caído en saco roto hasta ahora ${ }^{6}$.

Téngase en cuenta que en nuestro país el contrato de transporte terrestre de mercancías ha estado regulado, hasta la fecha, en un texto normativo de finales del siglo XIX (Código de Comercio de 1885: artículos 349-379 Ccom), que, además, ya había recibido en su época un influjo inequívoco, en algunos extremos relevantes (por citar un solo ejemplo, el artículo 379

estaba en condiciones de dar respuesta a las muy cambiantes necesidades del transporte actual. De hecho, en la práctica, tales preceptos del Código en la materia rara vez eran objeto de aplicación. Y es que el Derecho contractual del transporte ha venido siendo objeto en los últimos años de una actualización que empleaba una vía oblicua, como era la intervención de la Administración del Estado. Son muchos, en efecto, los ejemplos de normas de control u ordenación del sector del transporte en las que se contenían reglas de derecho privado-contractual. Si a ello se añaden las condiciones generales de la contratación de los transportes de mercancías por carretera establecidas por el Ministerio de Fomento mediante Orden de 25 de abril de 1997, se comprende la afirmación de que el Derecho codificado fuese escasamente aplicado en la práctica diaria del transporte».

${ }^{4}$ Preámbulo I, párrafo segundo.

${ }^{5}$ En este sentido, véanse los trabajos de C. Llorente Gómez de Segura ( «La reforma de la regulación mercantil del transporte terrestre en la España del siglo XXI»), E. Sidera Leal («Apuntes para una modificación de la regulación mercantil del contrato de transporte») y F. Martínez Sanz («En torno a una eventual reforma del contrato de transporte terrestre»), en Actualidad Jurídica del Transporte por Carretera. In Memoriam F.M. Sánchez Gamborino, Madrid 2005, pp. 269-276, pp. 277-283 y 285-298, respectivamente. Igualmente, L. J. Cortés, «Los aspectos mercantiles del transporte terrestre en la legislación vigente. La adecuación del Código de comercio a la realidad actual» (ponencia), en Jornadas de estudio del nuevo marco ordenador de los transportes terrestres, Barcelona, 4, 5 y 6 de abril de 1989, pp. 161 y ss. (también en $A D M, 1989$, VII, pp. 181 y ss.); F. Sánchez Calero, «El Código de comercio y los contratos mercantiles», en Centenario del Código de comercio, I, Madrid, 1986, pp. 211 y ss.

${ }^{6}$ De ahí que no se pueda calificar a la ley como oportuna, porque la oportunidad de una nueva legislación sobre el contrato de transporte terrestre de mercancías ya se había puesto de manifiesto con décadas (sí, décadas) de antelación [Oportuno: «Que se hace o sucede en tiempo a propósito y cuando conviene», según el Diccionario de la Lengua Española, Real Academia Española, 22. ${ }^{a}$ edición, Madrid]. Probablemente, el impulso tardío de la nueva legislación ha tenido mucho que ver con el lento desarrollo del mercado de transporte en nuestro país, pero también con el hecho de que hasta finales del siglo Xx no surgiese una nueva, numerosa y joven escuela española de Derecho del transporte, que es la que, precisamente, ha estado detrás de los estudios preliminares que han servido de base a la ley que ahora se ha aprobado y que, dicho sea de paso, no siempre han sido seguidos, como hubiera sido deseable, por el texto finalmente aprobado por el Congreso de los Diputados. 
Ccom), provenientes del Código de Sainz de Andino (1829) ${ }^{7}$. El de 1885 era, además, un código de la primera época ferroviaria (el único «toque» de modernidad que se le puede atribuir), pero que pensaba más en una actividad de transporte realizada por medio de carretas y animales sobre caminos de tierra. No es de extrañar, por tanto, que, no obstante la correctísima y frecuentemente alabada calidad técnica de sus preceptos (una de las razones que han justificado su consentida longevidad), la regulación del código hubiese de complementarse, de tanto en cuando, con el recurso a actualizaciones parciales recogidas en normas de ordenación, o jurídico-públicas (p. ej., LOTT-ROTT) ${ }^{8}$, una técnica legislativa (que el Preámbulo de la nueva ley califica, con excesiva amabilidad y una cierta dosis de corrección política, como «vía oblicua») de la que, de una vez por todas, y a pesar de su innegable utilidad cortoplazista, habría que desprenderse ${ }^{9}$.

Junto a la necesidad de modernizar una regulación que desde el punto de vista patrio era a todas luces obsoleta, la reforma también se ha planteado como un paso adelante en la adaptación de nuestra normativa a las exigencias del mercado del transporte del siglo XXI en el que realizan su actividad económica nuestros transportistas terrestres, particularmente en el contexto comunitario. A esta justificación parece referirse, calificándola como «motivo de oportunidad histórica», el Preámbulo de la ley, al aludir a la liberalización del transporte ferroviario que se está produciendo en el entorno de la Comunidad Europea y que ha tenido un reflejo reciente en nuestro ordena-

${ }^{7}$ Tal y como puso de manifiesto J. Rubio en su monografía Sainz de Andino y la Codificación mercantil, Madrid, 1950.

${ }^{8}$ LOTT=Ley 16/1987, de 30 de julio, de ordenación de los transportes terrestres (BOE núm. 182, de 31 de julio de 1987) y ROTT= Real Decreto 1211/1990, de 28 de septiembre (BOE núm. 241, de 8 de octubre de 1990), modificados posteriormente en varias ocasiones. Véase, p. ej., A. Barrio, «Aspectos mercantiles de la LOTT», RGD, 1989, pp. 307 y ss. Igualmente, A. Carretero, «Las innovaciones de la Ley de ordenación de los transportes terrestres en la vertiente mercantil» (Comunicación), en Jornadas de estudio del nuevo marco ordenador de los transportes terrestres, Barcelona, 4, 5 y 6 de abril de 1989, pp. 167 y ss.

${ }^{9}$ P. Martínez-Gijón Machuca, «Consecuencias de la "intromisión” de normas jurídicopúblicas en la regulación del contrato de transporte nacional de mercancías por carretera», $R D M$, núm. 253, 2004, pp. 1005-1339. En general, sobre una correcta técnica legislativa (y su enseñanza), F. Díaz Estella y J. Hernando Masdeu, «La redacción de textos legales», en J. Rodríguez-Arana Muñoz y R. Palomino Lozano (Dirs.) y M. Goñi Rodríguez de Almeida y S. Messeguer Velasco (Coord.), Enseñar Derecho en el Siglo XXI. Una guía práctica sobre el Grado en Derecho, Cizur Menor (Navarra), 2009, pp. 215-ss., especialmente, 224-ss.

${ }^{10}$ Ley 39/2003, de 17 de noviembre, del Sector Ferroviario (BOE núm. 276, de 18 de noviembre de 2003). 
miento a través de la promulgación de la Ley $(\mathrm{LSF})^{10}$ y el Reglamento $(\mathrm{RSF})^{11}$ del sector ferroviario ${ }^{12}$.

No está mal elegido el motivo, sin duda, si bien no acierta a explicar plenamente en esta sede el verdadero impacto que, sobre nuestra legislación del contrato de transporte terrestre, ha tenido, y sigue teniendo, el desarrollo de un verdadero mercado interior en el sector de los transportes. Porque, en sus orígenes, ha sido no tanto en el sector del transporte ferroviario, cuanto en el del transporte por carretera, donde desde hace bastantes años los países europeos comunitarios han venido dando pasos decisivos en su liberalización y en la reforma de su legislación interna para adaptarla a la legislación internacional (más propiamente europea) reguladora del contrato de transporte de mercancías por carretera ${ }^{13}$, de tal modo que se pudieran reducir las diferencias entre la legislación aplicable a uno u otro tipo de transporte dentro del espacio económico de la Comunidad ${ }^{14}$. Se trata de un fenómeno imparable en el que finalmente, aunque con tardanza, nuestro país también ha querido participar como era debido.

El Preámbulo de la ley también apunta a otro motivo de oportunidad histórica que habría justificado su promulgación: la inserción de esta reforma en el marco de un movimiento más general de reforma que afecta a todo el Derecho de los transportes ${ }^{15}$. Sin duda, la apreciación es certera porque coincide con una realidad innegable. En efecto, en los últimos tiempos se está produciendo una actualización imparable, y muy necesaria, del Derecho de

11 Real Decreto 2387/2004, de 30 de diciembre de 2004 (BOE núm. 315, de 31 de diciembre de 2004).

${ }^{12}$ Preámbulo I, párrafo tercero: «El primero de ellos tiene que ver con el transporte ferroviario. En efecto, no puede olvidarse cómo, en el ámbito ferroviario, la Ley 39/2003, de 17 de noviembre, del Sector Ferroviario, abrió un nuevo escenario de liberalización, que bien requiere de un nuevo marco legal en lo que son las relaciones de derecho contractual. Es cierto que la liberalización, por el momento, no alcanza a todos los ámbitos del transporte ferroviario, y que la misma tardará algún tiempo en materializarse. Pero no lo es menos que conviene sentar un nuevo marco de relaciones contractuales en un entorno de apertura a la libre competencia».

${ }^{13}$ Una referencia a este fenómeno se recoge en el Preámbulo de la ley («siguiendo así el camino antes trazado por otros países europeos»), en su apartado II, párrafo primero, al describir el modelo de política legislativa seguido por la ley.

${ }^{14}$ Preámbulo II, párrafo primero: «La consideración que subyace a esta decisión es sin duda alguna la de reconocer que no resultan tan distintos, en el momento actual, el transporte internacional y el puramente interno, al que van destinados los preceptos de la presente ley».

${ }^{15}$ Preámbulo I, párrafo cuarto: «El segundo de los motivos guarda relación con la reforma que se está llevando a cabo en otros modos de transporte. En efecto, parece una ocasión magnífica aprovechar el impulso que ha supuesto la tramitación de la Ley General de Navegación Marítima para acometer también la reforma del contrato de transporte de mercancías efectuado por otros modos, como pueda ser la carretera y el ferrocarril. Con ello se obtendría una actualización de una parte importante del Derecho del transporte». 
los transportes, tanto en su dimensión interna como en el plano internacional. Y es bueno que el legislador español no haya querido desaprovechar esta oportunidad.

Ahora bien, lo deseable sería no quedarse, sin más, en la satisfacción de saber que no se ha perdido definitivamente el tren de la actualización, sino trabajar por conseguir, además, una mayor, y mejor, armonización de la legislación aplicable, de tal modo que, como se apuntaba antes, cada vez sean menores las diferencias entre la regulación interna e internacional del contrato de transporte de mercancías y que también lo sean las diferencias entre la regulación del contrato de transporte por un modo u otro (carretera, ferrocarril, marítimo, aéreo, sin perder de vista la promoción del transporte multimodal. En los ámbitos de la carretera y el ferrocarril, esa aspiración es real y su virtualidad ha quedado puesta de manifiesto con la nueva ley. En el sector aéreo también se están dando pasos importantes, particularmente en el ámbito de la legislación comunitaria (no obstante, la vigencia de la vetusta Ley de Navegación Aérea). Y, sin duda, es en el sector marítimo donde mayores dificultades habremos de encontrar.

De aquí que la referencia que se hace en el Preámbulo de la ley, en este contexto, al Proyecto de Ley General de Navegación Marítima (PLGNM) nos produzca alguna duda.

Primero, porque, como es bien sabido, ese proyecto, en la parte relativa a la contratación del transporte marítimo, y después de algunos vaivenes provocados por la intervención decisiva, y legítima, de determinados grupos de intereses (lobbies), ha renunciado a las plenas pretensiones de modernidad que inspiraban su redacción primigenia.

$\mathrm{Y}$, segundo, porque, mientras se está tramitando dicho proyecto, ha tenido lugar en septiembre de 2009 la firma de las Reglas de Rotterdam, llamadas, según aseguran algunos (no todos), a ser el futuro inminente de la regulación del contrato de transporte marítimo internacional de mercancías ${ }^{16}$. Mucho me temo que, si queremos actuar correctamente en esta materia, en algún momento habremos de plantearnos la virtualidad futura del PLGNM a través del prisma de las Reglas de Rotterdam. Mal elegido, por tanto, el ejemplo de la LGNM en el Preámbulo de la ley. Porque si hay algún modelo de modernidad y uniformidad reguladora en el que se debe amparar e inspirar el transporte marítimo es precisamente el del transporte terrestre y no al contrario.

El Preámbulo de la ley identifica con claridad cuál ha sido el modelo de política legislativa elegido por sus redactores ${ }^{17}$. O, por ser más fieles a las

${ }^{16}$ Convenio de las Naciones Unidas sobre el contrato de transporte internacional de mercancías total o parcialmente marítimo (11 de diciembre de 2008).

${ }^{17}$ Preámbulo II, párrafo primero: «En cuanto al modelo de política legislativa que se ha tenido en cuenta a la hora de redactar la ley, puede decirse que la misma adapta, en lo sustancial, el Derecho del contrato de transporte terrestre español al modelo que suponen los 
palabras del Preámbulo, los modelos, en plural. Porque la inspiración legislativa se ha tomado de dos convenios internacionales reguladores del contrato de transporte terrestre, el CMR (1956) (carretera) ${ }^{18}$, por un lado, y el COTIF-CIM (Protocolo de Vilna de 1999) (ferrocarril), por otro ${ }^{19}$. Pero, en realidad, no sería del todo incorrecto hablar de modelo, en singular, porque bien es sabido que la versión del COTIF-CIM de 1999 está inspirada en el CMR (así como el CMR, en su día, se inspiró en las Reglas CIM de 1952). De hecho, las distintas reformas de la regulación nacional del contrato de transporte terrestre que se han llevado a cabo en otros países europeos durante las últimas décadas se han inspirado inequívocamente en el CMR, de manera directa o indirecta ${ }^{20}$. Es, por lo tanto, este último instrumento el modelo preponderante de legislación elegido por nosotros.

Lo tenía fácil el legislador español, sin duda, a la hora de elegir el modelo a seguir, al menos en su diseño general. Porque, además, hubiese sido un error plantear una reforma de nuestra legislación que hubiera dejado de lado lo que un buen número de países de nuestro entorno (todos ellos de enorme influencia en el sector transportador y la inmensa mayoría de ellos países comunitarios) habían hecho hasta entonces. No nos olvidemos, en este sentido, que, como dijimos, una de las aspiraciones de la ley es conseguir una aproximación entre las normativas interna e internacional del contrato de

convenios internacionales en la materia, básicamente al Convenio de transporte internacional de mercancías por carretera (CMR) y a las Reglas Uniformes CIM/1999, siguiendo así el camino antes trazado por otros países europeos. La consideración que subyace a esta decisión es sin duda alguna la de reconocer que no resultan tan distintos, en el momento actual, el transporte internacional y el puramente interno, al que van destinados los preceptos de la presente ley».

${ }^{18}$ Convenio de Ginebra de 19 de mayo de 1956 (BOE núm. 109, de 7 de mayo de 1974), modificado por el Protocolo de Ginebra de 5 de junio de 1978 (BOE núm. 303, de 18 de diciembre de 1982). Sobre este Convenio, véase C. Llorente Gómez de Segura, «Contratos internacionales de transporte por carretera, ferrocarril y marítimo», en A.-L. Calvo Caravaca y J. Carrascosa González (Dirs.), Curso de contratación internacional, Madrid, 2006, pp. 687-757.

${ }^{19}$ Protocolo de Vilna de 3 de junio de 1999 (BOE núm. 149, de 26 de junio de 2006). Véase, C. Llorente Gómez de Segura, «El nuevo régimen del transporte ferroviario internacional. El Protocolo de Vilnius de 1999», Derecho de los Negocios, enero 2003, pp. 1-12. Con mayor detalle, A. Emparanza Soberano y A. Recalde Castells, El contrato de transporte internacional de mercancías por ferrocarril, Cizur-Menor, 2008.

${ }^{20}$ Véanse, p. ej., los trabajos en este sentido de A. Schindler («La nueva Ley alemana de transportes de 1998 y su modelo la Convención CMR»), P. Csoklich («Las reglas CMR como derecho aplicable al transporte nacional: la favorable experiencia en Austria»), J. Putzeys («El transporte nacional de mercancías por carretera en Bélgica, bajo las reglas CMR: una experiencia positiva»), J. L. Saragoça («El nuevo régimen jurídico del contrato de transporte nacional de mercancías por carretera en Portugal: la asunción de las reglas CMR»), todos ellos en Actualidad jurídica del transporte por carretera. In Memoriam F.M. Sánchez Gamborino, Madrid, 2005, pp. 185-194, pp. 195-202, pp. 211-225, pp. 331-349, respectivamente. 
transporte terrestre de mercancías, particularmente en el ámbito del mercado interior $^{21}$. Y qué mejor modelo que el del Convenio CMR, que desde 1956 ha demostrado su utilidad y eficacia contrastada en la regulación del contrato de transporte de mercancías por carretera ${ }^{22}$.

Cierto es, no obstante, que no todos los países que han adoptado como modelo de regulación nacional el CMR lo han hecho de un mismo modo. Algunos han elegido una vía directa consistente en acordar la aplicación, tal cual, del texto internacional al transporte interno (Austria, Bélgica, etc.), sin más elaboración (técnica de «cortar y pegar»). Y otros, los demás, reconociendo que el CMR ha sido su modelo central de política legislativa (en más o en menos), han optado por dar a luz un texto de elaboración propia ${ }^{23}$. Este ha sido también el planteamiento de la norma española, tal y como pone de manifiesto expresamente el Preámbulo de la ley ${ }^{24}$.

Probablemente, la opción empleada por el legislador español (o por los restantes legisladores europeos que han seguido anteriormente una vía similar) era inevitable, pero no deja uno de tener la sensación de que, a pesar del mínimo común denominador que proporciona el CMR, las «adaptaciones» nacionales del CMR, como es el caso de la ley española, no contribuyen, sino más bien lo contrario, a conseguir que, al menos en el mercado interior, todos los transportes, sean internos o internacionales (intracomunitarios), estén regulados por unas mismas normas ${ }^{25}$. Por este motivo, en otras ocasio-

${ }^{21}$ C. Llorente Gómez de Segura, «Integración europea y unificación de la reglamentación del contrato de transporte terrestre de mercancías por carretera: algunos datos y reflexiones», en F. Martínez Sanz (Dir.) y M. ${ }^{a}$ Victoria Petit Lavall (Coord.), I Congreso internacional de transporte. Los retos del transporte en el siglo XXI, tomo I, pp. 847-867.

${ }^{22}$ C. Llorente Gómez de Segura, «La incidencia del CMR en la armonización del contrato de transporte en los Estados miembros de la Comunidad Europea», en A.-L. Calvo Caravaca y S. Areal Ludeña, Cuestiones actuales del derecho mercantil internacional, Madrid, 2005, pp. 745-764.

${ }^{23}$ Ha sido el caso, p. ej., de la regulación alemana. Véase, C. Llorente Gómez de Segura, «La nueva regulación del contrato de transporte en Alemania.-Transportrechtsreformgesetz (TRG)», Revista de Derecho Mercantil, núm. 234, octubre-diciembre 1999, pp. 16011650. Igualmente, I. Koller, «La reforma del derecho del transporte: balance de la experiencia alemana», en F. Martínez Sanz (Dir.) y M. ${ }^{a}$ Victoria Petit Lavall (Coord.), I Congreso internacional de transporte. Los retos del transporte en el siglo XXI, tomo I, pp. 789-807; F. Martínez Sanz, «La reforma del Derecho del transporte en Alemania», RDM, 1997, pp. 1267-1295.

${ }^{24}$ Preámbulo II, párrafo segundo, primer inciso: «Ahora bien, si se tiene en cuenta que tales convenios distan de contener una regulación completa del contrato de transporte, no debe extrañar que la ley no se limite a incorporar acríticamente las soluciones contenidas en dichos textos, sino que, en una medida muy elevada, presenta soluciones propias a muchos de los problemas que ofrece el transporte terrestre de mercancías».

${ }^{25}$ Una visión escéptica en J. Putzeys, «El CMR como modelo de política legislativa para la regulación del transporte interno. El caso belga», en F. Martínez Sanz (Dir.) y M. ${ }^{a}$ Victoria Petit Lavall (Coord.), I Congreso internacional de transporte. Los retos del transporte en el siglo XXI, tomo I, pp.869-878. 
nes nos hemos pronunciado a favor de la intervención legislativa directa del «legislador» comunitario en una materia de tanta trascendencia económica como es el transporte ${ }^{26}$. Mientras esto no suceda, y si sucede en algún momento, debemos conformarnos al menos con haber dado un paso adelante en el camino de la «armonización» (que no «unificación»), homologando de este modo nuestra legislación con la de nuestros socios comunitarios.

No ha rechazado, por su parte, el legislador español recurrir a nuestra tradición jurídica en la materia a la hora de acoger o proponer determinadas normas (y de relevancia) en la nueva ley ${ }^{27}$. Se trata de una opción legislativa razonable en la medida en que nuestro Derecho precedente en esta materia había consagrado reglas bien pensadas, útiles y, lo que es muy importante, generalmente aceptadas por los operadores del sector.

En cualquier caso, en este contexto, la nueva ley no podía obviar la necesidad de determinar cuáles de esas normas anteriores quedan derogadas y cuáles siguen vigentes, lo que hace a través de la denominada Disposición Derogatoria Única («Derogaciones y vigencias») ${ }^{28}$.

${ }^{26}$ Quizás sea en este contexto donde pueda encontrar sentido la frase del Preámbulo I, párrafo primero cuando señala que «[E]n sentido estricto, esta ley no venía obligada por la incorporación al Derecho español de directivas comunitarias». Lo que ha querido decir el legislador español es que la nueva ley no es fruto de la necesidad de trasponer directivas en la materia, lo cual es correcto porque no hay tales directivas. Llama la atención, no obstante, que el legislador español haya querido hacer esa afirmación tan explícita e innecesaria en una exposición de motivos ¡Como si toda la actividad legislativa de nuestro país hubiera de depender del previo impulso comunitario! Lo cual, por otro lado, no significa que no se puedan encontrar títulos competenciales que permitan al legislador comunitario desarrollar una regulación armonizada o uniforme del contrato de transporte terrestre de mercancías en el ámbito comunitario, que es lo que sugerimos en el texto.

${ }^{27}$ Preámbulo II, párrafo segundo, inciso segundo: «Sin embargo, sería erróneo pensar que la ley implica una ruptura total con la tradición española en la materia. En un número importante de casos, las soluciones que se acogen en el nuevo texto legal son actualización de las que ya se acogían en el Derecho anterior, o suponen una actualización o reubicación normativa de las mismas. Es lo que ocurre, por ejemplo, con las obligaciones de carga, estiba, desestiba y descarga, contenidas hasta ahora en la Ley 16/87, de 30 de julio, de Ordenación de los Transportes Terrestres (LOTT), o con la responsabilidad por paralización de los vehículos en el lugar de toma en carga o con la determinación de los límites máximos de responsabilidad del porteador por pérdidas, averías o retraso, igualmente contenidos en la ley referida».

${ }^{28}$ Disposición derogatoria única. «Derogaciones y vigencias.

1. Quedan derogadas las siguientes disposiciones:

a) Los artículos 349 a 379, ambos inclusive y, en cuanto afecten al transporte terrestre de mercancías, los artículos 951 y 952 del Código de Comercio de 1885.

b) Las normas recogidas en la legislación sectorial de los transportes por carretera y ferrocarril que se opongan a lo dispuesto en esta ley.

c) Cuantas normas de igual o inferior rango se opongan a esta ley.

2. En lo que no se opongan a lo dispuesto en esta ley, se declaran vigentes las condiciones generales de contratación de los transportes de mercancías por carretera, aprobadas 
Por un lado, la nueva ley deroga expresamente los preceptos del Código de Comercio aplicables a esta materia, es decir, los artículos 349-379 (Libro II, Título VII: «Del contrato mercantil de transporte terrestre»), en una manifestación más del ¿inevitable e imparable? fenómeno de la descodificación del Derecho mercantil. También se derogan expresamente, por otra parte, los artículos 951 y 952 del Código de 1885 en cuanto afecten al transporte terrestre de mercancías. Como se recordará, estos dos preceptos regulan la prescripción de las acciones mercantiles en los ámbitos marítimo y del transporte terrestre en general.

También se derogan expresamente, además de cuantas normas de igual o inferior rango se opongan a la ley, las reglas contenidas en la legislación sectorial de los transportes por carretera y por ferrocarril que se opongan a lo dispuesto en la nueva ley. Con esa expresión de «legislación sectorial», el legislador español se está refiriendo, fundamentalmente, a la LOTT (ROTT) y a la LSF (RSF), que, no obstante su carácter jurídico-público, han servido tradicionalmente de recipiente y acomodo de normas propias del contrato de transporte terrestre, normas de Derecho privado por lo tanto, exigidas, en cada momento, por la necesidad de actualizar la regulación del sector. La técnica de derogación no es directa, porque no se identifican las normas concretas objeto de derogación, sino que remite a un análisis posterior de cuáles de esas normas se oponen o no a la nueva legislación. Probablemente no había otra opción (eficiente). Y tampoco creemos que, por este motivo, se planteen problemas de aplicación normativa, pues la regla general habrá de ser que los contratos de transporte terrestre de mercancías se regulen por la nueva ley sin que haya que recurrir, por lo general, a preceptos contenidos en leyes especiales.

Mayores reparos ofrece, sin embargo, el mantenimiento de la vigencia de la O. M. de 25 de abril de 1997, modificada en 2008, que, prácticamente desde su entrada en vigor, ofreció serias dudas acerca de su legalidad y, en general, acerca de su calidad técnica y, en último extremo, de su utilidad para regular adecuadamente (o complementar la regulación) de este contrato (en realidad, las condiciones generales de la contratación recogidas en dicha orden ministerial apenas han tenido una aplicación práctica y real que justificase su existencia a lo largo de casi trece años $)^{29}$. Señala la Disposición Derogatoria, afortunadamente, que la O. M. de 1997 habrá de adaptarse a la nueva ley en el plazo de doce meses a partir de su entrada en vigor. Y no dudamos de que así se hará, dado el grado de compromiso con esta nueva ley

por la Orden del Ministerio de Fomento de 25 de abril de 1997, modificada por la Orden FOM/2184/2008, de 23 de julio. Dicha orden ministerial se adaptará al contenido de la presente ley en el plazo de doce meses a partir de su entrada en vigor».

${ }^{29}$ A. Emparanza Sobejano, «Un intento desencaminado de reformar el régimen jurídico del transporte por carretera: la Orden de 25 de abril de 1997», DNeg, 2000, pp. 1 y ss. 
y el alto expertise técnico de los profesionales del Ministerio de Fomento que habrán de abordar esta labor. Pero no les arrendamos la ganancia, porque se tratará de una tarea ardua e ingrata, en la que habrá que definir bien qué y cómo se regula, y cómo se encaja en la nueva legislación, para evitar el modelo «pastiche» que caracterizó a la redacción de las reglas contenidas en las condiciones generales que se aprobaron con la fallida O. M. de 1997.

La previsión de revisión de la O. M. de 1997 contenida en la Disposición Derogatoria debe ser vista, por su parte, en el contexto de lo que establece la Disposición final tercera de la Ley («Condiciones generales de contratación»), que, una vez derogada la LOTT, y su Reglamento (ROTT) en lo que afecta al ámbito de aplicación de la nueva ley, se constituye en la base legal que soporta la competencia de la Administración a la hora de establecer contratos-tipo o condiciones generales de contratación ${ }^{30}$. Esta Disposición, cuyo modelo se encuentra en la LOTT, va más allá del mero ámbito del transporte de mercancías, pues también comprende el transporte de viajeros, y, desde una perspectiva estrictamente contractual, recoge dos reglas de enorme trascendencia práctica, traídas también de la LOTT, que merece la pena recordar en estos momentos en la medida en que afectan a la regulación del contrato de transporte terrestre de mercancías.

La primera se recoge en su apartado 2, cuando señala que las condiciones generales de la contratación aprobadas por la Administración serán aplicables en forma subsidiaria o supletoria a las que libremente pacten las partes en los correspondientes contratos singulares de transporte. Se respeta, por lo tanto, en este contexto, el principio de autonomía de la voluntad de las partes, por supuesto dentro del ámbito de lo que la nueva ley no considere imperativo. Lo cual significa, a su vez, que los operadores de transporte, dentro

${ }^{30}$ Disposición final tercera. «Condiciones generales de contratación.

1. El Ministro de Fomento, de acuerdo con esta ley, podrá establecer contratos-tipo o condiciones generales de contratación para las distintas clases de transporte terrestre, en los que se determinen los derechos y obligaciones recíprocas de las partes y las demás reglas concretas de cumplimiento de los contratos singulares.

2. Las reglas de los contratos-tipo o condiciones generales, cuando se refieran a contratos de transportes de mercancías por carretera o por ferrocarril, o transportes de viajeros en ferrocarril o autobús contratados por coche completo, incluyéndose, a tal efecto, los regulares de uso especial, serán aplicables en forma subsidiaria o supletoria a las que libremente pacten las partes en los correspondientes contratos singulares.

3. En los transportes de viajeros por carretera en vehículos de turismo, así como en los transportes en autobús o por ferrocarril con contratación por asiento, los contratos-tipo o condiciones generales de contratación aprobados por la Administración se aplicarán con carácter imperativo, pudiendo, no obstante, incluirse cláusulas anexas a dichos contratostipo que se apliquen únicamente con carácter subsidiario o supletorio a los que pacten las partes.

4. No obstante lo dispuesto en los apartados anteriores, los porteadores podrán ofrecer a los usuarios condiciones más favorables a las establecidas en los contratos-tipo, teniendo en este caso, estas últimas, el carácter de condiciones mínimas». 
de ese marco dispositivo legal (artículo 3 de la nueva ley), y con el matiz que indicaremos a continuación, pueden tener sus propias condiciones generales de contratación distintas de las propuestas por la Administración (circunstancia esta que, por lo general, es la regla en otros países de nuestro entorno, donde son las asociaciones de transportistas u operadores de transporte las que elaboran esas condiciones).

La segunda regla de la que hablamos es la contenida en su apartado 4, mediante la que se establece que, no obstante la existencia de condiciones generales de contratación aprobadas por la Administración, los transportistas podrán ofrecer a los usuarios condiciones más favorables a las establecidas en los contratos-tipo, y en este caso, estas últimas, tendrán el carácter de condiciones mínimas. Se introduce aquí, en consecuencia, una corrección al principio de la autonomía de la voluntad articulado a través de la propuesta de condiciones generales de contratación de producción privada, en la medida en que las condiciones aprobadas por la Administración tendrán siempre ese carácter de mínimo inderogable (con independencia de lo que signifique tener «carácter de condiciones mínimas», que no es, dicho sea de paso, un problema de fácil solución).

Finalmente, en esta introducción no queremos dejar pasar la oportunidad de recordar que el texto legislativo ahora aprobado por las Cortes Generales tiene su origen en los trabajos realizados por una Sección especial de la Comisión General de Codificación, que fue la que elaboró, de manera concienzuda y, a mi juicio, muy completa, el Anteproyecto de Ley de Contrato de Transporte Terrestre. En esa Sección estuvo representada una parte muy relevante de la moderna doctrina española del Derecho del transporte, así como cualificados expertos de los Ministerios de Fomento y Justicia. Algunos aspectos relevantes de la normativa propuesta en el anteproyecto se han quedado fuera de la nueva ley, de manera más o menos (in-)explicable, pero sigue siendo un texto imprescindible para entender los orígenes de la ley actual y valorar, y juzgar, el alcance de la intervención parlamentaria en la concreción del texto final de la ley.

Dicho lo anterior, en los apartados siguientes abordaremos el análisis del contenido de la ley, para lo cual vamos a seguir, fundamentalmente, la estructura y orden articulado de su texto. Primero, analizaremos su Capítulo I («Disposiciones generales», artículos 1-9, que, no obstante ese carácter general, contiene algunos preceptos de enorme relevancia. Luego abordaremos el Capítulo II («Documentación del contrato», artículos 10-16. El Capítulo III («Contenido del contrato de transporte de mercancías», artículos 17-43, por su parte, es el más extenso de todos, lo que resulta comprensible dado que es el lugar en el que se aborda la regulación de los derechos y obligaciones de las partes de un contrato de transporte terrestre de mercancías. Más breve resulta, por su parte, el Capítulo IV («Depósito y enajenación de las mercancías», artículos 44-45, que también goza de una extraordinaria importancia en la resolución de algunos conflictos habituales en la ejecución de los contratos 
de transporte. Se podría discutir la necesidad de contemplar estas cuestiones en un capítulo diferenciado, pero en modo alguno la necesidad de su regulación en el marco de la ley. El Capítulo V («Responsabilidad del porteador», artículos 46-63, también merece la extensión y dedicación reguladora que le ha concedido la ley. No en vano, el problema de la responsabilidad del porteador es el más relevante de todos los que puede presentar un contrato de transporte, tanto desde una perspectiva dogmática como, sobre todo, de orden práctico y exigía, en consecuencia, un especial tratamiento por parte del legislador. También constituye un clásico en cualquier regulación del contrato de transporte un capítulo como el VI («Porteadores sucesivos», artículos 64-66, pero en este ámbito de la regulación de la colaboración entre transportistas es donde la ley presenta sus mayores debilidades, como habremos de poner de manifiesto al hablar de la subcontratación. Como novedades, sin duda destacadísimas, de la nueva legislación se nos presentan, por último, los Capítulos VII («Transporte multimodal»), artículos 67-70, y VIII («Normas especiales del contrato de mudanza», artículos 71-77, probablemente las partes más flojas y desorientadas (aunque no por ello menos bienintencionadas) de la nueva ley. Y luego, para concluir, está el Capítulo IX («Prescripción de acciones», artículos 78-79, de indudable trascendencia y en el que se introducen algunas modificaciones sustanciales respecto al régimen normativo vigente hasta la fecha.

La ley concluye, por último, con las consabidas Disposiciones adicionales, transitorias, derogatorias y finales. A varias de ellas ya hemos hecho referencia en las páginas anteriores de este trabajo y por lo que respecta a las restantes (algunas bastante curiosas) no las trataremos de manera autónoma sino en el contexto de la exposición general de nuestra explicación.

Por supuesto, no daremos cuenta de aquellas Disposiciones que no tienen nada que ver con el objeto de la regulación de la ley (el contrato de transporte terrestre de mercancías), pero que se incluyen en su texto aprovechando que el Pisuerga pasa por Valladolid (o el Manzanares por Madrid).

Nos referimos, y las transcribimos en nota para una mejor referencia del lector, a las reglas contenidas particularmente en la Disposición final primera («Modificación de la Ley 39/2003, de 17 de noviembre del Sector Ferroviario»), tanto en sus apartados primero $^{31}$, segundo ${ }^{32}$ y terce-

${ }^{31}$ Disposición final primera. «Modificación de la Ley 39/2003, de 17 de noviembre, del sector ferroviario.

Uno. La letra e) del artículo 90.2 de la Ley 39/2003, de 17 de noviembre, del Sector Ferroviario, queda redactada como sigue:

“e) Viajar sin título de transporte o con título que resulte insuficiente en función de las características del viaje y condiciones generales de contratación establecidas que sean de aplicación, así como el uso indebido del título que se posea o viajar en lugares distintos de los habilitados para los viajeros"».

${ }^{32}$ Dos. Se añade una nueva disposición adicional décima en la Ley 39/2003, de 17 de noviembre, del Sector Ferroviario con la siguiente redacción: 


\section{ro $^{33}$. Y, también a la normas que se recogen en la Disposición final cuarta}

"Disposición adicional décima de la Ley 39/2003, de 17 de noviembre, del Sector Ferroviario. Servicios internacionales de transporte ferroviario de viajeros. Acuerdos marco.

1. A partir del 1 de enero de 2010 las empresas ferroviarias tendrán libre acceso a la Red Ferroviaria de Interés General para la explotación de servicios internacionales de transporte de viajeros. Para la realización de dichos servicios de transporte será preciso haber obtenido la correspondiente licencia de empresa ferroviaria otorgada por la autoridad competente de un Estado miembro de la Unión Europea. A dicho efecto se entiende por servicio internacional de transporte de viajeros, el servicio de transporte de viajeros en el que el tren cruce al menos una vez la frontera de España y cuyo principal objeto sea transportar viajeros entre estaciones situadas en Estados miembros distintos; el tren podrá formarse y/o dividirse, y las distintas partes que lo constituyan podrán tener procedencias y destinos diferentes, siempre que todos los coches crucen al menos una frontera. Se entiende por tránsito el paso a través del territorio español que se efectúa sin que se recojan o dejen viajeros y/o sin que haya carga o descarga de mercancías en el mismo.

A partir de la indicada fecha no será aplicable al transporte internacional de viajeros el régimen sobre gestión del transporte ferroviario de viajeros establecido en la disposición transitoria tercera de esta ley.

Durante la realización de los servicios internacionales de transporte de viajeros las empresas ferroviarias podrán recoger y dejar viajeros en cualquiera de las estaciones situadas en la citada Red en las condiciones que se indican a continuación:

a) Que el Comité de Regulación Ferroviaria, a petición de las autoridades competentes o de las entidades ferroviarias interesadas haya determinado previamente que el principal objeto del servicio internacional de transporte ferroviario de viajeros que se pretenda llevar a efecto es transportar viajeros entre estaciones españolas y las de otros Estados miembros de la Unión Europea.

b) Asimismo, el Comité de Regulación Ferroviaria determinará, previamente, si el equilibrio económico de un contrato de servicio público ferroviario preexistente puede verse comprometido cuando las estaciones españolas en que se pretenda tomar y dejar viajeros estén afectadas por la realización del servicio internacional de transporte ferroviario de viajeros proyectado.

A tal fin, el Comité de Regulación Ferroviaria, a petición previa del órgano que haya adjudicado el contrato de servicio público, de cualquier otra autoridad competente interesada que tenga derecho a limitar el acceso, del administrador de la infraestructura ferroviaria, o de la empresa ferroviaria que ejecute el contrato de servicio público, efectuará un análisis económico objetivo y de criterios predefinidos.

Las autoridades competentes y las empresas ferroviarias que presten los servicios públicos deberán facilitar al Comité de Regulación Ferroviaria la información suficiente para tomar una decisión.

El Comité estudiará la información facilitada, consultará a todas las partes interesadas y les comunicará su decisión motivada en un plazo de dos meses a partir de la recepción de toda la información pertinente. El Comité expondrá los motivos de su decisión y precisará dentro de qué plazo y bajo qué condiciones las autoridades competentes, el administrador de infraestructuras ferroviarias, la empresa ferroviaria que ejecute el contrato de servicio público, o la empresa ferroviaria que solicite el acceso, podrán solicitar una revisión de dicha decisión. La decisión tendrá eficacia ejecutiva, y podrá ser recurrida ante la jurisdicción contencioso-administrativa sin perjuicio del derecho a interponer recurso de reposición.

El candidato que se proponga solicitar una capacidad de infraestructura con el fin de explotar un servicio internacional de transporte de viajeros informará al administrador de infraestructuras ferroviarias y al Comité de Regulación Ferroviaria. 


\section{de la Ley («Modificación de la Ley 20, 2007, de 11 de julio, del Estatuto del}

Con el fin de permitir la evaluación de la finalidad del servicio internacional de transporte de viajeros entre estaciones situadas en distintos Estados miembros, así como el impacto económico potencial en los contratos de servicio público en vigor, el Comité de Regulación Ferroviaria velará por que se informe a la autoridad competente que haya adjudicado un servicio de transporte de viajeros por ferrocarril definido en un contrato de servicio público, a cualquier otra autoridad competente interesada que tenga derecho a limitar el acceso y a las empresas ferroviarias que ejecuten el contrato de servicio público en el trayecto del citado servicio internacional de transporte de viajeros.

2. Las empresas ferroviarias que deseen realizar transporte internacional de viajeros por ferrocarril a partir del 1 de enero de 2010 podrán solicitar al Ministerio de Fomento, desde el día siguiente al de publicación de esta disposición en el Boletín Oficial del Estado, la solicitud de licencia ferroviaria acompañando a tal efecto la documentación justificativa pertinente.

3. Vigencia de los acuerdos marco entre el administrador de infraestructuras ferroviarias y los candidatos:

a) En principio, los acuerdos marco tendrán una vigencia de cinco años, renovable por períodos iguales a la vigencia inicial. En casos concretos podrá acordarse un período mayor o más breve. Todo período superior a cinco años estará justificado por la existencia de contratos comerciales, inversiones especializadas o riesgos.

b) En el caso de los servicios que utilicen una infraestructura especializada que requiera inversiones de gran magnitud y a largo plazo, debidamente justificadas por el candidato, los acuerdos marco podrán tener un período de vigencia de quince años.

c) Será posible un período de vigencia superior a quince años solo en casos excepcionales y, en concreto, en caso de inversiones de gran magnitud y a largo plazo, y especialmente cuando estas sean objeto de compromisos contractuales que incluyan un plan de amortización plurianual. En dicho caso, las necesidades del candidato podrán requerir que se definan con precisión las características de la capacidad -con inclusión de las frecuencias, el volumen y la calidad de las franjas ferroviarias que se adjudicarán al candidato durante la vigencia del acuerdo marco. En el caso de infraestructuras congestionadas, el administrador de infraestructuras ferroviarias podrá reducir la capacidad reservada cuando, en un periodo de al menos un mes, esta haya sido utilizada por debajo de la cuota asignada al candidato.

d) No obstante lo anterior, a partir del 1 de enero de 2010 se podrá elaborar un contrato marco inicial con una vigencia de cinco años, renovable una vez, en función de las características de capacidad que utilicen los candidatos que exploten los servicios antes del 1 de enero de 2010, a fin de tener en cuenta las inversiones particulares o la existencia de contratos comerciales.

4. Las resoluciones que, en el marco de lo establecido anteriormente, sean dictadas por el Comité de Regulación Ferroviaria tendrán eficacia ejecutiva y serán vinculantes para las entidades que actúen en el ámbito ferroviario, siendo las mismas directamente recurribles ante la jurisdicción contencioso administrativa"».

33 «Tres. Se modifica la disposición transitoria segunda de la Ley 39/2003, de 17 de noviembre, del Sector Ferroviario, con la siguiente redacción:

"Podrán obtener, con arreglo a esta ley, asignación de capacidad de infraestructura, los candidatos nacionales de otros países de la Unión Europea que deseen prestar servicios de transporte ferroviario en España”. 
Trabajador Autónomo) $)^{34}$. No negamos la importancia de estas normas, que la tienen (y muchísima en algunos casos), sino que dudamos de la adecuación de su inclusión en un texto legislativo regulador del contrato de transporte terrestre de mercancías, por mucho que aquellas normas se refieran a la actividad de transporte. Son normas de ordenación y su ubicación debiera haber sido otra bien distinta ${ }^{35}$.

\section{Disposiciones generales}

El Capítulo I de la ley contiene una serie de disposiciones generales, de distinto orden, en sus artículos 1-9, todos ellos de trascendencia a la hora de delimitar el alcance de la nueva legislación.

Su artículo 1 comienza indicando que el «objeto de la presente ley es la regulación del contrato de transporte terrestre de mercancías realizado por medios mecánicos con capacidad de tracción propia».

De este pronunciamiento se derivan claramente tres circunstancias.

En todo caso, las previsiones de esta ley resultarán de aplicación a los referidos candidatos en la fecha en la que expire el plazo para que los Estados miembros de la Unión Europea liberalicen, con arreglo a las directivas comunitarias, cada tipo de servicio.

Se reconoce, asimismo, el derecho de acceso a la Red Ferroviaria de interés General a las empresas ferroviarias que presten servicios de transporte internacional combinado de mercancías».

${ }^{34}$ Disposición final cuarta. «Modificación de la Ley 20/2007, de 11 de julio, del Estatuto del Trabajo Autónomo.

El segundo párrafo de la disposición transitoria tercera de la Ley 20/2007, de 11 de julio, del Estatuto del Trabajo Autónomo, queda redactado como sigue:

"El trabajador autónomo en el que concurra la circunstancia de ser económicamente dependiente en el supuesto al que se refiere la disposición adicional undécima y en el supuesto del agente de seguros, deberá comunicarlo al cliente respecto al que adquiera esta condición, en el plazo comprendido desde la entrada en vigor de la presente ley hasta un año después de la entrada en vigor de las citadas disposiciones reglamentarias" ».

${ }^{35}$ No obstante, el Preámbulo de la ley, en su apartado VI, las comenta con toda normalidad: «Finalmente, en la disposición final primera de esta ley, se reforma la Ley 39/2003, de 17 de noviembre, del Sector Ferroviario, para cumplir los siguientes objetivos:

En primer lugar, colmar una laguna jurídica en relación con la infracción de los viajeros sin título de transporte, conducta hoy carente de tipificación legal como infracción administrativa.

$Y$ en segundo lugar, liberalizar el transporte internacional de viajeros por ferrocarril, de acuerdo con lo exigido en la Directiva 2007/58/CE del Parlamento y del Consejo de 23 de octubre de 2007 por la que se modifican la Directiva 91/440/CEE del Consejo, sobre el desarrollo de los ferrocarriles comunitarios, y la Directiva 2001/14/CE, relativa a la adjudicación de la capacidad de infraestructura ferroviaria y la aplicación de cánones por su utilización; directiva cuya incorporación al derecho interno español es obligado se produzca antes del 4 de junio de 2009, fecha límite para su transposición». 
Una, que el contrato de transporte terrestre de pasajeros o viajeros queda fuera del ámbito de aplicación de la ley. El comentario es procedente en la medida en que en el Anteproyecto de Ley sobre el Contrato de Transporte Terrestre, por el contrario, sí se recogieron con detalle normas reguladoras del transporte de personas, pero, finalmente, se decidió su exclusión del proyecto de ley, principalmente para evitar solapamientos con las normas y proyectos que al respecto se han elaborado, o se están elaborando, en el seno de la Comunidad Europea. Habrá que ver en qué queda finalmente toda la regulación comunitaria, vigente y proyectada, en esta materia, pero que este dato no nos impida recordar que existe en nuestro ordenamiento la necesidad de contar con normas reguladoras del contrato de transporte de personas por vía terrestre, en general; no solo, por tanto, en el sector ferroviario, en particular, que es donde la Comunidad Europea ha sido más activa hasta la fecha, sino, también y muy especialmente, en el sector de la carretera, que está huérfano de regulación.

En el texto de la ley, por cierto, y dicho sea de paso, hay una referencia específica al transporte de viajeros en su Disposición adicional segunda («Encargos en el transporte de viajeros») ${ }^{36}$, pero se trata de una regla especial de regulación de aquellos supuestos en los que se utiliza un medio de transporte de pasajeros para transportar un objeto (el llamado «encargo»), razón por la cual se señala que, en esos casos, el transporte de ese objeto, desde la perspectiva contractual, se regirá por las normas de la ley. Regla esta, por lo tanto, de especial interés para los empresarios de transporte terrestre de viajeros (y, particularmente, de la carretera) que, a cambio de un precio, se obliguen a transportar objetos que no guardan relación con ninguna de las personas que viajan en el mismo medio: la relación jurídica con la persona que les solicite el encargo será, propiamente, la de un contrato de transporte (de mercancías) de los sometidos a las reglas de la nueva ley.

La referencia a las mercancías como objeto exclusivo del contrato de transporte terrestre regulado por la nueva ley exige que también debamos recordar ahora la regla prevista en la Disposición adicional tercera («Transportes postales» $)^{37}$, en la medida en que regula el transporte de una «mercancía» con características particulares, los llamados «envíos postales». Lo que hace esta disposición es recordar que el transporte postal está sujeto a un

${ }^{36}$ Disposición adicional segunda: Encargos en el transporte de viajeros.

En el transporte de viajeros, cuando el porteador, a cambio de una remuneración, se obligue a transportar a bordo del vehículo cualquier objeto que no guarde relación directa con ninguno de los viajeros que ocupan plaza en el vehículo, dicho transporte se regirá por las normas de esta ley.

${ }^{37}$ Disposición adicional tercera: Transportes postales.

La contratación de los servicios de recogida, transporte y distribución de envíos postales en el marco del servicio postal universal se regirá por las normas reguladoras del sector postal y, en lo no previsto por estas, por la presente ley. 
régimen normativo especial y específico y que, por lo tanto, la nueva ley solo entrará en juego en este tipo de transportes para cubrir las lagunas que pueda presentar aquel régimen ${ }^{38}$.

La segunda referencia característica del artículo 1 es que la ley solo se aplicará en relación con el transporte terrestre, lo que incluye a la carretera y al ferrocarril, y excluye el transporte marítimo y aéreo. No así el transporte multimodal (si bien parcialmente), al que dedica la ley su novedoso Capítulo VII, del que hablaremos más adelante con alguna atención. Y tampoco se excluye, sino todo lo contrario, el transporte fluvial, en virtud de lo que establece la Disposición adicional primera de la ley ${ }^{39}$. Lo cierto es que, a diferencia de lo que sucede en otros países europeos, en nuestro país el transporte fluvial es de escasísima importancia comparada, por lo que esa referencia que hace la citada Disposición adicional primera a la eventual elaboración de una ley especial reguladora del contrato de transporte fluvial de mercancías nos parece un brindis al sol. Pero no lo es la cobertura que se da a los eventuales contratos de transporte de mercancías por vía fluvial que puedan concertarse en nuestro país. La aplicación en estos casos de la nueva Ley nos parece una medida razonable y justificada, que, responde, además, a nuestra tradición en este sector, ya recogida en el artículo 349 Ccom.

En este contexto es importante recordar también que, como indica expresamente el Preámbulo de la ley, se «opta por regular unitariamente el contrato de transporte terrestre de mercancías en sus dos variantes, por carretera y por ferrocarril. En principio, los preceptos son comunes a ambos modos, sin perjuicio de ofrecer soluciones específicas para el transporte ferroviario de mercancías en los lugares oportunos, cuando ello resulta necesario o conveniente». Solución muy adecuada en aras de la unificación de la regulación del contrato de transporte terrestre y que mantiene, en casos concretos (muy pocos), como no podía ser de otro modo, las peculiaridades de cada sector.

Finalmente, el artículo 1 de la ley circunscribe su aplicación a los contratos de transporte terrestre de mercancías en los que utilicen «medios mecánicos con capacidad de tracción propia». Se trata de una caracterización del objeto de la ley no ajena a otras normativas de nuestro entorno ${ }^{40}$, pero que tampoco tiene una trascendencia jurídica de fondo, sino que viene a constatar una realidad que, sencillamente, se deriva de la propia naturaleza técnica de los medios que se utilizan en la ejecución de contratos de transporte (terrestre, en este caso).

${ }^{38}$ El CMR excluye de su ámbito de aplicación a los transportes postales (artículo 1.4a).

${ }^{39}$ Disposición adicional primera: Transporte fluvial.

Mientras no se regule por ley especial el contrato de transporte fluvial de mercancías, este quedará sometido a la presente ley.

${ }^{40}$ Por ejemplo, el artículo 1.2 CMR define, por referencia a otros textos, lo que ha de entenderse por «vehículo». 
Quizás, si tiene alguna significación destacar en estos momentos esta característica particular del objeto de la nueva ley es por comparación con la mención pintoresca que hace su Disposición adicional quinta al «transporte realizado con bicicleta ${ }^{41}$, que, al igual que sucede con el transporte fluvial, podría ser objeto en el futuro de una regulación en sus aspectos contractuales («contrato de transporte realizado mediante la utilización de la bicicleta»).

Si el lector tuviera la curiosidad de analizar el proceso de debate parlamentario que hubo de llevar finalmente al texto de la ley ahora aprobada, podrá comprobar cómo esta regla sobre el contrato de transporte de mercancías realizado por medio de bicicleta fue prácticamente ignorada hasta el final del proceso de elaboración de la ley, momento en que consiguió colarse definitivamente en su texto, barrunto que, simplemente, para contentar (compensar) al grupo político que propuso esta medida llevado por sensibilidades ambientales e, incluso, culturales y deportivas. No descarto que en ese futuro sostenible que nos proponen nuestros gobernantes del siglo XXI, la bicicleta pueda jugar algún papel determinado (que no determinante) en el sector empresarial del transporte de mercancías. De hecho, muy poco antes de comenzar a redactar estas líneas, mientras paseaba por el centro de una ciudad europea no comunitaria, me topé con un ciclista que, debidamente ataviado con el uniforme de su empresa, con sus logos y demás parafernalia (al igual que su medio de desplazamiento), todo muy bien puesto y muy comercial, realizaba labores de transporte de paquetería de manera (creo) profesional. Ahora, sinceramente, no veo a nuestro legislador regulando por ley el contrato de transporte de mercancías por medio de la bicicleta (otro brindis al sol de la corrección política). Y, lo que es más importante, a diferencia de lo que sucede con el transporte fluvial, la aplicación de las normas de la nueva ley al contrato de transporte de mercancías realizado por ese medio tan ecológico habrá de sufrir un proceso de adaptación analógica de cierta intensidad y magnitud.

Moviéndonos hacia el artículo 2, este precepto aborda dos cuestiones diversas. Una primera, la definición del contrato regulado por la ley (artículo 2.1). Y otra, la identificación del régimen jurídico del contrato (artículo 2.2).

Por lo que respecta a la definición del contrato, en su apartado 1, el artículo 2 de la ley establece que «[e]l contrato de transporte de mercancías es aquel por el que el porteador se obliga frente al cargador, a cambio de un precio, a trasladar mercancías de un lugar a otro y ponerlas a disposición

${ }^{41}$ Disposición adicional quinta: Transporte realizado con bicicleta.

En tanto no se dicten disposiciones reguladoras del contrato de transporte realizado mediante la utilización de bicicleta, este quedará sujeto a las normas contenidas en la presente ley que le resulten de aplicación. 
de la persona designada en el contrato». Nada nuevo bajo el cielo y nada, por tanto, que objetar a una definición que asume, por vez primera en nuestra legislación general sobre el contrato de transporte, una posición conceptual sencilla y plenamente aceptada desde hace mucho tiempo en el sector ${ }^{42}$. Luego haremos una referencia a los sujetos principales que figuran identificados en esta definición (cargador y porteador), pues aparecen delimitados específicamente en el artículo 4 de la ley. Y, quizás, lo único que merezca la pena destacar en estos momentos de esa definición legal es la referencia al carácter esencialmente oneroso del contrato («a cambio de un precio»), rasgo que deja fuera de la regulación de la ley a los transportes que se llevan a cabo sin contraprestación. La onerosidad ha sido tradicionalmente un elemento esencial del contrato de transporte, pero recientemente se ha venido desdibujando, o desapareciendo, como tal, como sucede, por ejemplo, en el transporte ferroviario internacional. En este aspecto, por tanto, la nueva legislación se mantiene en los cánones clásicos.

Mayor perplejidad suscita el apartado 2 del artículo 2 relativo al régimen jurídico del contrato, que, para ser más precisos, habría que calificar de «regulación» del contrato. Según este apartado, «[e]l contrato de transporte terrestre de mercancías se regirá por los Tratados internacionales vigentes en España de acuerdo con su ámbito respectivo, las normas de la Unión Europea y las disposiciones de esta ley. En lo no previsto serán de aplicación las normas relativas a la contratación mercantil». Este es otro de esos preceptos de la ley (de los pocos habría que decir) a los que cabría aplicar aquella regla establecida por el conocido señor Murphy según la cual «lo que empieza mal, acaba mal». Si uno analiza la tramitación parlamentaria de la ley desde sus inicios hasta su conclusión, y conoce algo de sus entresijos, claramente se da cuenta de que la elaboración de este precepto ha dado demasiados (e innecesarios) quebraderos de cabeza, causados, muy probablemente, porque nunca se ha sabido cuál era el papel que debía jugar un precepto de tal naturaleza en la ley. Y aquí sí que se ha echado en falta alguna aportación particular, aunque fuese mínima, en la elaboración de la ley de un experto en Derecho internacional privado (DIPr), que hubiera podido arrojar alguna luz al respecto. Pero, ya se sabe, que, por su complejidad y por desconocimiento, el DIPr nunca ha sido, precisamente, manjar del gusto de nuestro legislador nacional de todos los tiempos.

Dejando a un lado esa referencia obvia al hecho de que el contrato de transporte terrestre de mercancías se regirá por «las disposiciones de esta ley», no resulta claro saber qué ha pretendido decir el legislador con su mención a los tratados internacionales y al Derecho comunitario.

${ }^{42}$ C. Llorente Gómez de Segura, «El contrato de transporte terrestre de mercancías», en

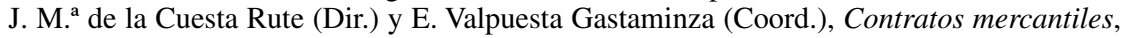
II, Barcelona, 2009, p. 989. 
Comenzado por esta última cita, no estoy muy convencido de que recordar la aplicación de las normas de la Unión Europea sea estrictamente necesario. O dicho de otro modo, ¿si no se hubiese establecido esa regla cabría entender que las eventuales normas comunitarias en la materia, si las hubiere, no serían de aplicación?

Por lo que respecta, por su parte, a los tratados o convenios internacionales en materia de contratación del transporte terrestre de mercancías, tampoco la referencia es demasiado afortunada. Parece evidente que los contratos de transporte terrestre de mercancías que caigan dentro del ámbito de aplicación de los respectivos convenios internacionales actualmente vigentes en este sector (p. ej., CMR o COTIF-CIM) se regirán por las normas de dichos convenios y no, en su caso, por las de la ley. Son contratos internacionales y, por lo tanto, serán gobernados, en primer lugar, por las normas materiales especiales que puedan existir (las previstas en los referidos convenios internacionales) y, en su defecto, por las normas del Derecho nacional (español o no) que resulten de aplicación en virtud de lo que establezcan las normas de DIP del foro (normas de conflicto). Y si se trata de contratos internacionales no cubiertos por el ámbito de aplicación de los correspondientes convenios, igualmente habrá que acudir a las normas de DIPr del foro para determinar el Derecho nacional (español o no) aplicable al fondo del asunto. Probablemente, aunque no hubiese resultado necesario, lo más adecuado hubiera sido indicar que la nueva ley se aplicará no solo a los contratos de transporte internos (es decir, aquellos que carecen de elemento de extranjería) sino, también, a los contratos internacionales de transporte terrestre de mercancías sujetos al Derecho español en virtud de lo que establezcan las correspondientes normas de DIPr del foro ${ }^{43}$.

Lo que, en todo caso, no ha hecho la ley (y podría haberlo hecho) es acoger una norma como la que contiene el HGB alemán, según la cual cuando estemos ante un contrato de transporte terrestre de mercancías de naturaleza internacional (por contener algún elemento extranjero en su estructura), pero cuyos puntos de origen y destino se encuentren dentro del territorio español, habrán de aplicarse necesariamente a dicho contrato las normas imperativas recogidas en la nueva ley, con independencia de cuál sea el Derecho nacional aplicable al contrato. De este modo, se hubiese reproducido en nuestro ordenamiento, al igual que se hizo en el vigente sistema alemán, la regla de la aplicación de las normas imperativas del Estado miembro de acogida a los

${ }^{43}$ En el DIPr español, las normas de conflicto aplicables al contrato de transporte son las establecidas en el Reglamento (CE) N. ${ }^{\circ}$ 593/2008, del Parlamento Europeo y del Consejo, de 17 de junio de 2008, sobre la ley aplicable a las obligaciones contractuales (Reg. Roma I) (DOUE n. ${ }^{\circ}$ L177, de 4 de julio de 2008): C. Llorente Gómez de Segura, «La Ley aplicable al contrato de transporte internacional según el Reglamento Roma I», Cuadernos de Derecho Transnacional, (Octubre 2009), Vol. 1, N. ${ }^{\circ}$ 2, pp. 160-178. 
contratos de transporte de cabotaje de mercancías, norma que está contenida en el artículo 6.1a del Reglamento (CEE) 3118/1993, de 25 de octubre ${ }^{44}$. O dicho de otro modo, hubiésemos incorporado a nuestro ordenamiento una norma de DIPr de las llamadas «de extensión» que establece la aplicación (extensión) de las normas internas imperativas españolas a determinados supuestos de naturaleza internacional. Estoy convencido de que en algún momento del debate del anteproyecto este tipo de consideraciones se tuvieron en cuenta por sus promotores, pero finalmente el fragor parlamentario ha dado como resultado un precepto con referencias internacionales que nada aporta y que, lo que es peor aún, confunde.

Por lo demás, y por cerrar el análisis de este precepto, la referencia a la aplicación supletoria de las normas relativas a la contratación mercantil no merece mayor comentario. Quizás cuando contemos con un cuerpo único de normas aplicables en conjunto a las obligaciones civiles y mercantiles (lo cual sería de desear) habrá que plantear esta cuestión de otro modo. En cualquier caso, tampoco se trata de una regla especialmente significativa.

El artículo 3 («Naturaleza dispositiva de la normativa») de la nueva ley es otro de los preceptos que hubiera quedado mejor, técnicamente hablando, si se hubiese respetado la propuesta del anteproyecto, dogmáticamente mucho más correcta. Pero, en suma, el texto definitivo es suficientemente claro: «Salvo expresa estipulación contraria de esta ley o de la legislación especial aplicable, las partes podrán excluir determinados contenidos de esta ley mediando el correspondiente pacto. También podrá ser así, respecto de las condiciones generales de los contratos de transportes cuando sus obligaciones resulten más beneficiosas para el adherente». Lo que nos viene a recordar este precepto es que la autonomía de la voluntad de las partes juega un papel muy importante en la regulación del contrato de transporte ${ }^{45}$, con el límite de la normativa imperativa o, si se emplean condiciones generales de contratación, siempre que estas sean más beneficiosas para el adherente respecto de lo establecido en la nueva legislación ${ }^{46}$. Por cierto, llama la atención esa referencia a la «legislación especial aplicable». ¿A qué se estará queriendo referir el legislador? Probablemente, a las normas de ordenación del transporte que, aun siendo normas administrativas o de Derecho

${ }^{44}$ DOCE n. ${ }^{\circ}$ L 279/1, de 12 de noviembre de 1993. Sobre este precepto, véase, Llorente, «Curso de contratación internacional», cit., p. 706.

${ }^{45}$ En el ámbito internacional, en particular, véase E. Castellanos Ruiz, Autonomía de la voluntad y derecho uniforme en el transporte internacional, Granada, 1999.

${ }^{46}$ Preámbulo II, último párrafo: «Aspecto básico de la regulación normativa para las partes, respetando siempre los contenidos imperativos y de orden público, es el relativo a su índole dispositiva general. Las partes, por ello, disponen de libertad contractual bien en los términos negociados individualmente o bien según las condiciones generales de adhesión más beneficiosas». 
público, puedan incidir en, o afectar a, la ejecución de los contratos de transporte terrestre de mercancías.

Por lo que se refiere al artículo 4 («Sujetos») ${ }^{47}$, la nueva ley se limita a ofrecer sendas definiciones de los principales sujetos que intervienen en el contrato de transporte. Cargador y porteador ${ }^{48}$, por un lado, que son las verdaderas y esenciales partes del contrato; por otro lado, está la figura del destinatario, al que la mejor doctrina siempre ha calificado como tercero beneficiario del contrato de transporte (dada la consideración dogmática mayoritaria de este contrato como contrato a favor de tercero ${ }^{49}$; y, por último, está la figura del expedidor, que es relativamente novedosa (surge entre nosotros, de una manera general, en la LOTT modificada en 2003). Nada hay, en suma, en las definiciones del artículo 4 que nos llame la atención, porque respetan lo que hasta la fecha ha sido consideración unánime entre nosotros. Pero, quizás sí merezca la pena destacar que la ley ha optado por fijar la denominación terminológica de los sujetos referidos de una manera más estricta. Al cargador se le llama cargador, y no remitente. Al porteador no se le llama transportista, expresión que utiliza, por ejemplo, la legislación ordenadora. Y al destinatario no se le llama consignatario, como sucedía en la legislación anterior. La expresión de porteador, en particular, no es un ejemplo de modernidad, ciertamente, pero, a falta de consenso para encontrar una expresión sustitutiva más adecuada, no vemos objeción para su mantenimiento.

Con los artículos 5 («Contratación del transporte en nombre propio») y 6 («Responsabilidad de los porteadores efectivos») entramos en lo que, sin duda alguna, son las zonas más oscuras de la ley. Nosotros hubiésemos deseado que el legislador hubiera sido más valiente en el tratamiento jurídico de los intermediarios del transporte (artículo 5) y del fenómeno de la subcontratación del transporte (artículo 6). Y, de hecho, el Preámbulo de la ley resulta muy prometedor en sus planteamientos al respecto, cuando dedica, ni más ni

\footnotetext{
${ }^{47}$ Artículo 4: Sujetos.

1. Cargador es quien contrata en nombre propio la realización de un transporte y frente al cual el porteador se obliga a efectuarlo.

2. Porteador es quien asume la obligación de realizar el transporte en nombre propio con independencia de que lo ejecute por sus propios medios o contrate su realización con otros sujetos.

3. Destinatario es la persona a quien el porteador ha de entregar las mercancías en el lugar de destino.

4. Expedidor es el tercero que por cuenta del cargador haga entrega de las mercancías al transportista en el lugar de recepción de la mercancía.

${ }^{48}$ Para un análisis detallado de la figura del porteador entre nosotros: A. Emparanza Sobejano, El concepto de porteador en el transporte de mercancías, Madrid, 2003.

${ }^{49}$ Véase un resumen de las distintas posiciones doctrinales al respecto en Llorente, «El contrato de transporte terrestre de mercancías», cit., pp. 1004-1005.
} 
menos, que prácticamente todo un apartado (IV) a explicar su postura en esta materia.

Comienza diciendo lo siguiente:

No cabe duda de que la determinación de los sujetos del transporte ha sido, en Derecho español, fuente de continuos problemas, tanto teóricos como prácticos, propiciados por una defectuosa regulación de tales cuestiones. No debe extrañar, por tanto, que la nueva ley dedique especial atención a la determinación de los sujetos del transporte y, de modo muy particular, a los problemas que plantea la intervención en el transporte de varios sujetos.

Leyendo el apartado anterior, uno no hubiese tenido la más mínima $d u d a$ razonable de que el legislador español, de una vez por todas, se había decidido a abordar la regulación de estas cuestiones con aires nuevos. Pues bien, nada más lejos de la realidad. Lo que ha hecho nuestro legislador, ha sido mantener el statu quo en la materia.

Por lo que respecta a la figura de los intermediarios del transporte, su tratamiento se recoge en el artículo 5, precepto que también alude a otras situaciones (en su apartado 3) que no vamos a comentar en particular porque entendemos que se han abordado de manera correcta ${ }^{50}$.

Según dicho artículo, los intermediarios de transporte (operadores y agencias de transporte, transitarios, almacenistas-distribuidores, etc.), no obstante su condición de intermediarios (comisionistas, en la jerga mercan-

${ }^{50}$ Artículo 5: Contratación del transporte en nombre propio.

1. Los contratos de transporte de mercancías se presuponen celebrados en nombre propio. Excepcionalmente podrá alegarse la contratación en nombre ajeno cuando se acredite que así se había hecho constar de forma expresa y suficiente en el momento de contratar, indicado la identidad de la persona en cuyo nombre se contrata, y que la intermediación se realizó con carácter gratuito.

2. Los empresarios transportistas, las cooperativas de trabajo asociado dedicadas al transporte, las cooperativas de transportistas y sociedades de comercialización de transportes, los operadores y agencias de transporte, los transitarios, los almacenistas-distribuidores, los operadores logísticos, así como cualesquiera otros que contraten habitualmente transportes o intermedien habitualmente en su contratación, solo podrán contratarlos en nombre propio.

3. La relación de las cooperativas de transportistas y sociedades de comercialización de transporte con el socio transportista que efectivamente realice el transporte se regirá por lo que al respecto se encuentre determinado en los estatutos de cada cooperativa o sociedad, sin que lo dispuesto en dichos estatutos pueda implicar, en ningún caso, la inaplicación de lo dispuesto en la presente ley en los contratos celebrados por la cooperativa o sociedad de que se trate con terceros.

Los socios de las cooperativas de trabajo asociado dedicadas al transporte solo podrán contratar transportes en nombre de la cooperativa a la que pertenecen, quedando esta obligada como porteador frente al cargador con quien contraten aquellos. 
til), habrán de contratar siempre el transporte en nombre propio. No podrán hacerlo, por tanto, en nombre ajeno. Con este mandato, como se señala expresamente en el Preámbulo, se clarifica la situación de dichos empresarios «consagrando, en líneas generales, la solución que ya se ofrecía en la normativa de ordenación del transporte terrestre (y, en última instancia, también en el artículo 379 del Código de Comercio), que obligaba a tales intermediarios a contratar el transporte siempre en nombre propio y a asumir la posición del porteador».

Parece mentira tener que leer, a estas alturas, que el procedimiento que ha empleado el legislador español del siglo XXI para clarificar la posición de los intermediarios del transporte en nuestro Derecho ha sido, ni más ni menos, que recurrir a una regla contenida en el Código de Comercio ;de 1885 !, el artículo 379 Ccom en particular, que es, sin duda alguna, el precepto que más polémica (y debate hasta el hartazgo) ha generado en la doctrina española del transporte de todos los tiempos ${ }^{51}$. Seamos sinceros: la regla incorporada a la nueva ley, heredada de la LOTT, lo ha sido por presión, legítima, de los transportistas, en contra de la posición de los intermediarios de transporte. Pero, en el fondo, este no es un problema de lobbying sino de decidir si queremos tener una regulación moderna y homologable en la materia a la de nuestros socios europeos. La regulación de la actividad contractual de los intermediarios del transporte debería recogerse en una ley específica para ellos que admitiera la diversidad de modalidades de actuación que para este tipo de operadores se contempla en los ordenamientos jurídicos de los países de nuestro entorno. Y en esta legislación se podría determinar cuándo los intermediarios responden o no de la ejecución del transporte llevado a cabo por los transportistas que han recibido de ellos tal encargo. No hay siquiera entre las disposiciones finales de la ley la previsión acerca de una futura regulación en la materia, algo que lleva reclamando nuestra mejor doctrina desde hace mucho tiempo ${ }^{52}$. En conclusión, que no se lleve nadie a

\footnotetext{
${ }^{51}$ Recientemente, véase L. M. Piloñeta, Las agencias de transporte de mercancías, Barcelona, 1997; A. M. Tobío Rivas, Los transitarios en el transporte nacional e internacional. Régimen jurídico privado, Granada 2007. Igualmente, C. Llorente Gómez de Segura, «La regulación jurídico-privada de la actividad del transitario en el derecho español. Un recordatorio», Estudios de Deusto, Vol. 55/2, julio-diciembre 2007, pp. 157-183; J. L. Gabaldón, «Intermediarios del transporte y porteadores contractuales», RDM, 2000, pp.1723-1747. Otros trabajos indicativos de esta polémica a lo largo de los tiempos son los siguientes: $\mathrm{M}$. García Amigo, «La relación contractual de transporte entre las agencias y sus usuarios, legislaciones y condiciones generales de contratación», $R D M, 1964$, pp. 311 y ss.; C. Pascual Arranz, «El contrato de expedición», RJC, 1958, pp. 499 y ss.; E. Seco, «El comisionista de transportes», $R D M, 1965$, pp. 237 y ss.; E. Valpuesta Gastaminza, «Naturaleza jurídica de la comisión de transporte tras la Ley de ordenación de los transportes terrestres», $C D C, 1991$, septiembre, núm. 9, pp. 79 y ss.

${ }^{52}$ Sánchez Calero, «El Código de Comercio y los contratos mercantiles», cit., pp. 211 y ss.
} 
engaño, la ley en este aspecto sin duda que clarifica la situación, pero lo hace retrocediendo en el tiempo y sin abordar decididamente un tratamiento jurídico del sector de la intermediación del transporte que sea más acorde con la realidad de los tiempos en que vivimos. Hubiese sido preferible, obviamente, y en todo caso, que el Preámbulo de la ley se hubiese pronunciado con mayor modestia.

Pero, donde el Preámbulo no solo no es modesto, sino hasta engañoso, es en la explicación que ofrece de la regulación prevista en el artículo 6 de la ley («Responsabilidad de los porteadores efectivos»).

Veamos lo que dice el Preámbulo:

De otra parte, y ello constituye verdadera innovación, la ley aborda la intervención de diversos sujetos por vía de subcontratación en el transporte y, de modo particular, la cuestión relativa a la determinación de las personas pasivamente legitimadas frente a las reclamaciones de responsabilidad, aportando seguridad jurídica en una materia notablemente litigiosa hasta el presente. Se consagra así definitivamente la posición del porteador efectivo.

Vaya por delante una explicación que afecta a una cuestión de técnica legislativa, que no se ha querido advertir durante la fase de enmiendas del proyecto de ley. El texto del Preámbulo que se acaba de transcribir procede del anteproyecto de ley, donde sí se introducían novedades muy significativas en el tratamiento de la subcontratación del transporte, tomadas de la legislación comparada e internacional más moderna y respetada. Lo que ha sucedido es que, posteriormente, se ha cercenado del texto de la nueva ley la propuesta de fondo del anteproyecto, pero manteniendo la explicación del Preámbulo.

Con lo que, volviendo al texto del Preámbulo, ni hay «verdadera innovación», ni se aborda este problema con criterios distintos a los que hasta la fecha se habían utilizado, ni se aporta más «seguridad jurídica» de la que en la materia existía hasta el momento. Y, en fin, decir que se consagra así definitivamente la posición del porteador efectivo es una boutade, porque la única vez que se cita a esta figura en el texto de la ley es, precisamente, en la rúbrica del artículo 6 y en el artículo 60.4. La consagración definitiva de la figura del «porteador efectivo» (o subtransportista) se hubiese producido si, como pretendía el anteproyecto, se hubiera acogido una regulación de la relación jurídica existente entre cargador y/o destinatario, por un lado, y porteador (contractual) y porteador efectivo, por otro, como la que la más moderna legislación comparada del sector (y la mejor doctrina) propone desde hace algún tiempo ${ }^{53}$. Nada de esto se encuentra en la nueva ley y créan-

${ }^{53}$ S. Zunarelli, La nozione di vettore (contracting carrier ed actual carrier), Milán 1987. 
me que es una lástima que nuestro país, también en esta materia, se haya quedado al margen de lo que constituye la regla general en otros países. Por cierto, aquí también han sido decisivas las presiones, legítimas, del sector transportista.

¿Cómo queda regulado, entonces, en nuestro ordenamiento, el fenómeno de la subcontratación del transporte ${ }^{54}$ Pues como siempre lo había estado (al margen de las correcciones jurisprudenciales, más atentas a la realidad del tráfico): aplicación del principio de relatividad de los contratos (el cargador o destinatario solo pueden dirigirse contra su contraparte contractual, el porteador con quien contrataron el transporte, sin perjuicio de la acción de repetición de este contra el porteador efectivo) y no se reconoce la acción directa $^{55}$ de cargador o destinatario contra el subtransportista o porteador efectivo del transporte.

El texto del artículo 6 es claro y no merece más comentario:

Artículo 6. Responsabilidad de los porteadores efectivos.

1. El porteador que contrate con el cargador responderá frente a este de la realización íntegra del transporte conforme a lo previsto en esta ley, aun cuando no la lleve a cabo por sí mismo en todo o en parte.

2. Cuando el porteador que haya contratado directamente con el cargador contrate, a su vez, la realización efectiva de la totalidad o una parte del transporte con otro porteador, quedará obligado frente a este como cargador conforme a lo dispuesto en esta ley y en el contrato que con él haya celebrado.

En suma, nos encontramos ante el texto más criticable de la ley, tanto por su contenido como, en particular, por esas alabanzas del Preámbulo pensadas para otra regulación. ¿Se podrá arreglar este entuerto?

Deslizándonos por la pendiente del Capitulo I de la ley nos encontramos ahora con el artículo 7 («Bultos y envíos»), que no nos merece mayor comentario $^{56}$. Se trata de un precepto que contiene las definiciones de «bulto» $\mathrm{y}$ «envío» $\mathrm{o}$ «remesa», cuyo alcance jurídico es limitado, pero que tiene el valor de proponer una terminología que sirve para homogeneizar el len-

\footnotetext{
${ }^{54}$ M. T. De Gispert, «Algunas consideraciones en torno a la ejecución del transporte por un tercero», en Estudios Broseta, II, Valencia, 1995, pp. 1615 y ss.

${ }^{55}$ En general, sobre esta acción, M. Pasquau, La acción directa en el Derecho español, Madrid, 1989.

${ }^{56}$ Artículo 7: Bultos y envíos.

1. Se entiende por bulto cada unidad material de carga diferenciada que forman las mercancías objeto de transporte, con independencia de su volumen, dimensiones y contenido.

2. Se considera un envío o remesa la mercancía que el cargador entregue simultáneamente al porteador para su transporte y entrega a un único destinatario, desde un único lugar de carga a un único lugar de destino.

3. El contrato de transporte puede tener por objeto un solo envío o una serie de ellos.
} 
guaje propio de esta materia a la hora de aplicar e interpretar la ley, particularmente entre los operadores del tráfico.

Mayor interés tienen los artículos 8 y 9 con los que se cierra el Capítulo I de la ley. Pero digo interés porque son dos preceptos susceptibles de alguna reflexión, no porque sean preceptos jurídicamente innovadores por sí mismos o, siquiera, porque posean demasiada trascendencia.

El artículo 8 («Transporte continuado»), por un lado, se limita simplemente a definir esta modalidad contractual y a ofrecer una regla muy general sobre su contenido ${ }^{57}$. Es cierto que hay otros preceptos en la ley que abordan la regulación de algunos aspectos concretos del (contrato de) transporte continuado (artículos 15, 38.3, 39.3 y 43), pero, en conjunto, la impresión que uno deriva de esta reglamentación específica sobre el (contrato de) transporte continuado es que es insuficiente. Parece, más bien, que lo que el legislador ha pretendido, y esto no es criticable en sí mismo, es dar testimonio de la existencia en la realidad del tráfico de esta modalidad contractual, que, como demuestra la práctica, es muy importante y frecuente, porque son muy numerosos los contratos de transporte individuales que se llevan a cabo en nuestro país bajo la cobertura de estos contratos de transporte de larga duración («contratos-marco») ${ }^{58}$ celebrados entre el porteador y un cargador que requiere la prestación regular de servicios de transporte para la distribución de sus mercancías ${ }^{59}$. A falta de una regulación más específica, en cualquier caso, los contratos de transporte continuado seguirán siendo tailor-made, hechos a medida en cada caso, sin perjuicio de que se deba respetar en ellos no solo los preceptos arriba indicados, sino las reglas imperativas de la ley que sean aplicables, en su caso, a cada uno de los contratos de transporte individuales que constituyen su objeto.

Finalmente, el artículo 9 ( «Transporte contratado en el marco de una operación logística») introduce una regla de segmentación reguladora en el ámbito de las operaciones logísticas, al establecer que «[c]uando se asuma la obligación de transportar mercancías en el marco de una operación logís-

${ }^{57}$ Artículo 8: Transporte continuado.

1. Por el contrato de transporte continuado, el porteador se obliga frente a un mismo cargador a realizar una pluralidad de envíos de forma sucesiva en el tiempo.

2. El número, frecuencia, características y destino de los envíos podrán determinarse en el momento de contratar o antes de su inicio.

${ }^{58}$ Véase el artículo 16.2 de la ley.

${ }^{59}$ Como reconoce el propio Preámbulo IV, párrafo cuarto: «El contrato de transporte se concebía en el Código de Comercio de 1885 como un contrato-viaje, sin tener aparentemente en cuenta que, en gran parte de las ocasiones, los contratos son, en realidad, relaciones contractuales duraderas en el marco de las cuales se lleva a cabo una pluralidad de envíos, en los términos, condiciones y periodicidad que las partes acuerden. Estos contratos de transporte continuado son reconocidos ahora expresamente por la ley, aunque el grueso de la regulación siga girando en torno a los contratos que tienen por objeto un envío concreto». 
tica de contenido más amplio, los derechos, obligaciones y responsabilidades relativos a dicho transporte se regirán por lo dispuesto en esta ley». Lo que este precepto nos viene a recordar, pues en realidad se trata de una regla prácticamente asumida y admitida desde hace tiempo en el sector de las operaciones de logística, es que cuando el problema que plantee la operación logística tenga que ver con la ejecución de un transporte, entonces habrá de aplicarse la nueva ley a dicho transporte, sin perjuicio de que este transporte se halle inserto en un marco contractual más amplio como los que suelen caracterizar a los contratos de logística ${ }^{60}$.

\section{Documentación del contrato}

El Capítulo II de la nueva ley regula la «documentación del contrato» en sus artículos 10-16. Sigue, casi sin divergencias y con bastante fidelidad, la regulación que sobre esta materia se contiene en los modelos elegidos por el legislador español, particularmente el $\mathrm{CMR}^{61}$.

La ley parte del carácter consensual del contrato de transporte terrestre de mercancías (artículo 13.1) ${ }^{62}$, lo que significa que la existencia del contrato solo depende del acuerdo de las partes, con independencia de la forma elegida para concluir dicho acuerdo. No obstante, la mera existencia en el texto de la ley de una regulación específica sobre esta materia pone de manifiesto que la documentación del contrato de transporte no solo no es una cuestión menor, sino que resulta muy recomendable promover su utilización en el tráfico, en atención a los efectos beneficiosos que su emisión produce (y que señalaremos más adelante). Lo que impone, en suma, que este tipo de contratos sean formalizados por escrito mediante un documento determinado, concretamente el documento que la ley, acogiendo la terminología tradicional, denomina «carta de porte».

La importancia de este documento ${ }^{63}$ se pone de manifiesto cuando la ley, tras conceder a cada parte del contrato de transporte el derecho a exigir a la

\footnotetext{
${ }^{60}$ En general, sobre este tipo de contratos, véase F. de la Vega García, Contratos de prestación de servicios logísticos: Delimitación, contenido y estructura típica, Madrid, 2006.

${ }^{61}$ Véase, A. Recalde, «La carta de porte CMR: la documentación en el transporte internacional de mercancías por carretera», en F. Martínez Sanz, Problemas en la aplicación del CMR. Especial referencia a la responsabilidad, Madrid, 2002, pp. 5-28.

${ }^{62}$ Artículo 13: Irregularidad o inexistencia de la carta de porte.

1. La ausencia o irregularidad de la carta de porte no producirá la inexistencia o la nulidad del contrato.

${ }^{63} \mathrm{Al}$ margen, en su caso, de su eficacia como «documento de control» en el sentido de nuestra legislación administrativa: C. Llorente Gómez de Segura, «La formalización documental del contrato de transporte de mercancías por carretera a la luz de los recientes cambios normativos: la Orden 238/2003, del Ministerio de Fomento, de 31 de enero», Revista de Actualización Aranzadi, n. ${ }^{\circ}$ 7-8, septiembre 2003, pp. 35-51.
} 
otra que se extienda una carta de porte (artículo 10.1), acoge una regla novedosa en nuestra legislación (aunque presente en las condiciones generales previstas en la O. M. de 25 de abril de 1997), según la cual «[c]uando la parte contratante requerida a formalizar la carta de porte se negase a ello, la otra podrá considerarla desistida del contrato, con los efectos que, en su caso, correspondan de conformidad con lo dispuesto en los artículos 18.2 y 19.1» (artículo 10.6).

La ley dedica particular atención, por otro lado, al contenido de la carta de porte (artículo 10), distinguiendo entre unas menciones que podríamos calificar de generales (aplicables en todo caso) (artículo 10.1) ${ }^{64}$, otras menciones que podrán ser incluidas por las partes en supuestos específicos (artículo 10.2$)^{65} \mathrm{y}$, finalmente, aquellas que la legislación especial pueda reque-

${ }^{64}$ 1. Cualquiera de las partes del contrato podrá exigir a la otra que se extienda una carta de porte que incluirá las siguientes menciones:

a) Lugar y fecha de la emisión.

b) Nombre y dirección del cargador y, en su caso, del expedidor.

c) Nombre y dirección del porteador y, en su caso, del tercero que reciba las mercancías para su transporte.

d) Lugar y fecha de la recepción de la mercancía por el porteador.

e) Lugar y, en su caso, fecha prevista de entrega de la mercancía en destino.

f) Nombre y dirección del destinatario, así como eventualmente un domicilio para recibir notificaciones.

g) Naturaleza de las mercancías, número de bultos y signos y señales de identificación.

h) Identificación del carácter peligroso de la mercancía enviada, así como de la denominación prevista en la legislación sobre transporte de mercancías peligrosas.

i) Cantidad de mercancías enviadas, determinada por su peso o expresada de otra manera.

j) Clase de embalaje utilizado para acondicionar los envíos.

k) Precio convenido del transporte, así como el importe de los gastos previsibles relacionados con el transporte.

l) Indicación de si el precio del transporte se paga por el cargador o por el destinatario.

m) En su caso, declaración de valor de las mercancías o de interés especial en la entrega, de acuerdo con lo dispuesto en el artículo 61.

n) Instrucciones para el cumplimiento de formalidades y trámites administrativos preceptivos en relación con la mercancía.

${ }^{65}$ 2. La carta de porte podrá contener cualquier otra mención que sea convenida por las partes en el contrato, tales como:

a) La referencia expresa de prohibición de transbordo.

b) Los gastos que el remitente toma a su cargo.

c) La suma del reembolso a percibir en el momento de la entrega de la mercancía.

d) El valor declarado de la mercancía y la suma que representa el interés especial en la entrega.

e) Instrucciones del remitente al transportista concernientes al seguro de las mercancías.

f) El plazo convenido en el que el transporte ha de ser efectuado.

g) La lista de documentos entregados al transportista. 
rir al respecto (artículo 10.5) ${ }^{66}$. En este contexto, resulta particularmente interesante el pronunciamiento del artículo 13.2 de la ley, novedoso también en nuestra legislación, que determina el alcance de la irregularidad de una carta de porte cuando falte en este documento alguna de las menciones previstas de modo obligatorio («incluirá») en el artículo 10.1. Conforme a este precepto, «la omisión de alguna de las menciones previstas en el artículo 10.1 no privará de eficacia a la carta de porte en cuanto a las incluidas». La ley, en este mismo marco, establece, además, la responsabilidad respectiva de cargador y porteador por los «gastos y perjuicios que se deriven de la inexactitud o insuficiencia de los datos que les corresponda incluir en la carta de porte» (artículo 10.7). Lo que exige un modicum de diligencia por su parte a la hora de incluir, o proporcionar, los datos que les incumben y deban figurar en la carta de porte.

Con respecto a la firma de la carta de porte, esencial para la plena regularidad de dicho documento, la ley requiere que lo hagan tanto cargador como porteador (artículo 11.1), si bien otorga, a su vez, validez a «la firma de la carta de porte por medios mecánicos, mediante estampación de un sello, o por cualquier otro medio que resulte adecuado, siempre que quede acreditada la identidad del firmante» (artículo 11.2). Esta última norma, traída del CMR, también es novedosa en nuestra legislación interna, si bien, con anterioridad, la doctrina ya se había manifestado a favor de su admisión en nuestro ordenamiento ${ }^{67}$.

Por lo que respecta a la gestión documental de la carta de porte, la ley exige que este documento se emita en tres ejemplares originales (artículo 11.1). El primer ejemplar se quedará con el cargador, el segundo viajará con la mercancía y el tercero será para el porteador (artículo 11.3). El papel desempeñado por el segundo ejemplar de la carta de porte es particularmente relevante como pone de manifiesto el artículo 12 de la ley:

\section{Artículo 12. Documentación de la entrega en destino.}

El destinatario podrá exigir que la mercancía le sea entregada junto con el segundo ejemplar de la carta de porte. El porteador podrá exigir al destinatario que le extienda en su ejemplar de la carta de porte, o en documento separado firmado por ambos, un recibo sobre las mercancías entregadas.

${ }^{66} 5$. En su caso, la carta de porte deberá contener cualquier otra mención que exija la legislación especial aplicable, por razón de la naturaleza de la mercancía o por otras circunstancias.

${ }^{67}$ A. Recalde Castells, «La firma de las partes del contrato en la carta de porte (firma manual y firma impresa, mecánica o electrónica). El régimen del Código de comercio y del Convenio internacional sobre transporte por carretera (CMR)», $R G D, 1995$, pp. 2229 y ss. 
La entrega del segundo ejemplar de la carta de porte al destinatario, junto con la mercancía, por lo tanto, es prueba de la consumación del contrato de transporte, regla que se complementa con el derecho del porteador a exigir que se le extienda un recibo de la mercancía sobre la propia carta de porte (como sucede con el modelo de carta de porte CMR) o en un documento aparte.

En este ámbito de la gestión documental, por su parte, también hay que destacar otras dos reglas más previstas en la nueva ley. Así, conforme al artículo 10.3 «[s]erá necesario emitir una carta de porte para cada envío» (sobre el concepto de «envío», véase el artículo 7.2). Y según el artículo 10.4 «[c]uando el envío se distribuya en varios vehículos, el porteador o el cargador podrá exigir la emisión de una carta de porte por cada vehículo».

La ley no propone ningún formato específico de carta de porte. No sería, por otro lado, su función. Hay un modelo de carta de porte muy conocido, el de IRU, que se utiliza particularmente en el transporte internacional de mercancías por carretera. Y, también, la O. M. de 1997 propuso en su día un modelo que sigue en vigor mientras lo esté dicha norma. Pero lo importante es recordar que pertenece al ámbito de libertad de las partes el diseño y configuración formal de dicho documento siempre que se respeten los contenidos mínimos previstos en la ley y a los que nos hemos referido en los párrafos anteriores.

Una novedad significativa de la ley, por cierto, en este contexto formal, es la admisión expresa de la utilización de cartas de porte electrónicas (artículo 15: «Carta de porte emitida electrónicamente»), si bien con una regulación muy básica, que remite a desarrollos ulteriores, normativos y técnicos, de esta materia ${ }^{68}$. No dudamos, en cualquier caso, que en el futuro inminente del sector, este desarrollo tecnológico estará bien presente.

Por lo que respecta a las funciones que cumple la documentación del transporte y, en concreto, la carta de porte, la nueva ley se refiere, en su artículo 14, a la fuerza probatoria de dicho documento, que constituye, sin duda, la función más importante de todas las que puede llegar a asumir este documento.

El primer apartado del artículo 14 recuerda, en concreto, que «[l]a carta de porte firmada por ambas partes hará fe de la conclusión y del contenido del contrato, así como de la recepción de las mercancías por el porteador, salvo prueba en contrario». Triple prueba, por tanto, la que proporciona la carta de porte que esté debidamente firmada por las partes

${ }^{68}$ Artículo 15: Carta de porte emitida electrónicamente.

1. Si las partes están de acuerdo, podrán emitir la carta de porte por medios electrónicos con arreglo a la legislación vigente.

2. En este supuesto, la carta de porte deberá consistir en un registro electrónico de datos que puedan ser transformados en signos de escritura legibles. 
(exigencia esta de la firma que, como dijimos, se constituye en requisito esencial y mínimo para considerar que una carta de porte se ha emitido regularmente): su emisión es prueba de la existencia del contrato (conclusión del contrato), de su contenido (es decir, de los derechos y obligaciones asumidos por las partes tal y como vienen reflejados en el texto del documento) y del hecho de la recepción de las mercancías por el porteador, datos todos ellos que tienen una extraordinaria trascendencia en el caso de que se produzca algún litigio respecto del contrato.

Además, conforme al apartado 2 del artículo 14, por regla general, la carta de porte se convertirá en un medio muy importante para que el porteador pueda formalizar sus protestas (o reservas) con respecto a determinados datos que figuran en dicho documento:

2. En ausencia de anotación en la carta de porte, o en documento separado firmado por el porteador y el cargador o expedidor, de las reservas suficientemente motivadas del porteador, se presumirá que las mercancías y su embalaje están en el estado descrito en la carta de porte y con los signos y señales en ella indicados.

Como puede comprobarse, esta regla también es de enorme relevancia en el contexto de la determinación de cómo, y en qué condiciones, se hizo cargo el porteador de la mercancía al comienzo del trasporte (momento que marca el inicio del llamado «periodo de responsabilidad» del porteador: artículo 47.1).

Finaliza el Capítulo II de la Ley con su artículo $\mathbf{1 6}^{69}$, un precepto aplicable específicamente a la formalización documental del transporte continuado, modalidad definida, como sabemos, en el artículo 8 de la ley. El precepto acoge la regla general ya conocida sobre la consensualidad del contrato de transporte (apartado 1) (salvo cuando se trate de contratos de transporte celebrados con un transportista autónomo económicamente dependiente: apartado 4), así como la facultad de desistimiento en caso de que una de las partes se niegue a la emisión del documento (apartado 3). En el apartado 2, por su parte, se nos recuerda la caracterización de este tipo de contrato como

${ }^{69}$ Artículo 16: Formalización de los contratos de transporte continuado.

1. El contrato de transporte continuado se formalizará por escrito cuando lo exija cualquiera de las partes.

2. Este contrato servirá de marco a las cartas de porte que hayan de emitirse para concretar los términos y condiciones de cada uno de los envíos a que diera lugar.

3. Cuando la parte contratante requerida a formalizar por escrito el contrato se negase a ello, la otra podrá considerarla desistida de este, con los efectos que, en su caso, correspondan de conformidad con lo dispuesto en los artículos 18.2 y 19.1.

4. A los efectos de lo dispuesto en la normativa reguladora del trabajo autónomo, el contrato de transporte continuado celebrado con un trabajador autónomo económicamente dependiente deberá celebrarse por escrito y de conformidad con dicha normativa. 
«contrato-marco», pero, técnicamente, su redacción podía haber sido más afortunada, porque, en realidad, el contrato de transporte continuado no da tanto cobertura a las «cartas de porte que hayan de emitirse para concretar los términos y condiciones de cada uno de los envíos a que diera lugar», como a los distintos contratos de transporte individuales que se ejecutan a su amparo, en los que se podrán emitir, o no, las correspondientes cartas de porte.

\section{Contenido del contrato de transporte de mercancías}

Como se apunta más adelante, el Capítulo III («Contenido del contrato de transporte de mercancías») de la nueva ley es el de mayor extensión, pues abarca los artículos 17-43. En este capítulo se contiene la regulación de los principales derechos y obligaciones de las partes del contrato y se ha optado por hacerlo, desde una perspectiva sistemática, no regulando las obligaciones de una y otra parte por separado, sino considerando, por regla general, los distintos momentos sucesivos de la ejecución de un contrato de transporte: la fase previa a la recepción de la mercancía en origen, el desarrollo del transporte y la fase final de entrega de la carga una vez llegada a su destino. A la primera fase pueden adscribirse los artículos 17-27; a la segunda, los artículos 28-32; y a la fase final, los artículos 33-36 y 42. El Capítulo III de la ley, además, dedica una atención particular, y ciertamente novedosa en nuestra legislación, a la obligación del pago del precio del transporte (artículos 37-41). Y contiene, además, una norma específica para el transporte continuado (artículo 43). En nuestra exposición sobre esta materia seguiremos a continuación el esquema establecido en la ley.

\section{Fase inicial del transporte}

Comienza el nuevo texto legal con un precepto relativo a la «idoneidad del vehículo» (artículo 17), según el cual «[e]l porteador deberá utilizar un vehículo que sea adecuado para el tipo y circunstancias del transporte que deba realizar, de acuerdo con la información que le suministre el cargador». La regla es ciertamente novedosa en nuestra legislación para el transporte terrestre y no deja de ser una evocación, sin duda no buscada, de la regla marítima sobre la «navegabilidad del buque». No se pretende, sin embargo, en el sector terrestre arrostrar las consecuencias que en el ámbito marítimo posee la falta de navegabilidad del buque, sino meramente poner de manifiesto una circunstancia que, en su caso, deberá ser tenida en cuenta a la hora de medir la responsabilidad del porteador en el supuesto de que su incumplimiento del contrato de transporte haya sido producido, en todo o en parte, como consecuencia de la falta de idoneidad del vehículo empleado. Es un precepto, por lo tanto, que ha de verse a la luz de reglas como las estableci- 
das en los artículos 48.2 y 51 de la ley y, muy particularmente, en el marco de la eventual pérdida del beneficio de limitación prevista en el artículo 62 .

El artículo 18 («Puesta a disposición del vehículo»), por su parte, precepto claramente susceptible de desarrollo reglamentario dicho sea de paso, regula una de las primeras obligaciones que para el porteador se derivan de la conclusión del contrato de transporte: la de poner el vehículo a disposición del cargador para que pueda iniciarse el transporte ${ }^{70}$. Se trata de un precepto que debe ser leído con cierta calma y ponderación, porque plantea varias hipótesis con consecuencias jurídicas diversas.

El precepto parte de una regla general («El porteador deberá poner el vehículo a disposición del cargador en el lugar y tiempo pactados»), para luego centrar su atención en la dimensión exclusivamente temporal (no espacial) relativa a la puesta a disposición del vehiculo (cuándo). Y en este ámbito, distingue los casos en los que no ha habido pacto entre las partes al respecto de aquellos otros en los que sí ha habido tal pacto.

En el primer supuesto («[S]i nada se pacta respecto a la hora») (artículo 18.1), el precepto establece que «el porteador cumplirá su obligación poniendo el vehículo a disposición del cargador con antelación suficiente para que pueda ser cargado el día señalado». Y añade, para el caso específico de que se trate de un transporte de mercancías por carretera (no se olvide que la ley también cubre el transporte de mercancías por ferrocarril), que si «no se hubiere pactado plazo, el transportista cumplirá con su obligación poniendo a disposición el vehículo para su carga antes de las dieciocho horas del día señalado».

Por su parte, «[S]i existe pacto expreso previo entre las partes acerca del día y la hora u hora límite para la puesta a disposición del vehículo», según el artículo 18.2 el porteador deberá lógicamente cumplir con dicho pacto y en caso de no hacerlo, «el cargador podrá desistir de la expedición de que se trate y buscar inmediatamente otro porteador». Junto a esta novedosa facultad de desistimiento (que ya vimos aplicada también al supuesto de falta de emisión de la carta de porte por voluntad de una de las partes), el apar-

\footnotetext{
${ }^{70}$ Artículo 18: Puesta a disposición del vehículo.

1. El porteador deberá poner el vehículo a disposición del cargador en el lugar y tiempo pactados. Si nada se pacta respecto a la hora, el porteador cumplirá su obligación poniendo el vehículo a disposición del cargador con antelación suficiente para que pueda ser cargado el día señalado. Si se trata de un contrato de transporte de mercancías por carretera, y no se hubiere pactado plazo, el transportista cumplirá con su obligación poniendo a disposición el vehículo para su carga antes de las dieciocho horas del día señalado.

2. Si existe pacto expreso previo entre las partes acerca del día y la hora u hora límite para la puesta a disposición del vehículo y el porteador no cumple dicho plazo, el cargador podrá desistir de la expedición de que se trate y buscar inmediatamente otro porteador.

Cuando el cargador haya sufrido perjuicios como consecuencia de la demora, y esta fuere imputable al porteador, podrá además exigir la indemnización que proceda.
} 
tado segundo del artículo 18 le reconoce, además, al cargador el derecho a una indemnización de daños y perjuicios como consecuencia del retraso siempre que este sea imputable al porteador.

A la luz de lo anterior, y en atención a la división sistemática del artículo 18 en dos apartados, parece evidente que la facultad de desistimiento y de solicitud de daños y perjuicios es solo aplicable en los supuestos en los que se haya pactado de modo expreso y con carácter previo el momento de puesta a disposición del vehiculo. Nada se dice, por el contrario, sobre las consecuencias del incumplimiento de las reglas previstas en el apartado 1. La conclusión no podrá ser en todo caso la de negar la posibilidad de exigir el correspondiente resarcimiento sino, simplemente, que aquel deberá sujetarse a los criterios generales de nuestro ordenamiento aplicables en materia de incumplimiento contractual.

En buena lógica, en correspondencia con la obligación del porteador de poner un vehículo idóneo a disposición del cargador en el correspondiente momento y lugar, surge la obligación del cargador de entregar al porteador la mercancía objeto del transporte. A este supuesto se refiere el artículo 19 («Entrega de las mercancías al porteador») ${ }^{71}$, donde se recoge la regla general en esta materia en el primer inciso de su apartado primero ( $\mathrm{El}$ cargador deberá entregar las mercancías al porteador en el lugar y en el tiempo pactados»), para, posteriormente, introducir dos reglas aplicables a supuestos patológicos en el cumplimiento de dicha obligación.

La primera regla contempla el caso en que el cargador incumpla plena y totalmente la obligación de entrega de las mercancías en el momento y lugar pactados. En este supuesto, el artículo 19.1 le concede al porteador el derecho a solicitar una indemnización de daños y perjuicios tasada en una cuantía equivalente al precio del transporte pactado («previsto» dice exactamente la norma) o bien alternativamente, pero a elección del cargador, la posibilidad de realizar un transporte de similares características al que se hubiere frustrado por el incumplimiento del cargador, siempre y cuando «se encuentre inmediatamente disponible», es decir, sea un transporte de ejecución inmediata y no cree demoras adicionales al porteador.

En segundo lugar, se contempla la hipótesis de que la entrega de la mercancía sea solo de una parte, en cuyo caso, también a opción del cargador,

${ }^{71}$ Artículo 19: Entrega de las mercancías al porteador.

1. El cargador deberá entregar las mercancías al porteador en el lugar y en el tiempo pactados. En caso de incumplimiento, el cargador le indemnizará en cuantía equivalente al precio del transporte previsto, o bien le ofrecerá la realización de un transporte de similares características que se encuentre inmediatamente disponible.

2. Si el cargador solo entrega al porteador una parte de las mercancías deberá, sin perjuicio del pago del precio del transporte de esa parte, abonarle una indemnización igual al precio del transporte de la mercancía no entregada, o bien ofrecerle la inmediata realización de otro transporte de similares características al inicialmente convenido. 
deberá abonársele al porteador una indemnización en cuantía igual al precio del transporte de la mercancía no entregada (además, por supuesto, de pagarle el precio por el transporte de la mercancía efectivamente entregada) u ofrecerle, como en el caso del artículo 19.1, la realización inmediata de un transporte de características similares al inicialmente convenido.

El artículo 20 ( «Sujetos obligados a realizar la carga y descarga»), por su parte, posee una importancia muy destacada, dada la incidencia que las operaciones de carga y descarga tienen sobre los supuestos de daños a la mercancía en las operaciones de transporte. Las reglas que se recogen en este precepto se inspiran, con algunas modificaciones, en la regulación que a este respecto ofrecía la LOTT, tras su modificación de 2003, y contemplan conjuntamente las operaciones de carga y descarga.

El precepto distingue, en primer lugar, entre los supuestos de transportes sometidos a reglamentación especial y los que podríamos calificar de supuestos sometidos a reglamentación general. Y lo hace, para aclarar, en su apartado 4, que en el caso de los primeros transportes habrá que estar a lo que se disponga particularmente en dicha reglamentación especial y no a lo que establece al respecto el artículo 20 de la nueva ley ${ }^{72}$.

En segundo lugar, el nuevo artículo ofrece reglas diversas para la carga y descarga según se trata de transportes de paquetería (o asimilados), por un lado, o de transportes de otra naturaleza, por otro. La ley ha renunciado, en contra de lo que establecía la LOTT, a utilizar en este contexto los conceptos de transporte de carga fraccionada y de carga completa, respectivamente.

Con respecto a estos últimos, el apartado 1 del artículo 20 indica que «[L]as operaciones de carga de las mercancías a bordo de los vehículos, así como las de descarga de estos, serán por cuenta, respectivamente, del cargador y del destinatario, salvo que expresamente se asuman estas operaciones por el porteador antes de la efectiva presentación del vehículo para su carga o descarga». Se ofrece, por lo tanto, un amplio margen de maniobra a la autonomía de la voluntad de las partes (siempre que el pacto sea expreso y se produzca en el marco temporal previsto en el precepto). Y no siendo así, se aplicará la regla supletoria de la voluntad de las partes (carga = cargador; descarga $=$ destinatario). Según el precepto, además, estas reglas serán aplicables a las operaciones de estiba y desestiba de las mercancías en el vehículo (apartado 1, inciso final). Añade el precepto, por su parte, como corolario de lo anterior, que «[e]l cargador y el destinatario soportarán las consecuencias de los daños derivados de las operaciones que les corresponda realizar de conformidad con lo señalado en el apartado anterior» (apartado 2 , primer párrafo). Ahora bien, cuando el daño sea consecuencia de una estiba inadecuada de la mercancía en el vehículo realizada por el cargador

72 4. Lo dispuesto en este artículo no se aplicará cuando la normativa reguladora de determinados tipos de transporte establezca específicamente otra cosa. 
siguiendo las instrucciones del porteador, será este quien deba responder de los daños ocasionados a la mercancía (apartado 2, segundo párrafo).

En el apartado 3 del artículo 20 de la nueva ley se establecen, por su parte, las reglas aplicables a la carga y descarga de la mercancía en los supuestos de transporte de paquetería y asimilados, es decir, tal y como los describe la ley, «cualesquiera otros similares que impliquen la recogida o reparto de envíos de mercancías consistentes en un reducido número de bultos que puedan ser fácilmente manipulados por una persona sin otra ayuda que las máquinas o herramientas que lleve a bordo el vehículo utilizado». En estos casos, las operaciones de carga y descarga serán realizadas conforme a lo que establezca el pacto entre las partes (pacto que, sin embargo, no aparece cualificado como en el caso de la regla del apartado 1) o, en su defecto, deberán ser efectuadas por el porteador, en cuyo caso este será el responsable de los daños a la mercancía que se produzcan como consecuencia de las referidas operaciones (apartado 3, segundo párrafo, inciso final). Por lo que respecta a las operaciones de estiba y desestiba de las mercancías, en todo caso corresponderán al porteador (apartado 3, segundo párrafo, primer inciso).

Otro aspecto de relevancia práctica en la fase inicial o previa del transporte es el relativo al «acondicionamiento e identificación de las mercancías», cuestión a la que la nueva ley dedica su artículo 21. En primer lugar, la cuestión de a quién corresponde realizar estas labores de acondicionamiento e identificación de las mercancías se resuelve, como regla general, acudiendo a la autonomía de la voluntad de las partes. Habrá que estar, por lo tanto, a lo que las partes del contrato hayan podido pactar al respecto. En defecto de pacto, la regla será la de atribuir al cargador estas labores (apartado 1 , primer inciso $)^{73}$.

La ley distingue, conceptualmente, entre el acondicionamiento y la identificación de las mercancías. Con respecto a las labores de acondicionamiento (concepto que incluye el embalaje), nada se dice respecto a cómo deben efectuarse. Y por lo que respecta a la identificación de las mercancías, el artículo 21.1, en su segundo inciso, señala que habrá de realizarse respecto de cada uno de los bultos que compongan el envío, que deberá ser hecha con claridad y que tendrán que utilizarse los correspondientes signos, los cuales deberán coincidir con la descripción que de los bultos se hubiere hecho en la carta de porte ${ }^{74}$.

${ }^{73}$ Curiosamente, el artículo 21.1 solo atribuye al cargador, en su caso, la obligación de acondicionamiento de la mercancía y no la de su identificación.

${ }^{74} \mathrm{La}$ ley emplea incorrectamente el verbo «señalizar» en este artículo (en dos ocasiones), pues según el Diccionario de la Lengua Española de la RAE, señalizar es «Colocar en las carreteras y otras vías de comunicación las señales que indican bifurcaciones, cruces, pasos a nivel y otras para que sirvan de guía a los usuarios». 
El apartado 2 del artículo 20 contiene una regla específica para transportes de naturaleza o sometidos a circunstancias especiales, según la cual, en estos casos «las mercancías deberán ser entregadas al porteador convenientemente acondicionadas, embaladas y, en su caso, identificadas y señalizadas mediante las oportunas marcas o inscripciones que avisen del riesgo que su manipulación pueda entrañar para las personas o para las propias mercancías». En realidad, con esta regla particular lo único que se pretende es reforzar la obligación de información que le es debida al porteador por parte del cargador cuando la manipulación de las mercancías objeto del transporte entrañe riesgo alguno.

Finalmente, el apartado 3 del artículo 20 recoge las consecuencias en el ámbito de la responsabilidad del incumplimiento de las reglas establecidas en los apartados precedentes. No es un precepto bien escrito, la verdad, pero tampoco es difícil entender su planteamiento.

Por un lado, se dice que «[e]l cargador responderá ante el porteador de los daños a personas, al material de transporte o a otras mercancías». Habrá que entender, claro está, que el cargador será responsable cuando los daños que afecten a las personas, material de transporte u otras mercancías sean consecuencia de su incumplimiento de las obligaciones de acondicionamiento e identificación reguladas en los apartados precedentes.

Por otro lado, en ese mismo apartado 3, se recoge una regla específica para el caso de que se generen «gastos ocasionados por defectos en el embalaje de las mercancías», de los que deberá responder también el cargador, «a menos que tales defectos sean manifiestos o ya conocidos por el porteador en el momento de hacerse cargo de las mercancías y no haya hecho las oportunas reservas» (el precepto se refiere concretamente a las reservas reguladas en el artículo 14.2). Habría que preguntarse, no obstante, si el legislador ha empleado la expresión de «gastos» como supuesto distinto o complementario del concepto de «daños» que figura en el primer inciso.

Precepto también de enorme trascendencia práctica es el artículo 24 («Paralizaciones»), cuyos antecedentes legislativos hay que reconducir a la LOTT modificada en 2003 y que ahora se mejoran en beneficio del porteador. El precepto es aplicable tanto a las operaciones de carga (y estiba) como a las operaciones de descarga (y desestiba) y se refiere a supuestos de paralización del vehículo no imputables al porteador.

En estos casos, según la nueva ley, «[c]uando el vehículo haya de esperar un plazo superior a dos horas hasta que se concluya su carga y estiba o desestiba y descarga, el porteador podrá exigir al cargador una indemnización en concepto de paralización» (apartado 1). La cuantía de la indemnización podrá ser objeto de pacto entre las partes, si bien este pacto no podrá nunca ofrecer un resultado inferior al que resulte de aplicar lo que establece, a estos efectos, el apartado 3 del artículo 24. Por otro lado, si no existiese pacto, se aplicará directamente la regla del artículo 24.3 para el cálculo de la 
indemnización (que se efectuará conforme al índice conocido como IPREM $)^{75}$.

El precepto se completa con su apartado 2 que establece que el plazo de paralización al que se refiere el apartado 1 (dos horas) «se contará desde la puesta a disposición del vehículo para su carga o descarga en los términos requeridos por el contrato». Lo que pone de manifiesto la trascendencia de que estos extremos figuren adecuadamente recogidos en el contrato.

Además de la documentación del contrato de transporte regulada en su Capítulo II, la nueva ley se refiere a otro tipo de documentación en su artículo 23, a la que denomina «documentación de la mercancía», para describir a la «documentación relativa a la mercancía que sea necesaria para la realización del transporte y de todos aquellos trámites que el porteador haya de efectuar antes de proceder a la entrega en el punto de destino» (apartado 1).

Pues bien, en estos casos, y en un plano obligacional, la ley establece que el cargador deberá adjuntar dicha documentación a la carta de porte o, en su caso, ponerla a disposición del porteador de otro modo (artículo 23.1, primer inciso). Asimismo, el cargador estará obligado a suministrar al porteador toda la información necesaria sobre la mercancía o para realizar los trámites indicados anteriormente (artículo 23.1 inciso final). Por su parte, conforme al artículo 23.2, en su primer inciso, «[e]l porteador no está obligado a verificar si estos documentos o informaciones son exactos o suficientes».

Finalmente, las consecuencias de las reglas establecidas precedentemente en el ámbito de la responsabilidad se establecen en un doble plano, que afecta respectivamente, y de manera diferenciada, a cargador y porteador. Por un lado, el segundo inciso del artículo 23.2 señala que «[E]l cargador es responsable ante el porteador de todos los daños que pudieran resultar de la ausencia, insuficiencia o irregularidad de estos documentos e informaciones, salvo en caso de culpa por parte del porteador». Y, por lo que respecta al porteador, el artículo 23.3 indica que este «responderá de las consecuencias derivadas de la pérdida o mala utilización de los citados documentos», añadiendo a continuación que «[e]n todo caso, la indemnización a su cargo

75 Salvo que se haya pactado expresamente una indemnización superior para este supuesto, la paralización del vehículo por causas no imputables al porteador, incluidas las operaciones de carga y descarga, dará lugar a una indemnización en cuantía equivalente al Indicador Público de Renta de Efectos Múltiples/día multiplicado por 2 por cada hora o fracción de paralización, sin que se tengan en cuenta las dos primeras horas ni se computen más de diez horas diarias por este concepto. Cuando la paralización del vehículo fuese superior a un día el segundo día será indemnizado en cuantía equivalente a la señalada para el primer día incrementada en un 25 por ciento. Cuando la paralización del vehículo fuese superior a dos días, el tercer día y siguientes serán indemnizados en cuantía equivalente a la señalada para el primer día incrementada en un 50 por ciento. 
no excederá de la que correspondería en caso de pérdida de la mercancía». Con esta última regla, se produce una remisión a las normas sobre limitación de la indemnización previstas en el artículo 57 (y, eventualmente, artículo 62) de la nueva ley.

El artículo 24 de la ley establece a cargo del remitente (cargador) una obligación de información específica cuando se trate del transporte de mercancías peligrosas. En estos casos, el cargador «habrá de especificar la naturaleza exacta del peligro que representan, indicándole las precauciones a tomar» (apartado 1, primer inciso); el precepto establece la recomendación de que esta información se recoja en la carta de porte pues, de lo contrario, sigue diciendo que «recaerá sobre el cargador o destinatario la carga de la prueba de que el porteador tuvo conocimiento de la naturaleza exacta del peligro que presentaba el transporte de dichas mercancías» (apartado 1, segundo inciso).

Por su parte, las consecuencias del incumplimiento de la obligación de información que se acaba de consignar, se recogen en el apartado 2 del citado artículo 24 de un modo preciso: «El porteador que no haya sido informado de la peligrosidad de las mercancías no estará obligado a continuar el transporte y podrá descargarlas, depositarlas, neutralizar su peligro, devolverlas a su origen o adoptar cualquier otra medida que resulte razonable en atención a las circunstancias del caso. El porteador deberá comunicarlo inmediatamente al cargador, el cual asumirá los gastos y daños derivados de tales operaciones».

Los tres últimos preceptos que el Capítulo III de la nueva ley dedica a la fase previa a la ejecución del transporte (artículos 25, 26 y 27) están referidos todos ellos a comportamientos esperados del porteador con ocasión de la recepción de la mercancía en su origen.

El artículo 25 («Reconocimiento externo»), en primer lugar, indica que «[e]n el momento de hacerse cargo de las mercancías, el porteador deberá comprobar su estado aparente y el de su embalaje, así como la exactitud de las menciones de la carta de porte relativas al número y señales de los bultos» (apartado 1) y, en su caso, "[l]os defectos apreciados se anotarán por el porteador en la carta de porte, mediante la formulación singularizada de reservas suficientemente motivadas» (apartado 2) (reservas a las que se refiere el artículo 14.2 de la ley). Añade el precepto, en su apartado 3, para concluir su regulación, que «[e]l porteador que carezca de medios adecuados para verificar la coincidencia del número y las señales de los bultos lo hará constar justificadamente en la carta de porte». En realidad, este precepto, a pesar de su dicción, no establece una obligación por parte del porteador de realizar el reconocimiento externo aludido, sino tan solo una carga, en sentido jurídico, de tal modo que, si no se comporta como el precepto exige, deberá sufrir las consecuencias derivadas de la falta de anotación de reservas en el plano probatorio con el régimen previsto a este respecto en el artículo 14 de la ley. 
En este mismo marco hay que situar al artículo 26 («Examen de las mercancías»), precepto que, en sus líneas básicas, toma sus raíces del derogado Comercio de Comercio.

En este precepto se contempla, fundamentalmente, el derecho que tiene el porteador a examinar las mercancías que le son entregadas por el cargador «cuando existan fundadas sospechas de falsedad en torno a la declaración del cargador» sobre dichas mercancías. En concreto, conforme a ese derecho, el porteador «podrá verificar el peso y las medidas de las mercancías, así como proceder al registro de los bultos», siendo de su cuenta los gastos derivados del examen «[s]i la declaración del cargador resulta cierta». En caso contrario, en buena lógica, los gastos se le imputarán al cargador (apartado 1).

El artículo 26, por otra parte, en su apartado 2, también reconoce al cargador el derecho a solicitar que el porteador realice el examen de la mercancía, con el mismo alcance que en el apartado 1 , y no puede negarse el porteador a efectuar dicho examen siempre y cuando el cargador asuma expresamente el pago de los gastos correspondientes.

Tanto en un caso como en otro, señala la ley (artículo 26.3) que el examen deberá ser realizado por el porteador en presencia del cargador o de sus auxiliares (concepto este que la ley no define y que habrá que referir a nuestra doctrina general al respecto) y, no siendo posible, habrán de estar presentes en el examen bien un notario o bien el presidente de la Junta Arbitral del Transporte Terrestre que resulte competente o persona por él designada. En todo caso, concluye el precepto, «[e]l resultado del reconocimiento se hará constar en la carta de porte o mediante acta levantada al efecto» (apartado $4)^{76}$.

Finalmente, el artículo 27 («Rechazo de los bultos»), un precepto de reminiscencias decimonónicas actualizado debidamente en otros aspectos, concede al porteador el derecho a rechazar el transporte de los bultos que le entrega el cargador en tres supuestos (artículo 27.1, primer inciso). Primero, cuando «los bultos (...) se presenten mal acondicionados o identificados para el transporte» (véase el artículo 21). Segundo, cuando los bultos «no vayan acompañados de la documentación necesaria» (entendemos que la ley se refiere a la documentación mencionada en su artículo 23: «documen-

${ }^{76}$ Como no podía ser de otro modo, la nueva ley introduce varias referencias en su texto a las Juntas Arbitrales del Transporte Terrestre, creadas por la LOTT, y que cada vez son más relevantes en nuestro país a la hora de resolver los conflictos derivados de la ejecución de contratos de transporte. En general, véase, A.-L. Calvo Caravaca y C. Llorente Gómez de Segura, «El arbitraje de transporte», en A. de Martín Muñoz y S. Hierro Anibarro (Coord.), Comentario a la Ley de Arbitraje, Madrid, 2006, pp. 823-887. Igualmente, véase el trabajo más específico de S. Rodríguez Sánchez, Las Juntas Arbitrales del Transporte: Constitución y funciones (en especial como «depositarias» de las mercancías), Valencia, 2005. 
tación de la mercancía»). Y, finalmente, cuando la naturaleza y características de dichos bultos no coincidan con las declaradas por el cargador. La ley exige expresamente, por su parte, que el porteador comunique al cargador su rechazo (artículo 27.1, inciso final).

El apartado 2 del artículo 27, por último, contempla una novedosa regla en cuya virtud «el porteador podrá supeditar la admisión de los bultos a la aceptación de las reservas que se proponga formular en la carta de porte, dejando constancia de los defectos apreciados». Se refuerza de este modo sustancialmente, frente al régimen anterior, la posición del porteador en la formulación de las reservas a las que se refiere el artículo 14.2 de la ley, con las correspondientes consecuencias en el plano probatorio.

\section{Desarrollo del transporte}

Los artículos 28-32 de la nueva ley pertenecen a la fase de ejecución o desarrollo, en sentido estricto, del transporte, Es decir, a aquella fase que discurre desde que el porteador recibe las mercancías del cargador hasta que las pone a disposición del destinatario.

El artículo 28 («Custodia y transporte»), cuya tramitación parlamentaria no fue pacífica, es, en cierto modo, un precepto de contenido dogmático (y algunos pensarán que, por ello, innecesario) en la medida en que viene a recoger el principio general de que todo porteador, en un contrato de transporte, asume, frente a su contraparte, una doble e inescindible obligación de desplazamiento (transporte) y custodia de la mercancía ${ }^{77}$.

A la primera obligación se refiere el artículo 28.2, en su primer inciso, cuando afirma que «[e]l porteador asume la obligación de conducir a destino las mercancías objeto de transporte para su entrega al destinatario». Por su parte, la obligación de custodia se recoge en el artículo 28.1: «El porteador está obligado a guardar y conservar las mercancías objeto de transporte desde que las recibe en origen hasta que las entrega en destino, de conformidad con lo estipulado en el contrato y las disposiciones de esta ley». Pero, junto a esas obligaciones esenciales de desplazamiento (transporte) y de custodia, el porteador puede asumir en el contrato de transporte otros deberes y obligaciones a los que también se refiere el artículo 28.3 cuando afirma que «[e]l porteador también se obliga a cumplir las demás prestaciones complementarias o accesorias que haya asumido con motivo u ocasión del transporte, en los términos y condiciones pactados en el contrato». Nada nuevo, por tanto, bajo el marco dogmático del contrato de transporte.

La única regla particular recogida en el artículo 28 , y que tampoco es novedosa, la encontramos en el párrafo segundo de su apartado 2 en relación con el itinerario del transporte. Este precepto se limita a señalar que «[s]alvo

${ }^{77}$ Llorente, «El contrato de transporte de mercancías», cit., pp. 1033 y ss. 
que se hubiese pactado un itinerario concreto, el porteador habrá de conducir las mercancías por la ruta más adecuada atendiendo a las circunstancias de la operación y a las características de las mercancías». Habitualmente, no suele pactarse el itinerario del transporte, por lo que, por regla general, habrá que estar a los criterios supletorios (y amplios) previstos en el precepto a la hora de medir la diligencia del comportamiento desplegado por el porteador en la elección del correspondiente itinerario y su eventual tratamiento en sede de responsabilidad.

Los artículos 29 y 30 de la nueva ley regulan el llamado «derecho de disposición» con un grado de detalle traído de la reglamentación internacional ${ }^{78}$ que, dicho sea de paso, no se compadece con su escasa aplicación en el tráfico. Lo cual no impide reconocer la importancia que tiene esta facultad para el derechohabiente del contrato de transporte.

El artículo 29 («Derecho de disposición»), en su apartado 1, comienza ofreciendo una definición ejemplificativa («en particular») del derecho de disposición al señalar que este derecho puede consistir en ordenar «al porteador que detenga el transporte, que devuelva la mercancía a su origen o que la entregue en un lugar o a un destinatario diferente de los indicados en la carta de porte». La nueva regulación en este aspecto no ofrece novedades.

El derecho de disposición, por su parte, corresponderá al cargador (artículo 29.1) o bien al destinatario siempre que, en este último caso, así se haya pactado expresamente en el contrato. Ahora bien, «[s]i el destinatario ejercita este derecho ordenando entregar la mercancía a otra persona, esta, a su vez, no puede designar un nuevo destinatario» (artículo 29.2).

El artículo 30, por su parte, aborda dos cuestiones diversas. Una primera, la relativa al ejercicio del derecho de disposición (apartados 1-2). Y otra, la de su extinción (apartado 3).

Con respecto a la primera cuestión, el artículo 30.1 exige la concurrencia de tres condiciones para que el ejercicio del derecho de disposición sea valido:

a) El cargador o el destinatario debe presentar al porteador el primer ejemplar de la carta de porte, en el que constarán las nuevas instrucciones, y resarcirle de los gastos y daños que se ocasionen por la ejecución de tales instrucciones.

b) La ejecución de las nuevas instrucciones debe ser posible en el momento en que se comuniquen al porteador, sin dificultar la explotación normal de su empresa ni perjudicar a cargadores o destinatarios de otros envíos. En caso contrario, el porteador deberá comunicar inmediatamente la imposibilidad de cumplir tales instrucciones a quien se las dio.

${ }^{78}$ A. Recalde Castells, «El "derecho de disposición” en el transporte internacional de mercancías por carretera», RDM, 2006, pp. 945-993. 

envío.

c) Las instrucciones no podrán tener como efecto la división del

Por su parte, el artículo 30.2 establece que «el porteador que no ejecute las instrucciones que se le hayan dado en las condiciones anteriormente señaladas, o que las haya ejecutado sin haber exigido la presentación del primer ejemplar de la carta de porte, responderá de los perjuicios causados por este hecho». Responsabilidad sobre cuya limitación, en términos indemnizatorios, no se pronuncia la ley como lo hace en el artículo 23.3.

Finalmente, por lo que respecta a la extinción del derecho de disposición, el artículo 30, en su apartado 3, establece que «[e]l derecho del cargador regulado en este artículo se extingue cuando el segundo ejemplar de la carta de porte se entregue al destinatario o cuando este reclame la entrega de la mercancía o haga uso de los derechos que le corresponden en caso de pérdida o retraso en la entrega. A partir de ese momento el porteador deberá someterse a las instrucciones del destinatario». Los supuestos a los que se refiere la ley en este precepto son aquellos previstos en su artículo 35 .

Los dos últimos preceptos (artículos 31 y 32) que la ley dedica a la fase de ejecución o desarrollo del transporte regulan los problemas derivados de aquellas situaciones que impiden llevar a cabo dicha ejecución. Son los que el artículo 31 denomina «impedimentos del transporte», es decir, cuando «el transporte de las mercancías no puede llevarse a cabo en las condiciones que fija el contrato por causas debidamente justificadas».

En estos casos, la ley indica cuál ha de ser el comportamiento que deberá desplegar el porteador. Y así, lo que el porteador deberá hacer, en primer lugar, es comunicar al cargador la existencia del impedimento y solicitar sus instrucciones (artículo 31.1) ${ }^{79}$. «A falta de instrucciones, el porteador tomará aquellas medidas razonables y proporcionadas que considere adecuadas para el buen fin de la operación, incluida la de restituir las mercancías a su lugar de origen, depositarlas en almacén seguro o conducirlas a su punto de destino en condiciones diferentes» (artículo 31.2). Gozará, por tanto, el porteador, en estos casos, de un amplio margen de actuación, siempre que lo haga dentro de los parámetros de razonabilidad y proporcionalidad predicados por la ley. Y, en todo caso, «[l]os gastos y los perjuicios derivados de la solicitud y ejecución de instrucciones o, en su caso, de la falta de estas o del retraso en su emisión serán de cuenta del cargador, a no ser que haya habido culpa del porteador» (artículo 31.3).

El artículo 32 ( «Riesgo de pérdida o daño de las mercancías»), por su parte, contempla la hipótesis de que, durante la ejecución del transporte, las

${ }^{79} \mathrm{El}$ artículo 31.1 solo se refiere al cargador, no al destinatario aún cuando este pueda ser el titular del derecho de disposición. El artículo 32.1, por su parte, sí habla del «titular del derecho de disposición». Nos preguntamos dónde puede estar la diferencia. 
mercancías corrieren el riesgo de sufrir pérdidas o daños. En estos casos, el apartado 1 de este precepto señala que «[s]i, a pesar de las medidas que hayan podido adoptarse, las mercancías transportadas corrieran el riesgo de perderse o de sufrir daños graves, el porteador lo comunicará de inmediato al titular del derecho de disposición solicitándole instrucciones». Nuevamente, por tanto, se le impone al porteador la obligación de solicitar instrucciones al cargador, y este asumirá los gastos derivados de la solicitud y ejecución de las instrucciones, salvo que hubiese concurrido culpa del porteador (artículo 32.2).

En una circunstancia concreta, no obstante, el porteador quedará liberado de la obligación de solicitar instrucciones en estos supuestos problemáticos: «cuando así lo justifique la naturaleza o el estado de la mercancía». En este caso, «[e]l porteador podrá solicitar ante el órgano judicial o la Junta Arbitral del Transporte competente la venta de la mercancía», y el producto de dicha venta quedará «a disposición de quien corresponda, previa deducción del precio del transporte y de los gatos ocasionados» (artículo 32.3).

\section{Fase final del transporte}

La fase final del transporte comienza cuando el transporte llega a su destino y el porteador pone la mercancía a disposición del destinatario ${ }^{80}$. Es una fase de importancia crítica en la vida jurídica del contrato de transporte, de ahí que la reglamentación le dedique una atención detallada.

Comienza la ley, en su artículo 33, estableciendo unas reglas relativas al «lugar y plazo de entrega de la mercancía al destinatario». Como no podía ser de otro modo, en atención a la orientación liberal de la ley, el apartado 1 del artículo 33 comienza señalando que «[e]l porteador deberá entregar la mercancía transportada al destinatario en el lugar y plazo pactados en el contrato». Primacía de la autonomía de la voluntad, por tanto.

En caso de que no haya pacto sobre el plazo de entrega, la ley establece reglas distintas según se trate del transporte por carretera o del transporte por ferrocarril, ofreciendo en este contexto una de las escasas normas específicamente ferroviarias de la nueva regulación.

En el primer caso, el artículo 33.1, en su párrafo segundo, dice que « $[e] n$ defecto de plazo pactado, la mercancía deberá ser entregada al destinatario dentro del término que razonablemente emplearía un porteador diligente en realizar el transporte, atendiendo a las circunstancias del caso». Con esta formulación se deja claramente en manos del intérprete la determinación del plazo atendiendo a esos criterios de razonabilidad, diligencia y circunstan-

${ }^{80}$ En el régimen anterior, véase F. Martínez-Conde, «La responsabilidad del transportista en la entrega de la mercancía», Revista de la Facultad de Derecho de la Universidad Complutense, núm. 79 (1991-1992), pp. 179 y ss. 
cias del caso previstos en el texto y que no siempre serán de fácil delimitación.

Tratándose de un contrato de transporte ferroviario, habrá que estar a lo previsto en el artículo 33.2, norma específicamente ferroviaria, que dice lo siguiente:

2. En el transporte ferroviario, en ausencia de acuerdo y sin perjuicio de lo establecido en los apartados 3 y 4, los plazos de transporte no podrán superar los siguientes límites:

a) Para vagones completos:

Plazo de expedición: 12 horas.

Plazo de transporte, por cada fracción indivisible de 400 kilómetros: 24 horas.

b) Para envíos en régimen de paquetería:

Plazo de expedición: 24 horas.

Plazo de transporte, por cada fracción indivisible de 200 kilómetros: 24 horas.

El apartado 2 habrá de ser complementado por el 3, también aplicable al transporte ferroviario de mercancías, conforme al cual «[e]n el transporte ferroviario, el porteador podrá ampliar el plazo de duración del transporte en lo estrictamente necesario cuando: a) los envíos se transporten por líneas con diferente ancho de vía, por mar o por carretera cuando no exista conexión ferroviaria; b) circunstancias extraordinarias entrañen un aumento anormal del tráfico o dificultades anormales de explotación».

Por último, y con alcance general, el apartado 4 del artículo 33 ofrece una regla de cómputo del plazo de entrega, en los siguientes términos:

4. El plazo de entrega empieza a correr con la recepción de las mercancías para su transporte. Se prorrogará por el tiempo que las mercancías estén paradas por causa no imputable al porteador y su cómputo se suspenderá los días festivos y los inhábiles para circular.

Delimitados el lugar y plazo de entrega de las mercancías en destino, la ley se centra a continuación en la regulación del estado de las mercancías en el momento de su entrega al destinatario, cuestión a la que dedica su artículo 34 .

Este precepto comienza recogiendo un principio general de la dogmática del contrato de transporte conforme al cual «[l]a mercancía transportada deberá ser entregada al destinatario en el mismo estado en que se hallaba al ser recibida por el porteador, sin pérdida ni menoscabo alguno, atendiendo a las condiciones y a la descripción de la misma que resultan de la carta de porte». Se trata, por lo tanto, de una manifestación directa y esencial de la obligación de custodia (artículo 28) que compete a todo porteador, en la que, además, la información recogida en la carta de porte 
sobre el estado de la mercancía juega un papel muy relevante a efectos probatorios.

Obviamente, las partes en conflicto, porteador y destinatario, pueden no estar conformes con el estado en que se entrega la mercancía en su destino, en cuyo caso el artículo 34 de la nueva ley establece dos reglas correlativas en sus apartados 2 y 3.

Conforme al primero de esos apartados, «si el porteador y el destinatario no consiguen ponerse de acuerdo en torno al estado de las mercancías entregadas o a las causas que hayan motivado los daños, podrán disponer su reconocimiento por un perito designado a tal efecto por ellos mismos o por el órgano judicial o la Junta Arbitral del Transporte que corresponda». Se faculta a las partes, por lo tanto, para que acudan a una investigación pericial contradictoria, intervención pericial que siempre será recomendable ${ }^{81}$. Por su parte, en el caso de que las partes implicadas «no se conformen con el dictamen pericial que, en su caso, se hubiese realizado ni transijan de otro modo sus diferencias, cada una de las partes usará de su derecho como corresponda» (artículo 34.3).

El artículo 35 («Derechos del destinatario»), por otro lado, describe de manera sucinta, pero suficiente, la posición jurídica del destinatario respecto del contrato de transporte. La consideración dogmática del destinatario como un tercero beneficiario del contrato de transporte encaja adecuadamente en el planteamiento normativo de la nueva ley cuando señala, en el apartado 1 del artículo 35, que «[e]l destinatario podrá ejercitar frente al porteador los derechos derivados del contrato de transporte desde el momento en que, habiendo llegado las mercancías a destino o transcurrido el plazo en que deberían haber llegado, solicite su entrega». Su derecho básico, por lo tanto, es el de solicitar al porteador la entrega de la mercancía y, consecuentemente, una vez realizada esta solicitud, ejercitar todos los demás derechos que se deriven del contrato de transporte.

La ley, no obstante, establece una condición para que el destinatario pueda ejercer los derechos a los que se refiere el artículo 35.1. Deberá «hacer efectivo el precio del transporte y los gastos causados o, en caso de disputa sobre estos conceptos, a prestar la caución suficiente» (artículo 35.2). Cuando la ley hace mención al pago del precio no concreta si está pensando sólo en los supuestos en que el transporte sea «a portes debidos»o, también, cuando el transporte fuese «a portes pagados» pero no se hubieran abonado.

La ley contempla en su artículo 36 («Impedimentos al transporte»), por su parte, determinadas situaciones, no infrecuentes en la práctica, en las que el porteador no puede hacer la entrega de la mercancía al destinatario ${ }^{82}$.

\footnotetext{
${ }^{81}$ Véase el artículo 60.2 de la ley.

${ }^{82} \mathrm{~F}$. Juan y Mateu, Los impedimentos para la entrega en el transporte de mercancías por carretera, Granada 2005.
} 
Estos supuestos de «impedimentos a la entrega» (que parecen ser numerus clausus) están recogidos en el apartado 1 del precepto y son concretamente los siguientes: «no hallarse el destinatario en el domicilio indicado en la carta de porte, (...) no hacerse cargo de la mercancía en las condiciones establecidas en el contrato, (...) no realizar la descarga correspondiéndole hacerlo o (...) negarse a firmar el documento de entrega».

En estos casos, la ley, siguiendo un planteamiento similar al que hemos visto en los casos de «impedimentos al transporte», le impone al porteador un determinado comportamiento, consistente, fundamentalmente, en comunicar al cargador la existencia del impedimento y solicitar sus instrucciones (artículo 36.1 in fine). Y «[s]i no fuera posible para el transportista solicitar nuevas instrucciones al cargador, o si dichas instrucciones no fueran impartidas por este en el plazo acordado por las partes, el transportista podrá proceder conforme se establece en el artículo 44 de la presente ley» (artículo 36.5). Por supuesto, «[e]l porteador tiene derecho a exigir del cargador el pago de los gastos y perjuicios que le ocasionen la petición y ejecución de instrucciones, así como el retraso o la falta de instrucciones, a menos que estos gastos sean causados por su culpa».

La regulación del artículo 36 sobre los «impedimentos a la entrega»se completa con dos reglas especiales.

Una es la prevista en su apartado 2, para el supuesto de que el impedimento cese antes de que el porteador haya recibido instrucciones del cargador, en cuyo caso el porteador «entregará las mercancías al destinatario, notificándolo inmediatamente al cargador».

La segunda regla especial se contiene en el apartado 4 del precepto: «si surgen impedimentos a la entrega después de que el destinatario haya dado orden de entregar las mercancías a una tercera persona en el ejercicio de su derecho de disposición, el destinatario sustituye al cargador y el tercero al destinatario a efectos de lo dispuesto en este artículo». Se aplicará solamente, como indica el precepto, cuando el derecho de disposición corresponda al destinatario.

Finalmente, y como indicamos en su momento, también puede adscribirse a la fase final de la ejecución del transporte la regulación prevista en el artículo 42 («Entrega contra reembolso»), supuesto específico, pero no infrecuente, que ya había recibido tratamiento en el $\mathrm{CMR}^{83}$ y que ahora se incorpora a nuestro sistema de normas de producción interna con una regulación más detallada que la recogida en la normativa internacional ${ }^{84}$.

${ }^{83}$ A. Recalde Castells, «La entrega de las mercancías contra reembolso en el transporte internacional por carretera», DNeg, 195, 2006, pp. 5-13.

${ }^{84}$ Artículo 42: Entrega contra reembolso.

1. Cuando se haya pactado que la mercancía solo puede ser entregada al destinatario a cambio de que este pague una cantidad de dinero, el porteador deberá percibirla en efectivo o por otro medio expresamente autorizado. Si el destinatario no hace efectivo el reem- 


\section{Pago del precio del transporte}

La regulación del precio (y gastos) del transporte recogida en la ley constituye, sin duda, una significativa novedad en nuestro ordenamiento, que nunca se había sentido especialmente inclinado a regular este aspecto tan relevante del contrato de transporte, ni en la normativa interna ni en la internacional ${ }^{85}$. La regulación sobre esta materia, que es extensa (artículos 3741), ha sido incorporada para satisfacer los intereses de los porteadores, que tradicionalmente se han visto perjudicados por la falta de una normativa más precisa sobre el que constituye el derecho más importante que nace a su favor del contrato de transporte (y el que, proporcionalmente, más litigios plantea ${ }^{86}$.

El primer aspecto que aborda la nueva regulación es el de quién debe abonar el precio (porte) y gastos del transporte y lo hace conforme a criterios plenamente aceptados. Así, «[c]uando nada se haya pactado expresamente, se entenderá que la obligación del pago del precio del transporte y demás gastos corresponde al cargador» (artículo 37.1). Es decir, se tratará de un transporte «a portes pagados». Y, por su parte, «cuando se haya pactado el pago del precio del transporte y los gastos por el destinatario, este asumirá dicha obligación al aceptar las mercancías» (artículo 37.2, primer párrafo) (transporte «a portes debidos»). Ahora bien, en este último caso, cuando el porteador no pague el precio del transporte, el cargador responderá subsidiariamente (artículo 37.2, párrafo final) ${ }^{87}$.

bolso, será de aplicación lo dispuesto en el artículo 36 en relación con los impedimentos a la entrega.

2. Recibido el reembolso, el porteador deberá entregar lo cobrado al cargador o a la persona designada por este en el plazo de diez días, salvo que se haya pactado otro mayor.

3. El porteador que entregue la mercancía sin cobrar la cantidad pactada responderá frente al cargador hasta el importe del reembolso, sin perjuicio de su derecho de repetir contra el destinatario.

4. La entrega contra reembolso podrá concertarse tanto cuando sea el destinatario el obligado al pago del precio del transporte como cuando lo sea el cargador.

${ }^{85}$ Lo recuerda el Preámbulo de la ley, en su apartado III, párrafo tercero, primer inciso: «No encuentra precedente en los convenios internacionales la regulación legal de la obligación de pago del precio del transporte».

${ }^{86}$ Preámbulo, apartado III, párrafo tercero, inciso final: «Con ello se busca poner fin a ciertos abusos de la práctica cometidos en perjuicio de los legítimos intereses del porteador».

${ }^{87}$ El Preámbulo de la Ley indica que «[l]a ley adopta aquí un planteamiento novedoso, en el que sin duda destaca la responsabilidad subsidiaria de pago que asume el cargador en aquellos casos en que se pacte el pago de los portes por el destinatario». Probablemente, la novedad radique en la incorporación de la citada regla a un texto legal, pero la regla en sí misma no es novedosa, porque siempre ha sido plenamente aceptada por la dogmática del contrato de transporte en atención a la naturaleza jurídica de dicho contrato. 
Por lo que respecta a la determinación del precio del transporte, el artículo 39.4 señala que «[e]n defecto de pacto entre las partes sobre la fijación del precio del transporte, el precio del transporte será el que resulte usual para el tipo de servicio de que se trate en el momento y lugar en el que el porteador haya de recibir las mercancías. En ningún caso se presumirá que el transporte es gratuito». Por su parte, en el artículo 38 se establecen unas reglas de revisión del precio del transporte por carretera en función de la variación del precio del gasóleo, que parecen más propias de un texto reglamentario, pero sobre cuya oportunidad no es posible hacer ninguna crítica por razones obvias ${ }^{88}$.

En relación con el devengo del derecho al pago del precio del transporte, por su parte, el artículo 39 ofrece tres reglas de interés, dos de carácter general y una aplicable en exclusiva al contrato de transporte continuado (artículo 8). Estas reglas son las siguientes:

a) «[C]uando otra cosa no se haya pactado, el precio del transporte y los gastos exigibles en virtud de una operación de transporte deberán ser abonados una vez cumplida la obligación de transportar y puestas las mercancías a disposición del destinatario» (apartado 1). La regla se compadece plenamente con la naturaleza del contrato de transporte como arrendamiento de obra. El pago se debe cuando la obra se termina.

${ }^{88}$ Artículo 38: Revisión del precio del transporte por carretera en función de la variación del precio del gasóleo.

1. En los transportes por carretera, salvo que otra cosa se hubiera pactado expresamente por escrito, cuando el precio del gasóleo hubiese aumentado entre el día de celebración del contrato y el momento de realizarse el transporte, el porteador podrá incrementar en su factura el precio inicialmente pactado en la cuantía que resulte de aplicar los criterios o fórmulas que, en cada momento, tenga establecidos la Administración en las correspondientes condiciones generales de contratación del transporte de mercancías por carretera.

Dichos criterios o fórmulas deberán basarse en la repercusión que la partida de gasóleo tenga sobre la estructura de costes de los vehículos de transporte de mercancías.

2. De la misma manera, el obligado al pago del transporte podrá exigir una reducción equivalente del precio inicialmente pactado cuando el precio del gasóleo se hubiese reducido entre la fecha de celebración del contrato y la de realización efectiva del transporte.

3. Los criterios o fórmulas señalados serán de aplicación automática siempre que el precio del gasóleo hubiera experimentado una variación igual o superior al 5 por ciento, salvo que, expresamente y por escrito, se hubiera pactado otra cosa distinta previa o simultáneamente a la celebración del contrato.

Salvo pacto en contrario, en los contratos de transporte continuado se aplicarán de forma automática los incrementos o reducciones determinados por la aplicación de los anteriores criterios o fórmulas con carácter trimestral en relación con el precio inicialmente pactado, sea cual fuere el porcentaje en que hubiese variado el precio del gasóleo.

4. El pacto en contrario se considerará nulo en todos aquellos casos en que tenga un contenido claramente abusivo en perjuicio del porteador y carecerá de efecto cuando se contenga en unas condiciones generales respecto de las que la parte que no las ha propuesto solo pueda mostrar su aceptación o rechazo global. 
b) «En caso de ejecución parcial del transporte, el porteador solo podrá exigir el pago del precio y los gastos en proporción a la parte ejecutada, siempre que esta reporte algún beneficio para el deudor.

No obstante, el porteador conservará su derecho al cobro íntegro cuando la inejecución se haya debido a causas imputables al cargador o al destinatario» (apartado 2).

c) «En los contratos de transporte continuado, si las partes hubiesen acordado el pago periódico del precio del transporte y de los gastos relativos a los sucesivos envíos, dicho pago no será exigible hasta el vencimiento del plazo convenido» (apartado 3 ).

También contempla la ley el problema de la «demora en el pago del precio», cuyas repercusiones prácticas son tan evidentes. En este aspecto, el artículo 41 establece un régimen imperativo mínimo destinado a proteger al porteador de los comportamientos abusivos (nada excepcionales, por cierto) en esta materia y que, seguramente, introducirá cierto orden en el sector ${ }^{89}$.

Finalmente, en este conjunto de reglas aplicables al precio del transporte, la nueva ley ha introducido un precepto, el artículo 40, relativo a la «enajenación de las mercancías por impago del precio del transporte» y que, también, plantea consecuencias prácticas de trascendencia.

En su primer apartado, el artículo recoge una regla que está en consonancia con lo establecido en los artículos 35.2 y 36.1 de la ley. Según este artículo 40.1, «si llegadas las mercancías a destino, el obligado no pagase el precio u otros gastos ocasionados por el transporte, el porteador podrá negarse a entregar las mercancías a no ser que se le garantice el pago mediante caución suficiente». Se establece, de este modo, un derecho de retención a favor del porteador, cuyo régimen se completa con lo previsto en el apartado 2 del precepto analizado: «[c]uando el porteador retenga las mercancías, deberá solicitar al órgano judicial o a la Junta Arbitral del Transporte competente el depósito de aquellas y la enajenación de las nece-

${ }^{89}$ Artículo 41: Demora en el pago del precio.

1. En todo caso, sin perjuicio de lo dispuesto en los dos artículos anteriores, el obligado al pago del transporte incurrirá en mora en el plazo de treinta días, en los términos previstos en la Ley 3/2004, de 29 de diciembre, por la que se establecen medidas de lucha contra la morosidad en las operaciones comerciales.

2. Cuando la fecha de recibo de la factura o la solicitud de pago equivalente se preste a duda, así como en todos los casos de autofacturación por parte del obligado al pago, los treinta días anteriormente señalados se computarán desde la fecha de entrega de las mercancías en destino.

3. El pacto en contrario se considerará nulo en todos aquellos casos en que tenga un contenido abusivo en perjuicio del porteador, conforme a las reglas que, a tal efecto, señala el artículo 9 de la Ley 3/2004.

Asimismo, carecerá de efecto el pacto en contrario cuando se contenga en unas condiciones generales respecto de las que la parte que no las ha propuesto solo puede mostrar su aceptación o rechazo global. 
sarias para cubrir el precio del transporte y los gastos causados, en el plazo máximo de diez días desde que se produjo el impago».

\section{Transporte continuado}

Como complemento a la regulación parcial del contrato de transporte continuado que recoge la nueva ley, el legislador ha creído conveniente incluir en su Capítulo II una norma relativa a la «extinción de los contratos de transporte continuado», que se recoge en su artículo $\mathbf{4 3}^{90}$.

\section{Depósito y enajenación de las mercancías}

En su Capítulo IV, la ley ha querido ofrecer, en dos artículos (44-45), una solución a los problemas que se plantean cuando el porteador se encuentra ante un supuesto de «impedimentos al transporte» (artículo 31) o de «impedimentos a la entrega» (artículo 36).

En ambos casos, el artículo 44.1 le ofrece al porteador la facultad de descargar las mercancías del medio de transporte y, a continuación, de proceder a su depósito bien en cabeza propia, bien recurriendo a un tercero o, finalmente, encomendándolo a la correspondiente Junta Arbitral del Transporte Terrestre. En el primer caso, el porteador seguirá siendo responsable de la custodia de la mercancía. En el segundo, responderá tan solo por culpa en la elección del depositario. Y en el tercero, el depósito «surtirá para el porteador los efectos propios de la entrega, considerándose terminado el transporte», por lo que esta última será siempre la opción más recomendable para el porteador.

Junto a la precedente facultad de depósito, la ley, en el apartado 2 de su artículo 44, también contempla el derecho del porteador a solicitar la enajenación de las mercancías, por vía judicial o acudiendo a la Junta Arbitral del Transporte Terrestre competente, sin necesidad de esperar a las instrucciones del derechohabiente sobre las mercancías, «si así lo justifican su naturaleza perecedera o el estado en que se encuentren o si los gastos de custodia son excesivos en relación con su valor». Pero fuera de este

${ }^{90}$ Artículo 43: Extinción de los contratos de transporte continuado.

1. Los contratos de transporte continuado que tengan un plazo de duración determinado se extinguirán por el transcurso del mismo, salvo prórroga o renovación. Si no se hubiera determinado plazo se entenderá que han sido pactados por tiempo indefinido.

2. Los contratos pactados por tiempo indefinido se extinguirán mediante la denuncia hecha de buena fe por cualquiera de las partes, que se notificará a la otra por escrito, o por cualquier otro medio que permita acreditar la constancia de su recepción, con un plazo de antelación razonable, que en ningún caso podrá ser inferior a treinta días naturales. 
supuesto concreto, la enajenación solo será procedente «si en un plazo razonable no ha recibido de quien tiene el poder de disposición sobre aquellas instrucciones en otro sentido cuya ejecución resulte proporcionada a las circunstancias del caso».

Los precedentes apartados 1 y 2 del artículo 44 son aplicables al transporte que no sea de «paquetería o similar» ${ }^{91}$, pues, en este último caso (transporte de carga fraccionada), la ley ofrece algunas reglas especiales en el apartado 3 de dicho precepto, que constituyen una novedad en nuestro marco legal del transporte terrestre y que confieren al porteador facultades de disposición sobre las mercancías de enorme alcance y trascendencia prácti$\mathrm{ca}^{92}$.

La regulación del artículo 44 se completa con su apartado 4, aplicable a todos los supuestos regulados en dicho precepto y conforme al cual «las mercancías quedan afectas a las obligaciones y gastos resultantes de estas operaciones y del contrato de transporte».

\section{Responsabilidad del porteador}

El Capítulo V de la ley regula el problema de la responsabilidad del porteador, al que dedica sus artículos 46-63 ${ }^{93}$. Lo hace, como reconoce expresamente el Preámbulo de la ley, de un modo muy próximo, casi idéntico, al de

${ }^{91}$ Entendemos que esta expresión habrá que identificarla con la que se describe en el artículo 20.3 de la ley.

92 «3. En el caso del transporte de paquetería o similar en que no se haya realizado declaración de valor, el porteador que haya optado por descargar la mercancía podrá entender abandonado el correspondiente envío si, transcurridos tres meses desde la fecha en que por primera vez intentó su entrega al destinatario, no ha recibido de quien tuviera el poder de disposición sobre aquél instrucciones al respecto.

En este caso, el porteador podrá ocuparlo y proceder a la enajenación de la mercancía, aplicando el producto de la venta a cubrir el precio y los gastos del transporte y los gastos de almacenaje que se hubieran generado hasta ese momento. En caso de que el valor venal de la mercancía fuera ínfimo, el porteador podrá destruirla y reclamar contra el cargador el importe total de lo debido por razón del transporte y del almacenaje. Para todo lo anterior, el porteador podrá abrir e inspeccionar los bultos cuyo transporte se le hubiera encomendado. El abandono del envío por parte de quien tuviera el poder de disposición sobre el mismo, no perjudicará al porteador quien, tanto en el caso de ocupación y enajenación como en el de destrucción del envío, quedará libre de cualquier reclamación formulada por terceros que sostengan algún derecho sobre la mercancía».

${ }^{93}$ Sobre este problema, entre nosotros, sigue siendo muy recomendable la lectura de la tesis de C. Górriz, La responsabilidad en el contrato de transporte de mercancías: carretera, ferrocarril, marítimo, aéreo y multimodal, Bolonia, 2001. Desde una perspectiva general, sobre la responsabilidad contractual véase la decisiva monografía de J. Jordano Fraga, La responsabilidad contractual, Madrid, 1987. 
la regulación internacional en la materia ${ }^{94}$. Por este motivo, quienes se dediquen al transporte internacional de mercancías, particularmente por carretera, se sentirán muy cómodos con la nueva regulación ${ }^{95}$. En este capítulo se abordan estrictamente cuestiones en materia de responsabilidad, así como todo lo referente a la determinación de la correspondiente indemnización. También se introduce una norma en materia de reclamaciones frente al porteador. Analizaremos estas tres cuestiones siguiendo el orden que se acaba de anunciar.

\section{Responsabilidad}

Comienza la regulación de la ley en esta materia con una referencia expresa al carácter del régimen de responsabilidad acogido en el texto legal, que se recoge en el artículo 46 («Carácter imperativo»). Según este precepto, las normas de responsabilidad de la ley tendrán carácter imperativo míni$m o$, es decir, no podrán ser modificadas por voluntad de las partes, salvo cuando se aumente o amplíe el régimen de responsabilidad del porteador previsto en la ley ${ }^{96}$.

También es importante, por su parte, desde una perspectiva general, el pronunciamiento del artículo 63 de la ley («Aplicación del régimen de responsabilidad a las diversas acciones»), según el cual «el régimen de responsabilidad previsto en este capítulo será aplicable a toda acción que persiga una indemnización por daños y perjuicios derivados del transporte, con independencia de cuál sea el procedimiento a través del que se ejercite o su fundamento contractual o extracontractual, tanto si se hace valer frente al porteador como si se dirige contra sus auxiliares». Este precepto tiene una importancia extraordinaria porque unifica el régimen de responsabilidad por daños en materia de transporte terrestre de mercancías en nuestro ordenamiento, de tal manera que con independencia del fundamento de la preten-

\footnotetext{
${ }^{94}$ Preámbulo, apartado III, párrafo cuarto: Una vez más, la influencia de los textos internacionales, fundamentalmente del CMR, se deja sentir muy profundamente en los preceptos dedicados a la responsabilidad del porteador por pérdidas, averías o retraso. Y es que, ciertamente, no se aprecian razones de peso para regular en términos muy distintos la responsabilidad del porteador en el ámbito internacional y en el nacional. Así, se acoge el mismo régimen de causas de exoneración, con la ya clásica distinción entre causas privilegiadas y ordinarias en atención a la existencia o no de facilidades probatorias.

${ }^{95}$ En este ámbito es muy recomendable la consulta de la monografía de F. Martínez Sanz, La responsabilidad del porteador en el transporte internacional de mercancías por carretera (CMR), Granada, 2002.

${ }^{96}$ Artículo 46: Carácter imperativo.

1. Las disposiciones de este capítulo tienen carácter imperativo.

2. Las cláusulas contractuales que pretendan reducir o aminorar el régimen de responsabilidad del porteador previsto en esta ley serán ineficaces y se tendrán por no puestas.
} 
sión ejercitada, del procedimiento elegido o de que se dirija la acción contra el porteador o contra sus auxiliares (siempre que esto sea posible: artículo 6), las normas aplicables será las mismas ${ }^{97}$.

Bajo la rúbrica de «supuestos de responsabilidad» se nos presenta, por su parte, el artículo 47 de la ley, que, sin embargo, como veremos, va más allá en su contenido de lo que se sugiere con la citada rúbrica.

Es cierto que el artículo 47 establece cuáles son los supuestos de responsabilidad del porteador, y destacan como supuestos principales aquellos que aparecen señalados en su apartado 1: en su primer inciso, la pérdida total o parcial de las mercancías y sus averías (también totales o parciales, habrá que añadir) y, en su segundo inciso, el retraso en la ejecución del transporte ${ }^{98}$. La ley no define ninguno de estos supuestos, pero se trata de conceptos sobradamente conocidos por nuestra dogmática. No obstante, en este marco conceptual, habrá que tener en cuenta el artículo 54, que regula algunos supuestos de responsabilidad que, a juicio de la ley, serán equiparables a la pérdida (o avería) total, con las correspondientes consecuencias jurídicas ${ }^{99}$.

Junto a los supuestos de la pérdida, averías o retraso, que, como dijimos, son los principales, la ley, sin embargo, no puede obviar que hay otros supuestos de responsabilidad del porteador derivados del incumplimiento de las obligaciones que este operador asume en un contrato de transporte y a ellos se refiere, con una formulación general, el artículo 47.2, cuando señala que «[a] falta de regulación específica, el incumplimiento por el porteador de otras obligaciones derivadas del contrato de transporte se regirá por las normas generales de la responsabilidad contractual». Fuera de los supuestos principales de responsabilidad, por lo tanto, habrá que estar a lo que pueda establecer de manera específica la regulación aplicable (por ejem-

${ }^{97}$ M. Yzquierdo Tolsada, «La zona fronteriza entre la responsabilidad contractual y la aquiliana. Razones para una moderada unificación», $R C D I, 1991$, pp. 443 y ss.

${ }^{98}$ En general, sobre el último supuesto, en el régimen anterior, F. Oleo, «Responsabilidad del transportista por retraso en el transporte terrestre de mercancías», $R G D, 1996$, pp. 5445 y ss.

${ }^{99}$ Artículo 54: Supuestos de equiparación a pérdida total.

1. El destinatario podrá rehusar hacerse cargo de las mercancías cuando le sea entregada tan solo una parte de las que componen el envío y pruebe que no puede usarlas sin las no entregadas.

2. Idéntico derecho asistirá al destinatario en los casos de averías, cuando las mismas hagan que las mercancías resulten inútiles para su venta o consumo, atendiendo a la naturaleza y uso corriente de los objetos de que se trate.

3. También podrán considerarse perdidas las mercancías cuando hayan transcurrido veinte días desde la fecha convenida para la entrega sin que esta se haya efectuado; o, a falta de plazo, cuando hubiesen transcurrido treinta días desde que el porteador se hizo cargo de las mercancías. 
plo, artículo 30.2 de la ley) y, en su defecto, a las normas generales de nuestro ordenamiento en materia de responsabilidad contractual.

Pero, como dijimos, el artículo 47 de la ley no solo regula los supuestos de responsabilidad del porteador sino, también, otros aspectos importantes de dicho régimen de responsabilidad.

Comenzando por el llamado «periodo de responsabilidad» del porteador, al que se refiere el apartado 1 del artículo 47 («desde el momento de su recepción para el transporte hasta el de su entrega en destino») y conforme al cual el porteador solo podrá ser declarado responsable por supuestos que hayan ocurrido (tengan su origen) durante ese periodo de tiempo que discurre desde la recepción de la mercancía en su origen hasta su entrega en destino.

También acoge el artículo 47, en su apartado 3, el principio tradicional de responsabilidad del porteador (deudor) por sus auxiliares o colaboradores en los siguientes términos ${ }^{100}$ : «El porteador responderá de los actos y omisiones de los auxiliares, dependientes o independientes, a cuyos servicios recurra para el cumplimiento de sus obligaciones». Este precepto no exige, para la plena operatividad de su mandato, que los auxiliares deban haber actuado «con ocasión de» o «en el ejercicio de» sus funciones, como requiere la normativa internacional que se ha seguido de modelo en esta materia $^{101}$. Lo cual llama la atención, salvo que por esta vía de la supresión del citado requisito se pretendan evitar los problemas interpretativos que dichas expresiones han venido causando en el plano internacional.

En relación con el principio asentado en el artículo 47.3, también habrá que tener en cuenta lo dispuesto por el apartado 4 del mismo precepto, aplicable exclusivamente al transporte por ferrocarril y conforme al cual « $[l]$ os administradores de la infraestructura ferroviaria sobre la que se realice el transporte se considerarán, a estos efectos, auxiliares del porteador». La figura del administrador de la infraestructura ferroviaria es una consecuencia del fenómeno de la liberalización del transporte ferroviario llevado a cabo en nuestro país por la LSF (RSF) y que corre a cargo, fundamentalmente, de ADIF. El artículo 47.4 viene simplemente a recordar que si el incumplimiento del contrato de transporte es consecuencia de una acción u omisión del

100 J. Jordano Fraga, La responsabilidad del deudor por los auxiliares que utiliza en el cumplimiento, Madrid, 1994. y P. Zelaya, La responsabilidad civil del empresario por los daños causados por sus dependientes. Naturaleza y requisitos, Pamplona, 1995. Igualmente, A. Cristóbal Montes, «La responsabilidad del deudor por sus auxiliares», $A D C, 1989$, pp. 5 y ss.; O. Torralba, «La responsabilidad de los auxiliares en el cumplimiento de las obligaciones», ADC, 1971, pp. 1143 y ss.

${ }^{101}$ Artículo 3 CMR. Véase E. J. Hermes, «El art. 3 de la convención CMR: un caso concreto de responsabilidad del transportista, que es el más habitual», en Actualidad jurídica del transporte por carretera. In Memoriam F.M. Sánchez Gamborino, Madrid, 2005, pp. 413-418. 
citado administrador, el porteador seguirá siendo responsable frente a su contraparte (cargador o destinatario) en los términos del artículo 47.3 (sin perjuicio, claro está, añadimos nosotros, de la acción de repetición que pueda corresponderle contra el auxiliar).

Lo único que nos queda por destacar del artículo 47 es la definición descriptiva del concepto de «mercancías» que ofrece en el segundo párrafo de su apartado 1, lo que se hace a los efectos de la aplicación del régimen de responsabilidad del porteador previsto en el Capítulo V de la ley. Según este precepto «se considerarán también como mercancías los contenedores, bandejas de carga u otros medios similares de agrupación de mercancías utilizados en el transporte cuando hubiesen sido aportados por el cargador» ${ }^{102}$.

Pieza relevante del nuevo sistema de responsabilidad establecido en la ley es el correspondiente a las circunstancias en las que el porteador queda exonerado de responsabilidad, cuyo régimen está recogido en los artículos 48-51. Para entender la operatividad de estas circunstancias exoneratorias hay que partir del principio general sobre la fundamentación de la responsabilidad del porteador que se recoge en el artículo 47.1 y que establece lo que se ha venido en llamar un sistema de «responsabilidad presunta», es decir, el porteador será considerado (se presumirá) responsable de la pérdida, avería o retraso causados durante el periodo de responsabilidad, a no ser que ofrezca prueba liberatoria en contra o, lo que es lo mismo, a no ser que pruebe que concurren en el caso alguna de las causas o presunciones de exoneración de responsabilidad que vienen previstas expresamente en la ley.

La ley se refiere a las «causas de exoneración» en su artículo 48 y a las «presunciones de exoneración» en su artículo 49, precepto este que deberá ser complementado, en supuestos concretos, por lo dispuesto en los artículos 50-51. La diferencia práctica última entre causas y presunciones de exoneración estriba, como comprobaremos enseguida, en el rigor de la prueba que se le exige al porteador en uno u otro caso para acreditar su exoneración.

Según el artículo 48.1, el porteador no responderá de los supuestos de responsabilidad previstos en el artículo 47 «si prueba que la pérdida, la avería o el retraso han sido ocasionados por culpa del cargador o del destinatario, por una instrucción de estos no motivada, por una acción negligente del porteador, por vicio propio de las mercancías o por circunstancias que el porteador no pudo evitar y cuyas consecuencias no pudo impedir». Por lo tanto, para exonerarse de responsabilidad, el porteador debe probar directa y positivamente que el supuesto de responsabilidad fue ocasionado por alguno de los hechos o circunstancias previstas expresamente en el artículo 48.1.

La regulación del artículo 48 se completa con dos apartados sobre cuestiones específicas propias de este ámbito. El apartado 2 señala que el por-

${ }^{102}$ En relación con el transporte de contenedores, J. Pulgar Ezquerra, «Especialidades del transporte de mercancías en contenedores», RDM, núm. 247, 2003, pp. 37-73. 
teador «[e]n ningún caso podrá alegar como causa de exoneración los defectos de los vehículos empleados para el transporte» ${ }^{103}$. Y su apartado 3 indica que «[c]uando el daño sea debido simultáneamente a una causa que exonera de responsabilidad al porteador y a otra de la que deba responder, solo responderá en la medida en que esta última haya contribuido a la producción del daño». Se trata de una formulación particular, traída del CMR ${ }^{104}$, del principio de «compensación de culpas».

Frente a las causas de exoneración del artículo 48, como adelantamos, el artículo 49 de la ley se refiere a las que califica como «presunciones de exoneración». Según este precepto (apartado 1), «[e]l porteador quedará exonerado de responsabilidad cuando pruebe que, atendidas las circunstancias del caso concreto, la pérdida o avería han podido resultar verosímilmente» de algunos de los riesgos que describe a continuación. Como puede observarse, al porteador, a diferencia de lo que sucede con el artículo 48 , no se le exige en estos casos que pruebe inequívocamente que el supuesto de responsabilidad es consecuencia directa de uno de los hechos previstos en la ley. Bastará, por el contrario, con que demuestre que «atendidas las circunstancias del caso concreto» el supuesto de responsabilidad «ha(-n) podido resultar verosímilmente» de alguno de los hechos (riesgos) que figuran recogidos en la ley. Es decir, se trata de casos en los que la ley presume que el porteador queda exonerado de responsabilidad, salvo que, como permite el apartado 2 del artículo 48, el reclamante aporte la prueba contraria a la presunción: «No obstante, el legitimado para reclamar podrá probar que el daño no fue causado, en todo o en parte, por ninguno de tales riesgos. Cuando resulte probado que el daño fue parcialmente causado por una circunstancia imputable al porteador, este solo responderá en la medida en que la misma haya contribuido a la producción del daño».

Las situaciones en las que conforme al artículo 48.1 operará la mencionada presunción de exoneración con las siguientes:

a) Empleo de vehículos abiertos y no entoldados, cuando tal empleo haya sido convenido o acorde con la costumbre.

b) Ausencia o deficiencia en el embalaje de mercancías, a causa de las cuales estas quedan expuestas, por su naturaleza, a pérdidas o daños.

c) Manipulación, carga, estiba, desestiba o descarga realizadas, respectivamente, por el cargador o por el destinatario, o personas que actúen por cuenta de uno u otro.

d) Naturaleza de ciertas mercancías expuestas por causas inherentes a la misma a pérdida total o parcial o averías, debidas especialmente a

${ }^{103}$ Artículo 17.3 CMR.

${ }^{104}$ Artículo 17.5 CMR. 
rotura, moho, herrumbre, deterioro interno y espontáneo, merma, derrame, desecación, o acción de la polilla y roedores. ${ }^{105}$

e) Deficiente identificación o señalización de los bultos.

f) Transporte de animales vivos en las condiciones previstas en el artículo siguiente ${ }^{106}$.

\section{Indemnización}

Una vez que se ha declarado la responsabilidad del porteador conforme a las normas indicadas precedentemente, corresponderá determinar las consecuencias de dicha responsabilidad en el plano indemnizatorio. Los artículos 52, 53 y 56 de la ley establecen los criterios generales de partida que deberán seguirse cuando se trate, respectivamente, de indemnización por pérdida, averías o retraso en la ejecución del transporte.

Conforme al artículo 52 («Indemnización por pérdidas»), «[e]n caso de pérdida total o parcial de las mercancías, la cuantía de la indemnización vendrá determinada por el valor de las no entregadas, tomando como base el valor que tuvieran en el momento y lugar en que el porteador las recibió para su transporte».

Por su parte, el artículo 53 («Indemnización por averías») establece que «[e]n caso de averías, el porteador estará obligado a indemnizar la pérdida de valor que experimenten las mercancías» (apartado 1, inciso primero), ofreciendo a continuación una regla de cálculo de dicha pérdida de valor en los siguientes términos: «La indemnización equivaldrá a la diferencia entre el valor de las mercancías en el momento y lugar en que el porteador las recibió para su transporte y el valor que esas mismas mercancías habrían tenido con las averías en idéntico tiempo y lugar». Este precepto ofrece, por su parte, dos reglas especiales para los supuestos respectivos de averías totales o parciales. Según el artículo 53.2, «[c]uando las averías afecten a la

${ }^{105}$ La regulación prevista en esta letra $d$ ) habrá de complementarse con lo que establece el artículo 51:

Artículo 51: Transporte con vehículos especialmente acondicionados.

Cuando el transporte haya sido contratado para realizarse por medio de vehículos especialmente acondicionados para controlar la temperatura, la humedad del aire u otras condiciones ambientales, el porteador tan solo podrá invocar en su favor la presunción de que la causa de la pérdida o avería fue la naturaleza de las mercancías cuando pruebe que ha tomado las medidas que le incumbían en relación con la elección, mantenimiento y empleo de las instalaciones del vehículo, y que se ha sometido a las instrucciones especiales que, en su caso, le hayan sido impartidas.

${ }^{106}$ Artículo 50: Transporte de animales vivos.

En los transportes de animales vivos el porteador tan solo podrá invocar a su favor la presunción de exoneración del artículo anterior cuando pruebe que, teniendo en cuenta las circunstancias del transporte, ha adoptado las medidas que normalmente le incumben y ha seguido las instrucciones especiales que le pudieran haber sido impartidas. 
totalidad de las mercancías transportadas, la indemnización no podrá exceder de la debida en caso de pérdida total». Y, por su parte, el artículo 53.3 señala que «[Cuando las averías ocasionen la depreciación de tan sólo una parte de las mercancías transportadas, la indemnización no podrá exceder de la cantidad que correspondería en caso de pérdida de la parte depreciada».

Finalmente, para el caso de retraso, el artículo 56 («Indemnización por retraso»), se limita a decir que «se indemnizará el perjuicio que se pruebe que ha ocasionado dicho retraso».

En consecuencia, en los tres supuestos anteriores, el reclamante deberá acreditar el valor real del perjuicio ocasionado atendiendo a las reglas previstas por la ley para cada caso. En los supuestos de pérdida y averías, en particular, esa acreditación deberá partir necesariamente de la determinación del valor que tengan las mercancías perdidas o averiadas, cuestión no exenta de dificultades, razón por la cual la propia ley ofrece en su artículo 55 («Valor de las mercancías») el criterio a seguir en esta materia: «El valor de las mercancías se determinará atendiendo al precio de mercado o, en su defecto, al valor de mercancías de su misma naturaleza y calidad. En caso de que las mercancías hayan sido vendidas inmediatamente antes del transporte, se presumirá, salvo pacto en contrario, que su valor de mercado es el precio que aparece en la factura de venta, deducidos el precio y los demás costes del transporte que, en su caso, figuren en dicha factura».

Pero una vez identificado el valor real del perjuicio ocasionado, debe entrar en juego el límite legal de indemnización previsto en la ley, que actúa como límite máximo, salvo en los supuestos excepcionales a los que haremos referencia más adelante.

A este límite máximo se refiere el artículo 57 («Límites de indemnización»), conforme al cual, en caso de pérdida o averías, la indemnización «no podrá exceder de un tercio del Indicador Público de Renta de Efectos Múltiples/día por cada kilogramo de peso bruto de mercancía perdida o averia$d a »(\text { apartado } 1)^{107}$. Si se trata de retraso, por su parte, conforme al apartado 2 del artículo 57, la indemnización «no excederá del precio del transporte».

Estos límites de indemnización no son inamovibles. Pueden ser modificados por voluntad de las partes del contrato. $\mathrm{O}$, incluso, eliminados en los supuestos previstos en la ley.

A la primera hipótesis (modificación por voluntad de las partes) se refiere el artículo 61 («Declaración de valor y de interés especial en la entrega»), que, no obstante su rúbrica, contempla no dos, sino tres, situaciones en

${ }^{107}$ Se abandona la referencia al límite en euros, como era el caso en la LOTT, y se acoge el IPREM. En el anteproyecto de ley se había propuesto la cuantificación de los límites indemnizatorios en Derechos Especiales de Giro (DEG). 
las que la voluntad de las partes del contrato podrá modificar los límites legales de indemnización previstos en el artículo 57 de la ley.

La primera situación («declaración de valor») es la que se recoge en el artículo 61.1 conforme al cual «el cargador puede declarar en la carta de porte, contra el pago de un suplemento del precio del transporte a convenir con el porteador, el valor de las mercancías, que sustituirá al límite de indemnización previsto siempre que sea superior a él». Por lo tanto, en este caso particular, el límite máximo de indemnización previsto por el artículo 57.1 vendrá sustituido por el límite consistente en el valor de las mercancías conforme a la declaración realizada por las partes en el contrato (la carta de porte). Téngase en cuenta, adicionalmente, la exigencia de que se abone un suplemento del precio.

A la segunda situación («declaración de interés especial en la entrega») se le dedica el artículo 61.2 en los siguientes términos: «Igualmente el cargador puede declarar en la carta de porte, contra el pago de un suplemento del precio del transporte a convenir con el porteador, el montante de un interés especial en la entrega de las mercancías, para los casos de pérdida, avería o retraso en la entrega. La declaración permitirá reclamar, con independencia de la indemnización ordinaria, el resarcimiento de los perjuicios que pruebe el titular de las mercancías hasta el importe del interés especial declarado». Con esta declaración, las partes del contrato, también a cambio de un sobreprecio, acuerdan la posibilidad de reclamar no solo el daño emergente sino el lucro cesante.

Y, finalmente, conforme al apartado 3 del artículo 61, «[s]in perjuicio de lo dispuesto en los apartados anteriores, las partes del contrato de transporte podrán acordar el aumento del límite de indemnización previsto en el artículo 57.1. El acuerdo dará derecho al porteador a reclamar un suplemento del porte, a convenir entre las partes». Esta tercera posibilidad es novedosa con respecto al modelo seguido por nuestro legislador (CMR) y, simplemente, concede a las partes una alternativa más para adaptar a sus intereses la rigidez del límite legal máximo de indemnización previsto en el artículo 57.1.

Pero el porteador puede, además, perder el derecho a limitar la indemnización debida conforme a las reglas precedentes. Esta situación está contemplada por el artículo 62 («Pérdida del beneficio de limitación»):

No se aplicarán las normas del presente capítulo que excluyan o limiten la responsabilidad del porteador o que inviertan la carga de la prueba, cuando el daño o perjuicio haya sido causado por él o por sus auxiliares, dependientes o independientes, con actuación dolosa o con una infracción consciente y voluntaria del deber jurídico asumido que produzca daños que, sin ser directamente queridos, sean consecuencia necesaria de la acción.

Como puede comprobarse, este precepto, que se proyecta más allá del mero ámbito de los límites de indemnización, establece que, en las circuns- 
tancias previstas en su texto, el porteador no podrá prevalerse de los beneficios que en esta materia le concede la ley. Lo relevante del precepto reside, precisamente, en la delimitación de las circunstancias en las que el porteador perderá el derecho a excluir o limitar su responsabilidad. Aquí no se ha seguido el modelo del $\mathrm{CMR}^{108}$, por entenderse seguramente que, en este aspecto en particular, el precepto correspondiente ha sido polémico en su aplicación nacional a lo largo del tiempo ${ }^{109}$. Pero tampoco se ha seguido el criterio adoptado por los más modernos textos internacionales en la materia, que era el acogido por el anteproyecto. Se ha optado, sin más, por una formulación propia, pergeñada en sede parlamentaria, cuyas consecuencias habrá que analizar a medida que se produzca la aplicación de este precepto en la práctica. No creemos que haya problema, en todo caso, en la determinación de cuándo una actuación deba ser calificada de «dolosa», pues el concepto y alcance del «dolo» es bien conocido entre nosotros. Más dudas tenemos, no obstante, con respecto a lo que significa «una infracción consciente y voluntaria del deber jurídico asumido que produzca daños que, sin ser directamente queridos, sean consecuencia necesaria de la acción». En uno u otro caso, no obstante, queda claro, a la luz de este precepto, que el porteador perderá su beneficio de limitación, tanto si la actuación analizada es atribuible a él directamente o indirectamente por ser reconducible a una actuación de sus colaboradores («auxiliares dependientes o independientes»).

Al margen de la indemnización que, en su caso, pueda percibirse en los supuestos de pérdida o avería, la ley también ha querido ser precisa en la determinación de qué otros conceptos o importes habrán de ser reembolsados al derechohabiente por parte del porteador, cuestión a la que se dedica el artículo 58 («Reembolso de otros gastos») de la nueva ley, en el que se establece un numerus clausus de supuestos resarcitorios adicionales (apartado 3: «No se resarcirá ningún otro daño o perjuicio»). Conforme al apartado $1 \mathrm{de}$ este artículo, «[e]n caso de pérdida o avería total, además de la indemnización a que haya lugar, serán reintegrados en su totalidad el precio del trans-

${ }^{108}$ Artículo 29 CMR. Véase F. Martínez Sanz, «Limitación de la deuda de responsabilidad y responsabilidad sin limitación: sobre los artículos 23 y 29 CMR», en F. Martínez Sanz, Problemas en la aplicación del CMR. Especial referencia a la responsabilidad, Madrid, 2002, pp. 63-69.

${ }^{109}$ Cuando se refería al «dolo o culpa grave equiparable al dolo». En este sentido, véase D. Morán Bovio, «El concepto de dolo y culpa grave equiparable al dolo por parte del transportista: artículo 29 del Convenio CMR» en Actualidad jurídica del transporte por carretera. In Memoriam F.M. Sánchez Gamborino, Madrid, 2005, pp. 453-459. En la misma obra, igualmente, J. L. Concepción («El dolo como causa de inaplicación del límite de responsabilidad. El artículo 29 de la Convención CMR»), pp. 445-451 y R. Wijffels («Uniformización y desuniformización del derecho del transporte por carretera: el art. 29 de la CMR y otros factores»), pp. 461-464. 
porte y los demás gastos devengados con ocasión del mismo. Si la pérdida o avería es parcial, se reintegrarán a prorrata». Además, también deberán ser reintegrados los gastos de salvamento en que hayan incurrido el cargador o el destinatario, pero dentro de los límites previstos en la ley: «siempre que hayan sido razonables y proporcionados» (apartado 2).

Finalmente, una norma particular en este ámbito indemnizatorio es la prevista en el artículo 59 («Recuperación de las mercancías perdidas»), que, como su propia rúbrica indica, establece el régimen que deberá seguirse en el caso de que se recuperen mercancías consideradas perdidas y por cuya pérdida se abonó en su día la correspondiente indemnización:

1. El que haya sido indemnizado por la pérdida de las mercancías podrá pedir por escrito, en el momento de recibir la indemnización, que se le avise inmediatamente en caso de que reaparezcan en el período de un año. El porteador le extenderá un recibo haciendo constar su petición.

2. En el plazo de treinta días desde el aviso, se podrá exigir la entrega de las mercancías reaparecidas, previo pago de las cantidades previstas en la carta de porte, si la hubiere, y la restitución de la indemnización recibida, deducción hecha de los gastos resarcibles, todo ello sin perjuicio del derecho a la indemnización por retraso en la entrega conforme a esta ley.

3. En defecto de petición de aviso o de instrucciones para la entrega o cuando la mercancía reaparezca después de un año contado desde el pago de la indemnización, el porteador dispondrá libremente de la mercancía.

\section{Reclamaciones}

La ley ha dedicado su artículo 60 («Reservas») a la regulación del comportamiento debido por parte del destinatario cuando la mercancía llega a su destino con pérdidas, averías o retraso.

Una primera opción prevista por la ley, para los casos de pérdidas o averías, es que las partes en conflicto (porteador y destinatario) recurran voluntariamente al análisis conjunto de la mercancía con la intención de ponerse de acuerdo sobre su estado y las causas que lo han motivado (artículo 60.2, párrafo primero). A falta de acuerdo sobre estos extremos, se les ofrece a las partes la facultad de recurrir al procedimiento previsto en el artículo 26.3.

La segunda posibilidad, a la que se refiere la rúbrica del artículo 60, es la interposición de reservas por parte del porteador, procedimiento admisible tanto para los supuestos de pérdidas y averías (artículo 60.1) como para los de retraso (artículo 60.3) ${ }^{110}$. En ambos casos se exige que las reservas se

${ }^{110}$ Sobre las reservas en el régimen internacional y en el régimen interno precedente, véase A. Emparanza Sobejano, «Las reservas o protestas en destino en el transporte terrestre y marítimo: contenido y alcance», RDT (2008) 1, pp. 77-98. 
hagan por escrito y dentro de los plazos previstos en la norma: inmediatamente, si son pérdidas o averías manifiestas, siete (7) días naturales en caso de pérdidas o averías no manifiestas y veintiún (21) días (no se dice si naturales) en caso de retraso. Los plazos se contarán desde el día siguiente al de la entrega de la mercancía.

Las consecuencias de la falta de interposición de reservas también se regulan con claridad en la ley. En el supuesto de pérdidas o averías, «cuando no se formulen reservas se presumirá, salvo prueba en contrario, que las mercancías se entregaron en el estado descrito en la carta de porte» (artículo 60.1, párrafo final). Es decir, la ausencia de reservas no impedirá el ejercicio de la eventual acción de responsabilidad contra el porteador, pero el reclamante deberá probar, en contra de la presunción, que la mercancía se le entregó con pérdidas o averías. Por lo que respecta al caso del retraso, las consecuencias de la falta de reservas son aún más graves, pues de su interposición dependerá que el reclamante pueda obtener la correspondiente indemnización (artículo 60.3).

La regulación del artículo 60 se completa finalmente con una regla aplicable a los supuestos contratos de transporte realizados por medio de un subtransportista («porteador efectivo») ${ }^{111}$.

\section{Porteadores sucesivos}

Como señalamos en su momento, al hablar de los porteadores efectivos, la ley ha perdido una magnífica oportunidad de ofrecer una regulación moderna de los fenómenos de colaboración entre transportistas. Por un lado, la ley se ha negado a regular de manera adecuada el fenómeno de la subcontratación del transporte, con todas sus consecuencias. Y, por otro, en su Capítulo VI ( «Porteadores sucesivos») (artículos 64-66), aborda el tratamiento normativo de una modalidad de colaboración entre transportistas (el llamado «transporte sucesivo»o «transporte cumulativo»), recogido en el artículo $373 \mathrm{CCom}^{112}$ (y

111 4. Las reservas por pérdidas, averías o retraso que deban dirigirse al porteador, podrán realizarse tanto ante este como ante el porteador efectivo y surtirán efecto frente a ambos. Si las reservas se dirigen exclusivamente a uno de los porteadores, este estará obligado a comunicárselo al otro. En caso contrario, aquel responderá frente a este de los daños y perjuicios que le cause tal falta de comunicación.

112 Para el régimen del Código de Comercio, N. Díaz Méndez, «Transporte combinado: obligaciones, derechos, responsabilidad», en R. Illescas (dir.), El transporte terrestre nacional e internacional, Madrid, 1997, pp. 13 y ss. También sobre esta figura en el artículo 373 CCom y en los principales textos internacionales, C. Llorente Gómez de Segura, «Régimen jurídico del transporte cumulativo de mercancías en el derecho español. Una nueva aproximación», La Ley, núm. 5690 (6 enero 2003) y núm. 5691 (7 enero 2003), donde se recogen las conclusiones de su tesis doctoral (inédita) sobre este tema (Pamplona, 1999). Igualmente, J. A. Gómez Segade, «El transporte combinado de mercancías a la luz del 
en la normativa internacional $)^{113}$, que está en franco desuso, salvo en el transporte ferroviario, que es donde, precisamente, tiene su origen histórico ${ }^{114}$. Y, probablemente, la única justificación práctica que tiene la presencia de los artículos 64-66 en nuestra nueva legislación sea la de su aplicación ferroviaria, si bien, todo sea dicho, ni siquiera en este ámbito creemos que tenga demasiado recorrido futuro.

Según el artículo 64.1 de la ley nos encontraremos ante un supuesto de transporte sucesivo «[c]uando diversos porteadores se obliguen simultáneamente, en virtud de un único contrato documentado en una sola carta de porte, a ejecutar sucesivos trayectos parciales de un mismo transporte (...)», entrando a formar parte de ese mismo contrato el porteador segundo y subsiguientes, conforme al artículo 64.2, «a partir del momento en que el porteador precedente les haga entrega material de las mercancías y de la carta de porte, en la que deberá haberse hecho constar su nombre y domicilio, y hayan entregado a aquel un recibo firmado y fechado en el que conste su aceptación de ambas» ${ }^{115}$. La principal consecuencia de este tipo de contrato es que todos los porteadores «responderán de la ejecución íntegra (del contrato), de acuerdo con las disposiciones de la carta de porte» (artículo 64.1). Se establece, por tanto, entre todos los porteadores una responsabilidad solidaria en el cumplimiento de la obligación indivisible de transporte asumida por todos ellos.

El artículo 65 («Ejercicio de reclamaciones»), por su parte, establece reglas, bien conocidas, sobre la determinación de la legitimación pasiva de los porteadores sucesivos, según las cuales «las acciones derivadas del contrato únicamente podrán dirigirse contra el primer porteador, contra el último o contra el que haya ejecutado la parte del transporte en cuyo curso se ha producido el hecho en que se fundamenta la acción», derecho de opción, calificado como tal por la nueva legislación, que «se extinguirá desde el momento en que el demandante ejercite su acción contra uno de ellos», pudiendo la acción «interponerse contra varios porteadores a la vez».

Finalmente, el artículo 66 ( «Acción de repetición entre porteadores sucesivos») resultará aplicable a las relaciones internas que median entre los

art. 373 del Código de Comercio», en Libro Homenaje al Profesor Alfonso Otero, Santiago de Compostela, 1981, pp. 105 y ss., un trabajo muy apegado a la postura defendida en su momento por G. Valeri.

${ }^{113}$ A. Zurimendi Isla, «Régimen jurídico de la pluralidad de porteadores en el CMR», RDT (2008) 1, pp. 99-143.

${ }^{114}$ A. Emparanza Soberano, «El transporte sucesivo en el Convenio CMR, arts. 34 a 40: un modelo agotado», en Actualidad jurídica del transporte por carretera. In Memoriam F.M. Sánchez Gamborino, Madrid 2005, pp. 465-474.

${ }^{115}$ Señala el artículo 64.3 que «cuando el porteador que reciba las mercancías de otro precedente considere necesario formular alguna reserva, deberá hacerla constar en el segundo ejemplar de la carta de porte, así como en el recibo en que conste su aceptación». 
porteadores sucesivos, responsables solidariamente ${ }^{116}$, una vez satisfecho el derechohabiente en la relación externa ${ }^{117}$.

\section{Transporte multimodal}

Extremadamente novedoso, y arriesgado, resulta el Capítulo VII («Transporte multimodal») de la ley, que comprende sus artículos 67-70. Novedad entendida en el sentido de que hasta la fecha nuestro ordenamiento no había conocido una regulación similar (que, dicho sea de paso, ha sido incorporada a nuestro Derecho siguiendo el impulso de modelos nacionales extranjeros) ${ }^{118}$. Y arriesgada en la medida en que el tratamiento jurídico del transporte multimodal sigue siendo una cuestión debatida, no obstante los numerosos intentos dogmáticos y legislativos que se han hecho hasta la fecha en esta materia ${ }^{119}$.

116 A. Cristóbal Montes, «El derecho de regreso en la solidaridad de deudores», $A D C$, 1991, pp. 1433 y ss.

117 Artículo 66: Acción de repetición entre porteadores sucesivos.

1. El porteador que se haya visto obligado a pagar una indemnización en virtud de lo dispuesto en los artículos 64 y 65 tiene derecho a repetir por el principal, intereses y gastos contra el resto de los porteadores que hayan participado en la ejecución del contrato, imputándose el coste de la indemnización conforme a las siguientes reglas:

a) Cuando el hecho causante del daño sea imputable a un único porteador, este habrá de soportar el coste total de la indemnización.

b) Cuando el hecho causante del daño sea imputable a varios porteadores, cada uno de ellos deberá soportar una parte del coste de la indemnización proporcional a su cuota de responsabilidad; si no cabe valorar dicha responsabilidad, el coste se repartirá en proporción al precio que a cada uno corresponda por el transporte.

c) Si no se puede determinar quiénes son los porteadores responsables, el coste de la indemnización se repartirá entre todos los que hayan intervenido en el transporte de forma proporcional al precio que corresponda por este.

d) Si uno de los porteadores obligado a asumir total o parcialmente el coste de la indemnización es insolvente, la parte que le corresponda y que no haya sido pagada se repartirá entre los demás obligados en proporción a su participación en el precio del transporte.

2. El porteador contra el que se ejercite el derecho de repetición no podrá formular protesta o promover discusión por el hecho de que el porteador contra el que se presentó la reclamación haya pagado la indemnización cuando esta hubiera sido fijada por decisión judicial o arbitral y se le hubiere informado debidamente del proceso y de su derecho a intervenir en el mismo.

118 Preámbulo IV, párrafo tercero: «Aunque breve, igualmente novedosa resulta la regulación que se contiene del contrato de transporte multimodal, cuando uno de los modos empleados sea el terrestre (...)».

${ }^{119}$ F. C. López Rueda, El régimen jurídico del transporte multimodal, Madrid, 2000; M. a de la Paz Martín Castro, El transporte multimodal: Concepto y sujetos, Cádiz, 2001. De esta misma autora, «La regulación del transporte multimodal internacional de mercancías: alternativas legales y prácticas», RDT (2008) 1, pp. 259-293. Igualmente, Y. Dutrey 
En realidad, la regulación propuesta plantea dos situaciones distintas de transporte multimodal. Una, que podríamos denominar como transporte multimodal en sentido estricto, se aborda en los artículo 67-69. Y la otra, relativa al transporte superpuesto, se acoge en su artículo 70.

El artículo 67 comienza ofreciendo una definición de transporte multimodal y señala que «[a] efectos de esta ley, se denomina multimodal el contrato de transporte celebrado por el cargador y el porteador para trasladar mercancías por más de un modo de transporte, siendo uno de ellos terrestre, con independencia del número de porteadores que intervengan en su ejecución». Se alude, por lo tanto, a la unicidad del contrato de transporte y a la presencia de dos o más modos de transporte en su ejecución (uno de ellos, al menos, terrestre), que son los elementos objetivos esenciales de todo contrato de transporte multimodal. Quizás el único matiz que habría que añadir es que, en puridad, es multimodal todo contrato de transporte en cuya ejecución concurran dos o más modos de transporte, sin perjuicio de lo que las partes hubieran podido prever a este respecto, pero entendemos que el legislador ha querido abordar esta cuestión en su artículo 69 $9^{120}$.

El precepto más importante, no obstante, es el artículo 68 («Regulación»), donde se aborda la cuestión esencial de todo contrato de transporte multimodal: ¿qué normas son aplicables a esta modalidad de transporte en la que aparecen implicados modos sometidos a regulaciones diversas? Comienza el artículo 68.1 estableciendo una regla clásica: «El contrato de transporte multimodal se regirá por la normativa propia de cada modo, como si el porteador y el cargador hubieran celebrado un contrato de transporte diferente para cada fase del trayecto». Se sigue, en consecuencia, un sistema de red, que determina la aplicación de la normativa correspondiente a cada modo empleado en el transporte. Pero, claro, el problema crítico se plantea

Guantes, «La responsabilidad en el transporte multimodal internacional: normativa y soluciones existentes», en Cuestiones actuales en materia de transporte, Granada, 2006, pp. 139-166.

${ }^{120}$ Artículo 69: Normas aplicables a supuestos especiales.

1. Cuando se haya pactado la realización del transporte por dos o más modos determinados y se utilice en la operación solo uno de ellos o bien otro u otros diferentes a los acordados, se aplicará el régimen de responsabilidad del porteador correspondiente a aquel modo de transporte de entre los contratados que resulte más beneficioso para el perjudicado.

2. Asimismo, cuando se haya contratado un transporte terrestre y se realice por otro $u$ otros modos diferentes, se aplicará el régimen de responsabilidad correspondiente a aquel modo de transporte, el terrestre o el efectivamente utilizado, que resulte más beneficioso para el perjudicado.

3. En los casos en que el contrato no especifique el modo de transporte y este se ejecute por vía terrestre, se aplicarán las normas correspondientes a dicho modo. Cuando en idéntico supuesto el transporte se realice por diversos modos, siendo uno de ellos terrestre, se aplicarán las normas establecidas en esta ley. 
cuando no pueda identificarse el modo de transporte al que deba reconducirse el origen del incumplimiento del contrato, situación que no es infrecuente en este tipo de transportes. Pues bien, para estos casos, el artículo 68.3 señala que «[c]uando no pueda determinarse la fase del trayecto en que sobrevinieron los daños, la responsabilidad del porteador se decidirá con arreglo a lo establecido en la presente ley». La ley opta en este caso por adoptar un sistema uniforme de regulación por referencia del transporte multimodal. Es decir, la ley no construye un sistema normativo propio y específico para los supuestos de falta de identificación del lugar del incumplimiento contractual, sino que se remite expresamente a la aplicación de las normas recogidas «en la presente ley», es decir, a las normas reguladoras del contrato de transporte terrestre de mercancías ${ }^{121}$.

Por último, como modalidad específica de transporte multimodal, aparece regulado en la ley el supuesto del transporte superpuesto en su artículo 70 («Contrato de transporte con superposición de modos»), que sigue el modelo del complejo, y polémico, artículo $2 \mathrm{CMR}$, si bien simplificándolo señaladamente ${ }^{122}$. Este precepto contempla los casos en los que el vehículo terrestre, junto con su mercancía, viaja sobre otro modo de transporte distinto durante una parte del trayecto total contratado. En estos casos, la ley establece la aplicación a todo el transporte de sus normas en materia de responsabilidad, sin perjuicio de que, en los casos y circunstancias previstos en la normativa (artículo 70.2) ${ }^{123}$, la responsabilidad del porteador terrestre pueda ser determinada conforme a las reglas propias del otro modo de transporte en el que el viajaban el vehículo terrestre y su mercancía. La relevancia práctica de este precepto para nuestro país es destacada, tanto por nuestras particulares circunstancias insulares como en el contexto general del denominado transporte marítimo de corta distancia (TMCD), cuya promoción constituye un objetivo reciente de la política comunitaria de transportes ${ }^{124}$.

${ }^{121}$ Preámbulo IV, párrafo tercero: «prestándose especial atención a la responsabilidad por daños en las mercancías y fijándose una solución supletoria para aquellos casos en que no pueda determinarse la fase del trayecto en que sobrevinieron tales daños».

${ }^{122}$ Sobre este precepto, véanse los trabajos de K. Haak ( «El transporte por superposición camión sobre buque 'ro-ro' -artículo 2 del Convenio CMR-: la solución holandesa») y J. Ramberg («Los transportes por superposición (camión sobre tren o buque): el art. 2 del Convenio CMR»), en Actualidad jurídica del transporte por carretera. In Memoriam F.M. Sánchez Gamborino, Madrid, 2005, pp. 397-406 y pp. 407-412, respectivamente.

123 2. No obstante, cuando la pérdida, la avería o el retraso se produzcan durante una fase del transporte distinta de la carretera, por hechos que solo han podido darse con ocasión del transporte a través de ese otro modo, y que no han sido debidas a un acto u omisión del porteador por carretera, la responsabilidad de este último se regirá por las reglas imperativas aplicables al modo de transporte en que se haya producido el daño.

${ }^{124}$ C. Llorente Gómez de Segura, «Transporte marítimo de mercancías de corta distancia y responsabilidad del transportista. Una aproximación jurídico-internacional en el contexto de su promoción en el ámbito comunitario», Estudios de Deusto, vol. 54/2, julio- 


\section{Normas especiales del contrato de mudanza}

El Capítulo VIII (artículos 71-77) de la ley está dedicado a ofrecer unas reglas especiales sobre el contrato de mudanza. Cabría discutir si una ley, como la que ahora se analiza es el lugar más idóneo para incorporar la regulación de este tipo de contrato. De hecho, en su momento, también los redactores del CMR pensaron en hacer algo similar, para luego abandonar la idea, por entender que el contrato de transporte y el de mudanza eran contratos significativamente distintos y debían ser abordados separadamente. Quizás por este motivo, la ley, como su propio Preámbulo pone de manifiesto ${ }^{125}$, se centra más en la dimensión de «transporte» propia de las operaciones de mudanza, que en aquellas otras actividades, no menos importantes, que comportan dichas operaciones. En este sentido resultan muy significativos, sobre todo, el artículo 71 («Objeto del contrato») $)^{126}$ y el pronunciamiento de su artículo 72 («Regulación») ${ }^{127}$. Pero, en general, el resto de los preceptos del Capítulo VIII también asumen una misma filosofía: así, las normas sobre documentación del contrato de mudanza (artículo 73) ${ }^{128}$, donde destaca la

diciembre 2006, pp. 251-277. Igualmente, W. Czapski, «El transporte marítimo de camiones, remolques y semirremolques a corta distancia: aspectos jurídicos», RGD, 1992, pp. 4303 y ss.

125 Preámbulo IV, párrafo final: También incorpora la ley a su articulado la regulación del contrato de mudanza, como transporte que recae sobre un objeto especial y que conlleva unas obligaciones accesorias igualmente especiales.

${ }^{126}$ Por el contrato de mudanza el porteador se obliga a transportar mobiliario, ajuar doméstico, enseres y sus complementos procedentes o con destino a viviendas, locales de negocios o centros de trabajo, además de realizar las operaciones de carga, descarga y traslado de los objetos a transportar desde donde se encuentren hasta situarlos en la vivienda, local o centro de trabajo de destino. El resto de las operaciones, como la preparación, armado o desarmado, embalaje, desembalaje y otras complementarias, quedarán a la voluntad contractual de las partes contratantes.

${ }^{127}$ El contrato de mudanza estará sometido a las normas aplicables al modo de transporte que se utilice en cuanto no se opongan a lo establecido en este capítulo.

128 Artículo 73: Documentación del contrato de mudanza.

1. Antes de iniciar la mudanza, el porteador estará obligado a presentar un presupuesto escrito al cargador en el que consten los servicios que se prestarán, su coste, el coste del presupuesto y el precio total de la mudanza, especificando, en su caso, si los gastos que generen los trámites administrativos o de los permisos que fuera necesario solicitar están o no incluidos. Una vez aceptado por el cargador, el presupuesto hará prueba de la existencia y contenido del contrato.

2. A falta de documento en el que se indiquen los bienes objeto de la mudanza, las partes podrán exigirse mutuamente, antes de iniciar el traslado, la realización y aceptación de un inventario de dichos bienes.

3. Cuando la parte contratante requerida a realizar o aceptar un inventario de los bienes se negase a ello, la otra podrá considerarla desistida del contrato, con los efectos que, en su caso, correspondan de conformidad con lo dispuesto en los artículos 18.2 y 19.1. 
regulación del presupuesto y del inventario; las normas sobre las obligaciones del porteador (artículo 74) ${ }^{129}$; las normas sobre presunciones de exoneración (artículo 75$)^{130}$, que complementan o modulan lo previsto en el artículo 48 de la ley; las normas sobre límites de indemnización (artículo 76) ) $^{131}$; y finalmente, la regulación de las reservas en este ámbito (artículo 77) ${ }^{132}$. Habrá que seguir con atención, sin duda alguna, la evolución de la aplicación

${ }^{129}$ Artículo 74: Obligaciones del porteador.

1. Las operaciones de carga y descarga, salvo que expresamente se pacte lo contrario, serán de cuenta del porteador. En los mismos términos, estará obligado a armar, desarmar, embalar, desembalar y colocar en el lugar que se le indique los bienes objeto de la mudanza.

2. El porteador deberá solicitar al cargador información sobre las circunstancias relevantes para la correcta ejecución de la mudanza, tales como las condiciones de acceso a las viviendas, locales y establecimientos para su personal y vehículos.

3. El porteador deberá informar, en su caso, al cargador acerca de las normas administrativas que sean aplicables al traslado pactado, pero no estará obligado a comprobar si los documentos puestos a su disposición son correctos y completos.

4. El porteador deberá informar al cargador acerca de la posibilidad de concertar un contrato de seguro que cubra el riesgo de daños a los bienes objeto de la mudanza. La conclusión del contrato de seguro no libera de responsabilidad al porteador.

No será de aplicación la limitación de responsabilidad del porteador señalada en el artículo 76 cuando este incumpla la obligación de información anteriormente reseñada.

${ }^{130}$ Artículo 75: Presunciones de exoneración.

1. Sin perjuicio de lo dispuesto en el artículo 48, el porteador quedará exonerado de responsabilidad cuando pruebe que la pérdida o avería de los bienes objeto de la mudanza ha podido resultar verosímilmente de alguno de los riesgos siguientes:

a) Deficiencias en el embalaje o marcado de los bienes realizado por el cargador.

b) La manipulación efectuada por el cargador.

c) Carga o descarga de bienes cuya dimensión o peso no sea adecuado para los medios de transporte acordados, siempre que el porteador haya avisado al cargador del riesgo de daños y este hubiera insistido en la ejecución de la prestación.

d) Falsedad o incorrección de la información proporcionada por el cargador.

e) Transporte de animales vivos o de plantas.

f) Naturaleza propia de los bienes objeto de la mudanza.

2. No obstante, el legitimado para reclamar podrá probar que el daño no fue causado, en todo o en parte, por ninguno de tales riesgos. Cuando resulte probado que el daño fue parcialmente causado por una circunstancia imputable al porteador, este solo responderá en la medida en que la misma haya contribuido a la producción del daño.

${ }^{131}$ Artículo 76: Límites de indemnización.

1. La responsabilidad del porteador por daños o pérdida de los bienes transportados no podrá exceder de veinte veces el Indicador Público de Efectos Múltiples/día por cada metro cúbico del espacio de carga necesario para el cumplimiento del contrato.

2. Esta limitación de la responsabilidad no será de aplicación a los daños que, con ocasión de la mudanza, puedan sufrir bienes del cargador distintos de los transportados.

132 Artículo 77: Reservas.

1. La acción por pérdida o avería de los bienes objeto de la mudanza se extingue si el destinatario no manifiesta por escrito sus reservas al porteador o a sus auxiliares en el momento de la entrega o, en caso de pérdidas y averías no aparentes, dentro de los siete días siguientes al de la entrega, descontando domingos y festivos. 
práctica de estas normas en el tráfico y, particularmente, el tratamiento de las condiciones generales de la contratación que suelen emplearse en este sector y que no podrán sustraerse al carácter imperativo mínimo establecido en la ley con respecto a la regulación de los transportes terrestres (artículos 3 y 46).

\section{Prescripción de acciones}

Llegamos al final de este breve repaso del contenido de la nueva ley sobre el contrato de transporte terrestre de mercancías haciendo referencia a su último capítulo, el Capítulo IX, dedicado a la prescripción de acciones, materia que se trata en dos preceptos, los artículos 78 y 79 .

El primero de estos preceptos es breve, pero resuelve una cuestión sobre la que ha habido un cierto debate en los últimos tiempos. El precepto, así como su rúbrica, son muy precisos y establecen inequívocamente que «las normas de este capítulo tienen carácter imperativo». Materia esta, por lo tanto, que queda sustraída a la voluntad de las partes, sin discusión.

Con mayor contenido, y no menor trascendencia, el artículo 79 aborda la regulación de los aspectos más relevantes del problema de la prescripción de las acciones derivadas de un contrato de transporte terrestre de mercancías sometido a la nueva ley.

Primero, se establecen cuáles son los plazos de prescripción, distinguiendo entre el plazo general de un (1) año ${ }^{133}$ y el plazo especial de dos (2) años cuando las «acciones se deriven de una actuación dolosa o con una infracción consciente y voluntaria del deber jurídico asumido que produzca daños que, sin ser directamente queridos, sean consecuencia necesaria de la acción, el plazo de prescripción será de dos años».

Posteriormente, en su apartado 2, el artículo 79 determina cuándo comenzarán a contarse dichos plazos, proporcionando reglas, a estos efectos, para los distintos tipos de acciones ${ }^{134}$. De particular interés, en este marco,

2. Lo dispuesto en el apartado anterior no se aplicará cuando el destinatario sea un consumidor y el porteador no le haya informado por escrito, de forma clara y destacada, antes de la entrega, acerca de la forma y plazos en que deberá manifestar las reservas así como de las consecuencias de su ausencia.

${ }^{133}$ Artículo 79.1: Las acciones a las que pueda dar lugar el transporte regulado en esta ley prescribirán en el plazo de un año.

${ }^{134}$ 2. El plazo de prescripción comenzará a contarse:

a) En las acciones de indemnización por pérdida parcial o avería en las mercancías o por retraso, desde su entrega al destinatario.

b) En las acciones de indemnización por pérdida total de las mercancías, a partir de los veinte días de la expiración del plazo de entrega convenido o, si no se ha pactado plazo de entrega, a partir de los treinta días del momento en que el porteador se hizo cargo de la mercancía. 
es el apartado 4 del artículo 79, que establece el dies ad quem del plazo de prescripción en los supuestos de acciones de repetición entre porteadores (no se dice si entre porteadores sucesivos o si también se aplicará esta regla a las acciones de repetición que se ejerciten entre porteador y porteador efectivo) ${ }^{135}$.

Distingue, por su parte, la ley, en su artículo 79.3, entre la interrupción y la suspensión de la prescripción, una distinción traída de la normativa internacional pero desconocida entre nosotros y que nos tememos que planteará algunos problemas de aplicación práctica, no solo por ese desconocimiento, sino por los problemas de coordinación, y de compatibilidad, que se plantean entre ambos instrumentos a la luz de su regulación ${ }^{136}$.

Sobre la interrupción de la prescripción, la ley dice simplemente que se producirá «por las causas señaladas con carácter general para los contratos mercantiles» (artículo 79.3, párrafo primero), lo que constituye una remisión a lo establecido no solo por nuestra legislación mercantil sino, no se olvide, por nuestra jurisprudencia más acertada.

Con respecto al otro expediente contemplado en la ley, la suspensión de la prescripción, el párrafo segundo del artículo 79.3 indica que «la reclamación por escrito suspenderá la referida prescripción, reanudándose su cómputo solo a partir del momento en que el reclamado rechace la reclamación por escrito y devuelva los documentos que, en su caso, acompañaron a la reclamación», regulación que se completa con otras reglas de aplicación sobre este instrumento especial de la suspensión de la prescripción ${ }^{137}$.

c) En todos los demás casos, incluida la reclamación del precio del transporte, de la indemnización por paralizaciones o derivada de la entrega contra reembolso y de otros gastos del transporte, transcurridos tres meses a partir de la celebración del contrato de transporte o desde el día en que la acción pudiera ejercitarse, si fuera posterior.

135 4. Entre porteadores, la prescripción de las acciones de regreso comenzará a contarse a partir del día en que se haya dictado una sentencia o laudo arbitral firme que fije la indemnización a pagar según lo dispuesto en esta ley, y si no existe tal fallo, a partir del día en que el porteador reclamante efectuó el pago.

${ }^{136}$ R. de Ángel Yaguez, «Interrupción y suspensión de la prescripción. Convenio de Ginebra sobre transportes por carretera», La Ley, 1985-4, pp. 358 y ss.; A. Emparanza Sobejano, «La prescripción de las acciones en el Convenio relativo al contrato de transporte internacional de mercancías por carretera (CMR)», $R G D, 1992$, pp. 11713 y ss.; A. Pérez Moriones, «La regulación de la prescripción de las acciones en el Convenio de Ginebra de 19 de mayo de 1956, relativo al contrato de transporte internacional de mercancías por carretera (CMR)», RDP, 1999, pp. 203 y ss.

${ }^{137}$ Artículo 79.3: (...) Una reclamación posterior que tenga el mismo objeto no suspenderá nuevamente la prescripción. En el caso de aceptación parcial de la reclamación, la prescripción se reanudará respecto de la parte aún en litigio.

La prueba de la recepción de la reclamación o de la contestación y devolución de los documentos justificativos, corresponde a la parte que la invoque. 